\title{
$9-22-2019$
}

\section{Monopsony Power and Guest Worker Programs}

\author{
Eric M. Gibbons \\ The Ohio State University \\ Allie Greenman \\ University of Wisconsin - Madison \\ Peter Norlander \\ Loyola University Chicago, pnorlander@luc.edu \\ Todd Sørensen \\ University of Nevada, Reno
}

Follow this and additional works at: https://ecommons.luc.edu/business_facpubs

Part of the Business Commons

\section{Author Manuscript}

This is a pre-publication author manuscript of the final, published article.

\section{Recommended Citation}

Gibbons, Eric M.; Greenman, Allie; Norlander, Peter; and Sørensen, Todd. Monopsony Power and Guest Worker Programs. The Antitrust Bulletin, 64, 4: , 2019. Retrieved from Loyola eCommons, School of Business: Faculty Publications and Other Works, http://dx.doi.org/10.1177/0003603X19875040

This Article is brought to you for free and open access by the Faculty Publications and Other Works by Department at Loyola eCommons. It has been accepted for inclusion in School of Business: Faculty Publications and Other Works by an authorized administrator of Loyola eCommons. For more information, please contact ecommons@luc.edu.

\section{(c) $($ () $\ominus$}

This work is licensed under a Creative Commons Attribution-Noncommercial-No Derivative Works 3.0 License. (c) Sage, 2019. 


\title{
MONOPSONY POWER AND GUEST WORKER PROGRAMS
}

\author{
Eric M. Gibbons, ${ }^{*}$ Allie Greenman, ${ }^{* *}$ Peter Norlander ${ }^{* * *} \&$ Todd Sørensen ${ }^{* * * *}$
}

Guest workers on visas in the United States may be unable to quit bad employers due to barriers to mobility and a lack of labor market competition. Using $H-1 B, H-2 A$, and $H-2 B$ program data, we calculate the concentration of employers in geographically defined labor markets within occupations. We find that many guest workers face moderately or highly concentrated labor markets, based on federal merger scrutiny guidelines, and that concentration generally decreases wages. For example, moving from a market with an HHI of zero to a market comprised of two employers lowers $H-1 B$ worker wages approximately 10 percent, and a pure monopsony (one employer) reduces wages by 13 percent. A simulation shows that wages under pure monopsony could be 47 percent lower, suggesting that employers do not use the extent of their monopsony power. Enforcing wage regulations and decreasing barriers to mobility may better address issues of exploitation than antitrust scrutiny.

* Visiting Assistant Professor of Economics, The Ohio State University at Marion.

** University of Nevada, Reno.

*** Assistant Professor of Management, Loyola University Chicago, Quinlan School of Business. **** Assistant Professor of Economics, University of Nevada, Reno. 


\section{MONOPSONY POWER AND GUEST WORKER PROGRAMS}

Eric M. Gibbons, Allie Greenman, Peter Norlander \& Todd Sørensen

\section{CONTENTS}

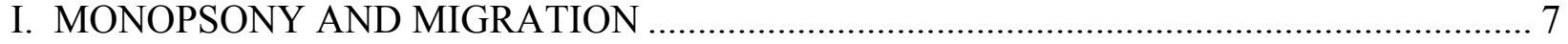

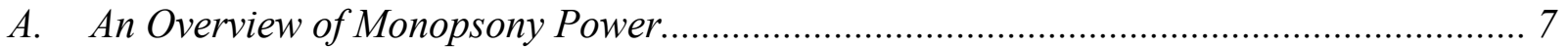

1. Perfect Competition and Monopsonistic Models..................................................... 8

2. Labor Markets Characterized by Frictions and Concentration ................................ 10

3. Implications of Monopsonistically Competitive and Oligopsonistic Markets .............. 13

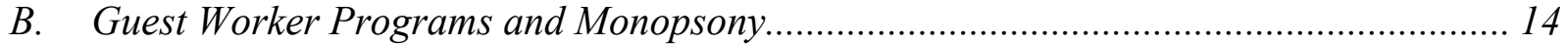

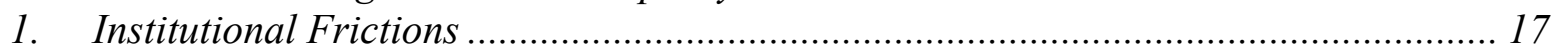

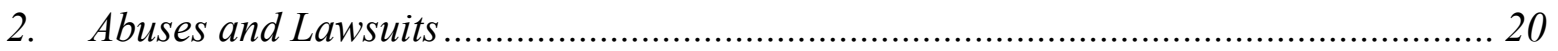

3. Oligopsony and Antitrust Law …………………............................................ 23

II. EVIDENCE OF OLIGOPSONY AND FRICTIONS IN GUEST WORKER WAGES ......... 26

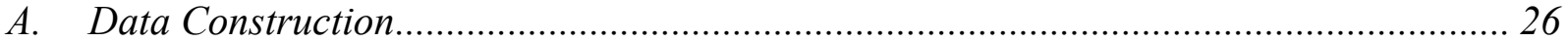

B. Are Guest Worker Labor Markets Oligopsonistic? .................................................... 32

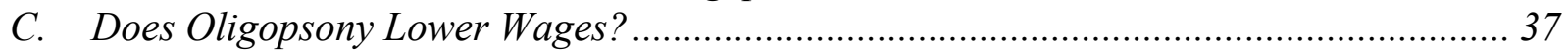

D. Modeling the Role of Frictions and Oligopsony on Wages ........................................... 42

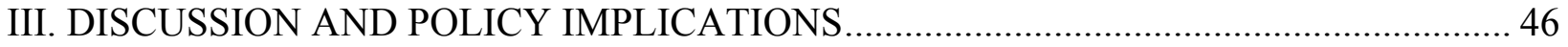

\section{TABLES}

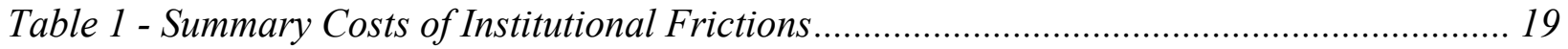

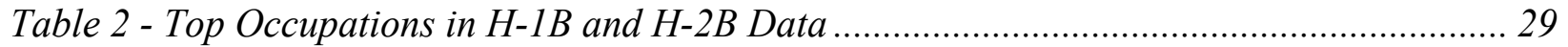

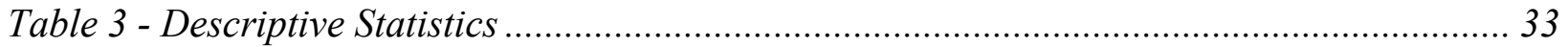

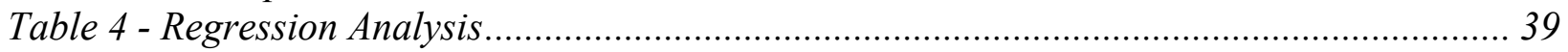

\section{FIGURES}

Figure 1 - Federal Claims Brought in Guest Worker Cases 1990-2017 ................................. 22

Figure 2 - Employer Concentration Levels (HHI) for H-2A, H-2B, and $\mathrm{H}-1 \mathrm{~B}$ Visas ................... 35

Figure 3 - Oligopsony on Wages ...................................................................................... 41

Figure 4 - Predicted and Simulated Change in Wages Under Monopsonistic Competition and

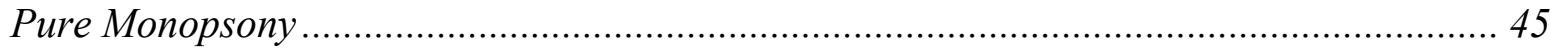

\section{APPENDICES}

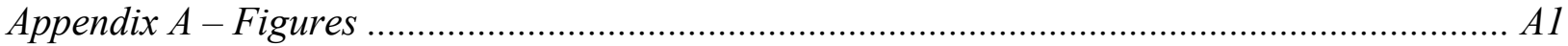

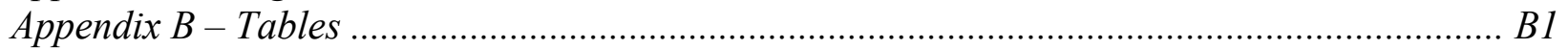


The emerging study of the power of employers to set wages below the market rate, i.e., monopsony power, ${ }^{1}$ has invigorated discussions on a variety of ailments in contemporary U.S. labor markets. Stagnant wages, labor shortages, labor market discrimination, growing inequality, and reduced workers' rights could each be explained by growing employer market power over workers. ${ }^{2,3}$ While a vigorous debate has emerged over the degree to which the U.S. labor market is monopsonistic or competitive, few involved in the discussion of the political economy of employer power would dispute that guest worker programs could be characterized by monopsony. Such programs have been referred to as "a benefit to their employers, enabling them to get workers at a lower wage" by Milton Friedman, the late economist associated with neoliberal economics, and "monopsony visas" by Heidi Shierholz, an economist with the unionbacked EPI. $^{4}$

Prominent scholars of both economics and law have recently proposed using existing regulations under antitrust law to counter monopsony power in the labor market. ${ }^{5}$ As a growing body of empirical research finds that employers possess oligopsony power and that this has negative effects on wages across the U.S., ${ }^{6}$ studying a specific context in which employer power

\footnotetext{
${ }^{1}$ Monopsony refers to a single buyer of an input, and is the counterpart to monopoly in output markets. Oligopsony refers to two or more large buyers of an input, and is the counterpart of oligopoly. Both situations can lead to departures from perfect competition. We refer to monopsony power interchangeably with employer power, imperfect competition in labor markets, monopsonistic labor markets, finite elasticity, or inelastic labor supply.

${ }^{2}$ The best available estimates of labor market competitiveness in the U.S. suggest that the average firm has some market power over workers. See Douglas A. Webber. Firm Market Power and the Earnings Distribution. Labour Economics. 35 (2015): 123-134.

${ }^{3}$ See Christopher L. Erickson \& Daniel J.B. Mitchell. Monopsony as a Metaphor for the Emerging Post-Union Labour Market. International Labour Review, 146(3-4), 163-187. (2007).

${ }^{4}$ Friedman is quoted in Paul Donnelly, H-1B Is Just Another Government Subsidy, Computerworld (July 22, 2002); Shierholz is quoted in Economic Policy Institute, Monopoly, Monopsony, and the Labor Market: Declining Worker Power in an Era of Market Concentration, Washington, D.C. (December 12, 2018), https://www.epi.org/event/monopoly-monopsony/.

${ }^{5}$ See Suresh Naidu et al., Antitrust Remedies for Labor Market Power. HARVARD LAw REVIEW. (2018); Ioana Marinescu \& Herbert J. Hovenkamp, Anticompetitive Mergers in Labor Markets, 93 IND. L.J. (forthcoming)

${ }^{6}$ See e.g., José Azar et al., Labor Market Concentration, National Bureau of Economic Research, WP 24147 (2017); Efraim Benmelech et al., Strong Employers and Weak Employers: How Does Employer Concentration Affect Wages?, National Bureau of Economic Research, WP 24307 (2018); Kevin Rinz, Labor Market Concentration, Earnings Inequality, and Earning Mobility, CARRA Working Paper Series, CARRA-WP-2018-10. (2018); Brad
} 
is assumed to exist provides an opportunity to address several important questions for this literature. One critical question involves the source of monopsony power. Frictions and barriers to job-to-job mobility could make it difficult for foreign-born nationals to quit, weakening employee bargaining power. An alternative explanation for these conditions could be that a small number of employers, or an oligopsony, can dominate the market for guest workers in a particular occupation and region, thus empowering firms to dictate wages and terms of employment. ${ }^{7,8}$ Several recent lawsuits brought by guest workers allege collusion among employers to suppress wages in specific labor markets, in violation of antitrust law. ${ }^{9}$

Determining the source of monopsony power is important for developing effective solutions for labor market dysfunction. The consequences of bad policy are substantial. For example, guest worker visa programs that permit foreign-born workers to be temporarily employed in occupations experiencing labor shortages have been criticized for well-documented cases of poor working conditions and exploitation. ${ }^{10}$ These conditions in some cases involve illegal employer conduct, such as wage theft, coercion, fraud, and abuse. ${ }^{11}$

\footnotetext{
Hershbein et al., Concentration in U.S. local labor markets: evidence from vacancy and employment. data, Working Paper (2018); Yue Qiu \& Aaron J. Sojourner, Labor-Market Concentration and Labor Compensation SSRN WP 3312197 (2019).

${ }^{7}$ Concerns about oligopsony and the capture of these programs by intermediaries have been recognized in government reports. In 2013, 44\% of U.S. employers hiring H-2A and H-2B guest workers indicated that they were using an intermediary. See U.S. Gov't Accountability Office, GAO-15-154, Increased Protections Needed for Foreign Workers (2015), at 26 [hereinafter GAO].

${ }^{8}$ The top 20 sponsors of H-1B visas increased their share of initial employment from $8 \%$ to $40 \%$ between 2000 and 2012. See Anna Maria Mayda et al. New Data and Facts on H-1B Workers Across Firms, in Ina Ganguli et. al. eds., The Role of Immigrants and Foreign Students in Science, Innovation, and Entrepreneurship, University of Chicago Press (2018).

${ }^{9}$ See Beltran v. InterExchange, Inc., 2018 U.S. Dist. LEXIS 23940; Llacua v. Western Range Ass'n., 2016 U.S. Dist. LEXIS 193120, and discussion, Infra., at Section 1.B.3.

${ }^{10}$ See e.g., Lance Compa, Migrant Workers in The United States: Connecting Domestic Law with International Labor Standards, 92 Chi.-Kent L. Rev. 211 (2017); Grace Meng, Cultivating Fear: The Vulnerability of Immigrant Farmworkers in the US to Sexual Violence and Sexual Harassment, Human Rights Watch. https://www.hrw.org/report/2012/05/15/cultivating-fear/vulnerability-immigrant-farmworkers-ussexual-violenceand-sexual (2012); Mary Bauer, Close to Slavery: Guestworker Programs in the United States, Southern Poverty Law Center. https://www.splcenter.org/sites/default/files/d6_legacy_files/downloads/publication/SPLCClose-toSlavery-2013.pdf, (2013).

${ }^{11}$ See GAO, supra, and for full discussion of the extent of documented abuses, see Infra, Section 1.B.2.
} 
Foreign-born nationals on temporary guest worker visas are likely to be more vulnerable to employer market power than the typical worker for several reasons. The key market check on bad working conditions is the power of a worker to freely quit a job and take up work with a new employer. Two forms of monopsony power, monopsonistic competition arising from frictions and oligopsony arising from concentration, can reduce an employee's ability to quit and thus might contribute to the situation guest workers find themselves in. "Natural frictions" include the practical barriers that keep a person from seeking a new job such as imperfect information, preferences, and customs that might deter a guest worker from searching for new jobs. "Institutional frictions" include administrative and legal factors which might increase the costs of worker mobility and decrease employer entry into these labor markets. Both natural and institutional frictions can lead to "monopsonistic competition" or the state in which the availability of outside job options fails to deliver all the benefits of a perfectly competitive labor market on account of high costs to switching jobs. Finally, "oligopsony" can occur when markets become too concentrated to deliver competitive outcomes. Oligopsony is potentially the only cause of heightened monopsony power over guest workers that can be addressed by antitrust law. $^{12}$

This paper contributes to the growing antitrust and monopsony literature by presenting new evidence on the question of whether oligopsony has an impact on guest worker wages, and then addressing whether antitrust policy is a fruitful venue through which to address many of the problems of the guest worker programs. Applying the theory of monopsony to real antitrust lawsuits involving collusion among firms poses significant challenges when trying to calculate

\footnotetext{
${ }^{12}$ Suresh Naidu, \& Eric A. Posner, Labor Monopsony and the Limits of the Law, Working Paper (2018).
} 
damages. ${ }^{13}$ Applying the principles and existing tools of antitrust law enforcement to concentrations of oligopsonistic labor markets holds promise, and empowering federal regulators to scrutinize mergers is a notable, yet untested, idea. ${ }^{14}$ While regulators have signaled an interest in aggressively enforcing antitrust policies in the labor market, it was only recently that they issued a memorandum warning employers of their intent to prosecute any future unlawful collusion. ${ }^{15}$ At the same time, empirical analysis of oligopsony in the context of labor markets must also be aware of other classical legal avenues to address and counter imbalances of employer power and monopsonistic competition even in the absence of oligopsony. For example, guest worker programs are regulated across the world, and typically include mobility restraints as well as wage regulations, a numerical cap on visas, and time limits that imply strong institutional and natural frictions to quitting apart from oligopsony. ${ }^{16}$

In this study, we analyze whether oligopsonistic concentrations of employers contribute to the suppression of guest worker wages for three guest worker programs in the United States. To identify whether oligopsony is relevant to guest worker concerns, we first search scholarly law and case law databases to examine whether there is an interest in monopsony and antitrust in the legal community. We find that of 163 federal lawsuits brought related to the guest worker programs since 1990, only two were under antitrust statutes. We then apply Department of Justice (DOJ) standards to employer and occupation level data from the Department of Labor's Labor Condition Application (LCA) database for the H-1B, H-2A, and H-2B programs. We use regression analysis to establish a correlation between concentration and wages. To our

\footnotetext{
${ }^{13}$ Christina DePasquale, Collusive Monopsony and Antitrust Damages. The Antitrust Bulletin, 54(4), 907-921 (2009).

${ }^{14}$ Naidu et al., supra; Marinescu \& Hovenkamp, supra.

${ }^{15}$ Department of Justice Antitrust Division, Antitrust Guidance for Human Resource Professionals, https://www.justice.gov/atr/file/903511/download (2016).

${ }^{16}$ See Adam S. Chilton et al., Optimal Design of Guest Worker Programs: An Introduction, The Journal of Legal Studies, 47, no. S1 (January 2018): S1-S4.
} 
knowledge, we are the first in this literature to explore this relationship in the guest worker market. ${ }^{17}$ We find that between approximately one quarter and one third of $\mathrm{H}-1 \mathrm{~B}$ and $\mathrm{H}-2 \mathrm{~B}$ guest workers are employed in labor markets that meet or exceed the DOJ criteria for a concentrated market, and that an increase in the level of market concentration from perfect competition to a market with only two firms is associated with a decline in wages up to 10 percent. Further, our calibration of a new theoretical model in this literature suggests that both oligopsonistic concentration and frictions play a role in imperfect competition in this market.

The rest of the paper proceeds as follows. In Section I.A., we provide an overview of economic thought on perfect and imperfect competition in labor markets and the implications of each for workers and firms. In Section I.B., we review the wide array of recent abuses alleged to occur to workers in the guest worker programs, and the institutional constraints they labor under. In Section II, we examine data on the guest worker programs to understand whether concentrations exist in excess of federal merger scrutiny guidelines, whether associations between higher concentration levels and lower wages exist. Using a new model, we analyze how the results can be informative about the roles of both frictions and concentration in depressing guest worker wages. In Section III, we discuss our results and offer some policy implications of our findings.

\section{MONOPSONY AND MIGRATION}

\section{A. An Overview of Monopsony Power}

\footnotetext{
${ }^{17}$ For prior research that considers concentration among H-1B employers, see Anna Maria Mayda et al., The Effect of the H-1B Quota on the Employment and Selection of Foreign-Born Labor, European Economic Review 108 (2018): 105-128.
} 
With the exception of a few specialized areas in baseball and collegiate sports, ${ }^{18}$ antitrust concerns have long focused on output (i.e., product) markets and not input (i.e., labor) markets. Among economists, the consensus neoclassical model of perfect competition in labor markets surely reduced beliefs in the need for antitrust enforcement. Likely influenced by earlier work in the fields of industrial organization and trade, ${ }^{19}$ as well as developments in the search literature within labor economics, ${ }^{20}$ the twenty-first century breakdown in assumptions of perfect competition in labor markets began with the publication of Alan Manning's book, Monopsony in Motion. ${ }^{21}$ Manning proposed that the existence of frictions, such as the costs of job search, explain several observed labor market outcomes not predicted under perfect competition. The frictions posited by Manning explain these outcomes even in cases where several firms are competing to hire from the same pool of workers. In this section, we discuss two labor market structures — the first being the perfectly competitive framework and the second being a monopsonistic model, which is a framework nested within neo-classical economics. We also catalog the sources of monopsony power that can lead to imperfect competition in labor markets.

\section{Perfect Competition and Monopsonistic Models}

In a perfectly competitive model, a firm pays the last worker hired exactly what he or she is worth to the firm. In a monopsonistic model, a firm will pay the last worker hired only a

\footnotetext{
${ }^{18}$ See e.g., Ted Tatos, Deconstructing the NCAA's Procompetitive Justifications to Demonstrate Antitrust Injury and Calculate Lost Compensation: The Evidence Against NCAA Amateurism. The Antitrust Bulletin, 62(1), $184-236$ (2017).

${ }^{19}$ See e.g., Steven Berry et al. Automobile prices in market equilibrium. Econometrica, 841-890 (1995); Paul Krugman. Scale economies, product differentiation, and the pattern of trade. The American Economic Review, 70(5), 950-959 (1980). Marc J. Melitz. The impact of trade on intra-industry reallocations and aggregate industry productivity. Econometrica, 71, no. 6: 1695-1725 (2003).

${ }^{20}$ Kenneth Burdett \& Dale T. Mortensen. Wage differentials, employer size, and unemployment. International Economic Review, 257-273 (1998).

${ }^{21}$ Alan Manning, Monopsony in Motion: Imperfect Competition in Labor Markets, Princeton University Press, (2003). The model was originally proposed in Joan Robinson, The Economics of Imperfect Competition, Springer, (1969). We discuss her pioneering contributions in more detail below.
} 
fraction of her or his worth. Under the perfectly competitive framework, firms are price takers in wages, facing a perfectly elastic labor supply curve. In such a case, no worker would willingly work at a firm paying even slightly less than other firms; thus, even a $0.01 \%$ cut in wages would yield a $100 \%$ decrease in labor supply to the firm, in other words, the firm faces an infinitely (perfectly) elastic labor supply curve. Under imperfect competition, the labor supply curve to an individual firm is no longer perfectly elastic. In the monopsonistic model, workers cannot easily quit low-paying firms on account of the sources of monopsony power we describe below, such as market concentration or frictions. In a monopsonistic labor market, if the elasticity is two, a $10 \%$ cut to a firm's wages will reduce the number of workers willing to work for the firm in question by $20 \%$, whereas in a perfectly competitive market, the elasticity of supply would be infinity, as no worker would work at a firm that pays even a cent below the market wage. In summary, firms in competitive labor markets must pay the "going rate" or lose all of their workers, while firms in a monopsony model face an upward sloping labor supply curve where a wedge exists between wages earned and the value of the worker, yielding what Joan Robinson and other economists have called exploitation.

With knowledge of the elasticity of labor supply to the firm, it is possible to calculate the markdown between an employee's wage (w) and what the employee would earn in a competitive market. In a competitive labor market, we assume that the last worker hired would earn exactly what they contribute to the firm's bottom line, their Marginal Revenue Product of Labor or MRPL. The markdown is one minus the elasticity divided by the elasticity plus one. ${ }^{22}$ For example, if the elasticity is two, this worker will be paid $67 \%$ of their worth to the firm and

\footnotetext{
${ }^{22}$ Thus, in a competitive labor market wages are $\mathrm{w}=$ MRPL, and in a monopsonistic labor market, wages are $\mathrm{w}=(M R P L)\left(\frac{\varepsilon}{\varepsilon+1}\right)$ where epsilon $\varepsilon$ is the elasticity of labor supply to the firm. Markdown can be conceptualized as the percentage decrease in a monopsonistic wage relative to a competitive wage.
} 
markdown is therefore $33 \%$, while if the elasticity is nine, the worker receives $90 \%$ of their worth, and the markdown is therefore $10 \%$. As the elasticity increases toward infinity, the share of worth paid approaches $100 \%$, consistent with the predictions of the perfectly competitive model. A recent meta-analysis that examined over 700 estimates from 38 publications finds elasticities consistent with employers having the power to markdown wages between one-sixth and one-third of the wage that workers would earn in a competitive market. ${ }^{23}$

When applied to a real labor market context and the antitrust policies of the United States, the utility of the monopsony model is limited by several constraints. Antitrust law makes only specific exercises of employer monopsony power unlawful or suspect. The economic model of monopsony does not make such stark distinctions. Under a simple model of monopsony, the degree of power that firms have over workers is determined entirely by the elasticity of labor supply to the firm, which can be finite due to unlawful as well as natural and other lawful causes. To further categorize the sources of monopsony, we now proceed to discuss these potential causes of monopsony power.

\section{Labor Markets Characterized by Frictions and Concentration}

If a single firm comprises the entirety of labor demand in a given market (such as in a “company town"), the employer will clearly hold power over workers. In this case of pure monopsony, the firm will face the upward sloping market labor supply curve as not all workers will quit even when wages are cut. In Joan Robinson's original conception of the monopsony model, she proposed three specific reasons why firms may face an upward sloping labor supply curve even when different firms compete for the same workers.

\footnotetext{
${ }^{23}$ Anna Sokolova \& Todd A. Sørensen. Monopsony in Labor Markets: A Meta-Analysis. Institute for the Study of Labor (IZA) WP No. 11966. (2018).
} 
First, moderate geographic isolation may limit the number of workers who are available to work for a firm and who bear negligible commuting costs. Once the supply of these very local workers has been exhausted, a firm must then seek workers from outside its immediate geographic area, and pay them at a higher rate that includes explicit compensation as well as implicit compensation for the commuting costs that the workers must bear. Second, she argues that the "preference or custom" of workers may keep the worker tied to specific firms; this is conceptually similar to how market power in product markets arises in the form of monopolistic competition, where firms offer differentiated products to consumers with heterogeneous tastes. Finally, Robinson argues that simple ignorance of competing job opportunities may prevent perfect mobility of workers from lower paying to higher paying jobs.

For many decades, despite Robinson's argument for the existence of monopsonistic labor markets, most of what little attention academics paid to the monopsony model centered around rare cases of pure monopsony. Contemporary thought began to change with the publication of Manning's book, which is rooted in labor search models. The "New Monopsony" framework builds on search models by Dale Mortensen, which contributed to his award of the Nobel Memorial Prize in economics. Specifically, the Burdett-Mortensen search model mathematically formalizes the role of frictions in the labor market. ${ }^{24}$ Just as frictions in physics explain why objects in motion eventually come to rest in spite of inertia, frictions in the labor market help to explain why all workers will not instantaneously and costlessly flow from one job to another in response to the slightest wage difference. In other words, search frictions imply that labor markets are not perfectly competitive.

\footnotetext{
${ }^{24}$ See Burdett \& Mortensen, supra.
} 
Manning's work implies that the existence of frictions in search models creates finite labor supply elasticities to the firm. Thus, even when many firms are competing to hire the same workers, firms will have the power to choose the wage that they set, rather than have a specific wage from a perfectly competitive market dictated to them. Additionally, Manning develops a new framework for empirical estimation of the elasticity of labor supply to the firm, spurring a large growth in empirical estimates of this parameter. In empirical estimations using Manning's framework, any factor which reduces the frequency at which workers receive outside job offers will lead to measurable increases of employer labor market power. From a policy standpoint, the source of monopsony power does matter, and measurements that do not separate the source of monopsony power may have limited utility.

Challenges to conventional wisdom, by their nature, must often begin with an antithetical rebuke of an existing paradigm before developing a new more comprehensive thesis. This process certainly seems to be in motion for the labor economics literature on monopsony. Recent literature has moved beyond simply providing empirical evidence consistent with the existence of labor market frictions, and thus inconsistent with perfect competition, to now attempting to identify the sources of such frictions more clearly. ${ }^{25}$ In addition, recent work has begun to focus on explicitly anti-competitive instruments such as no-poach and non-compete agreements, ${ }^{26}$ moving costs, ${ }^{27}$ and market concentration. ${ }^{28}$

\footnotetext{
${ }^{25}$ For one exception, see Peter Brummund, Variation in Monopsonistic Behavior Across Establishments: Evidence from the Indonesian Labor Market, Working Paper (2011).

${ }^{26}$ Natarajan Balasubramania et al., Locked In? The Enforceability of Covenants Not to Compete and the Careers of High-Tech Workers, US Census Bureau Center for Economic Studies Paper No. CES-WP-17-09 (2018); Alan B. Krueger \& Orley Ashenfelter, Theory and Evidence on Employer Collusion in the Franchise Sector, Princeton IRS Working Paper No. 614 (2017).

${ }^{27}$ Tyler Ransom, Labor Market Frictions and Moving Costs of the Employed and Unemployed, Working Paper (2018).

${ }^{28}$ Benmelech et al., supra; Azar et al., supra.
} 


\section{Implications of Monopsonistically Competitive and Oligopsonistic Markets}

Market concentration limits the number of firms competing to hire workers in the labor market, yielding reduced outside options for workers. We can think of this as a concentrated or oligopsonistic labor market. When frictions other than concentration limit how easy it is to move between jobs, we can think of this as leading to monopsonistically competitive markets. As noted above, Robinson proposed that in addition to geographic isolation, factors such as worker preferences and ignorance of outside options can increase firm market power. In essence, ignorance is the cornerstone of the information frictions present in search models.

Oligopsonistic markets can be addressed in part by traditional antitrust policies such as increased scrutiny over mergers, especially when market concentration is already high and any merger will further increase this concentration. ${ }^{29}$ Measures used in product markets, such as the Herfindahl-Hirschman Index (HHI), can be used to subject any proposed merger to scrutiny using a market definition and concentration approach. ${ }^{30} \mathrm{~A}$ similar approach based on market definition and market concentration could be a means of examination of market power in specific labor markets that are highly regulated, such as the market for guest workers.

Frictions, whether natural or institutionally constructed, will effectively thin the size of the labor market for a given worker seeking a new job. There is a clear role for antitrust policy involving "institutional frictions" such as explicitly anti-competitive firm behavior involving monopsonistic collusion (e.g., no-poaching agreements, anti-enticing law, non-compete agreements) ${ }^{31}$ Antitrust policy may help restore labor markets to a more competitive state in this situation and litigation can right certain wrongs. In the case of guest workers, however, legally

\footnotetext{
${ }^{29}$ See Naidu, et al., supra.

${ }^{30}$ See U.S. Dep't of Justice \& Fed. Trade Comm'n, Horizontal Merger Guidelines, (2010).

${ }^{31}$ See Naidu \& Posner, supra.
} 
imposed barriers to mobility create institutional frictions that thin the labor market. Where this is the case, legislation would be required to address these inadequacies of the programs.

In addition to oligopsony and "institutional frictions," labor markets may be plagued by "natural frictions" that arise from the environment but are not enforced by the law. Naidu \& Posner argue that antitrust policies alone are not sufficient for addressing the consequences of imperfect competition which would arise even under laissez-faire. ${ }^{32}$ In a simulation, they show the impact of different levels of concentration as measured by HHI on wage. To address the implications of monopsony power, Naidu \& Posner suggest policies including stronger wage regulation, mandatory benefits, and stronger unions. While it is rare to see strong wage regulations in the United States, in the case of guest worker programs, the federal government has a heavy hand in setting the wages paid to workers by private sector firms.

Above, we distinguished sources of monopsony power between concentration - leading to oligopsony - and frictions - leading to monopsonistic competition. Below, in Section II.D., we attempt to quantify the relative importance of these different causes of deviation from a competitive labor market. In the following section, we proceed to describe the state of the art with respect to research on monopsony and immigration, provide institutional details about the guest worker programs, and details of the manner in which courts and advocates have pursued claims against employers under antitrust and other laws.

\section{B. Guest Worker Programs and Monopsony}

Features of guest worker programs provide an excellent setting to study monopsony and antitrust problems in general, and a handful of empirical studies in the economics literature

\footnotetext{
${ }^{32}$ See Id.
} 
already find some evidence that firms hold monopsony power over immigrants. ${ }^{33}$ As background, guest worker programs provide an important supply of labor to the U.S., with estimates of the number of guest workers ranging from 740,000 - 1.4 million workers in the U.S. in 2013. ${ }^{34}$ Depew, Norlander \& Sørensen ${ }^{35}$ (DNS) provide estimates that demonstrate that the degree and nature of mobility that H-1B and L-1 workers experience in the U.S. is not consistent with the notion that these workers are completely immobile indentured servants, tied to a single firm for the duration of their visa. While DNS rejects the claim the guest workers are completely immobile, their estimates are consistent with a monopsonistic labor market in which firms enjoy a significant degree of wage setting power over these workers. Using estimates calculated with the monopsony model wage setting equation, DNS found that workers on H-1B visas were paid $63.5 \%$ of their worth to their firm at an average unemployment rate of 7.89 percent. ${ }^{36}$ Naidu et al. examine labor markets for low-skilled guest workers in the United Arab Emirates, finding much more firm power over workers, along with evidence that the frictions imposed by such programs significantly lower wages further. ${ }^{37}$

\footnotetext{
${ }^{33}$ For studies of monopsony and undocumented immigrants, see Julie L. Hotchkiss \& Myriam Quispe-Agnoli, Employer Monopsony Power in the Labor Market for Undocumented Workers, Federal Reserve Bank of Atlanta, Working Paper 2009-14D (2009); Boris Hirsch \& Elke J. Jahn, Is there Monopsonistic Discrimination Against Immigrants? ILR Review, 68(3), 501-528 (2012).

${ }^{34}$ U.S. Dep't of Homeland Security. Office of Immigration Statistics Policy Directorate. Estimates of the Size and Characteristics of the Resident Nonimmigrant Population in the United States: Fiscal Year, 2014, (2016); See also Daniel Costa \& Jennifer Rosenbaum, Temporary Foreign Workers by the Numbers, Economic Policy Institute, (2017).

${ }^{35}$ Briggs Depew, Peter Norlander \& Todd A. Sørensen. Inter-firm Mobility and Return Migration Patterns of Skilled Guest Workers, Journal of Population Economics, 30(2), 681-721 (2017)[hereinafter DNS]. See also Jennifer Hunt \& Bin Xie. How Restricted is the Job Mobility of Skilled Temporary Work Visa Holders?, Journal of Policy Analysis and Management, 38: 41-64 (2017).

${ }^{36}$ These results are based on the assumption that the elasticity of labor supply to the firm is -2 multiplied by the voluntary separation elasticity.

${ }^{37}$ Suresh Naidu et al., Monopsony Power in Migrant Labor Markets: Evidence from the United Arab Emirates, Journal of Political Economy, 124(6), 1735-1792, (2016). That paper examines a policy reform that eased mobility restrictions for guest workers. While the U.S. relaxed mobility restrictions in AC21, which was signed into law in October 2000, that event that precedes the coverage of the data examined here.
} 
One would expect that abuses of workers in these programs would at least be partially reined in by competition in the labor market. Previous statements made by policymakers in support of liberalizing reforms support this. The American Competitiveness and Worker Investment Act for the $21^{\text {st }}$ Century of 2000 (AC21) reformed the H-1B program in order to ease mobility restrictions for workers seeking to switch employers. Senator Orrin Hatch motivated the role for competitive market pressures by stating "the market would not tolerate exploitation, especially given the fierce competition for skilled workers." ${ }^{, 38}$ Indeed, the first theorem of Welfare Economics states that any competitive market will always produce Pareto-Efficient outcomes, given some conditions. ${ }^{39}$

Those admitted legally through guest worker visa programs are vulnerable to employer abuse and exploitation because the markets are not perfect, although the sources of these imperfections have not been quantitatively parceled out. The core issue is that guest workers are less free to quit than their counterparts who have green cards or are citizens. ${ }^{40}$ In the next section, we address institutional frictions in guest worker programs that limit the freedom to quit and may lead to abuse independent of oligopsony. We then report on abuses that occur in guest worker programs based upon the results of a search for relevant law review articles and court cases related to exploitation seen in guest worker programs. We conclude with a discussion of several

\footnotetext{
${ }^{38}$ See DNS, supra, at 4, citing Orrin Hatch, U.S Senate, Senate Committee on the Judiciary Report, American Competitiveness in the 21st century, 106-260 (2000).

${ }^{39}$ Kenneth J Arrow \& Gerard Debreu, Existence of an Equilibrium for a Competitive Economy, 22 Econometrica, 256 (1954).

${ }^{40}$ Guest worker visas are called nonimmigrant visas because they do not lead to citizenship. Every guest worker visa restricts the ability of the visa holder to switch jobs by making it either explicitly unlawful to quit a job and remain in the country lawfully, or by requiring guest workers to obtain sponsorship from another employer in order to lawfully leave employment and remain in the country. Several of these visas are considered dual intent, under which guest workers can apply for citizenship while on the non-immigrant visa. See Ron Hira, Bridge to Permanent Immigration or Temporary Labor?, US Engineering in a Global Economy, 263 (2018); Norman Matloff, On the Need for Reform of the H-1B Non-Immigrant Work Visa in Computer-Related Occupations, 36 U. Mich. J.L. Reform 815 (2002-2003) on frictions created by the process.
} 
relevant cases and law review articles that raise questions that are particularly germane to antitrust issues and guest worker programs.

\section{Institutional Frictions}

Guest worker programs layer additional institutional frictions that may enhance monopsony power on top of the typical frictions of a labor market, and it is possible that remedies fundamentally lie not with antitrust, but through immigration, labor policy, and enforcement, whether by regulatory process, court decisions, or new legislation. For such legislation or enhanced enforcement of antitrust law to be effective, it is imperative to ascertain the extent to which different sources of monopsony influence the outcomes seen in guest worker programs. Institutional frictions limit employees' ability to search for new jobs and reduce the incentive for employers to enter the market for guest workers. Nearly all visas prohibit a guest worker from working for more than one firm at a time. Certain visas, such as the L-1 visa for intra-company transfer, prohibit workers from switching employers at all. While on such a visa, a guest worker who wishes to quit their employer must leave the United States and apply for a new visa sponsored by a new employer if they wish to stay in compliance with immigration law. This general threat of "loss of status" (or permission to stay lawfully in the U.S.) combined with fear

of loss of employment, gives employers of guest workers greater power over these workers than over a typical worker on account of reduced ability to separate from employment.

Most visas do allow guest workers to obtain a new job by receiving sponsorship from another employer. As part of the process, however, there are many institutional frictions faced by both the employee and employer alike. Due to barriers to firms sponsoring guest workers (additional visa costs, paperwork, political/reputational costs), the market to hire guest workers is not as broad as the overall labor market. An employer who wishes to hire guest workers already 
in the U.S. must undergo both a typical recruitment and hiring process with its attendant HR costs, as well as a change of employer process that carries additional costs for the employer. For the $\mathrm{H}-1 \mathrm{~B}$ program, visa costs are often a $75 \%$ increase over the baseline cost of filling a job vacancy for a skilled professional. ${ }^{41}$ Consider the process as it applies to each of the $\mathrm{H}$ visas. ${ }^{42}$ Any employer that seeks to hire guest workers, be they new entrants to the U.S. or already employed as guest workers elsewhere in the economy, must first obtain a LCA from the Department of Labor's (DOL) Education and Training Administration Office of Foreign Labor Certification (OFLC). While the DOL does not charge a fee, the paperwork burden includes an employer's time searching for the accurate occupational classification ${ }^{43}$ and the correct prevailing or minimum wage, as well as a legal attestation that the information provided by the employer is accurate and that they are experiencing shortages. ${ }^{44}$ Employers can be prosecuted both civilly and criminally for willfully misrepresenting information on the petitions under 20 CFR $\S 656.31(a)$.

The needed paperwork under the LCA process is estimated to have a burden of 1-2 hours to complete. After the DOL approves an LCA, an employer must file an I-129 form for a specific worker with the U.S. Citizenship and Immigration Services (USCIS). Costs for the H-1B program can be quite high as there are additional fees to combat fraud and to fund education for U.S. workers. Fees add up if the employer is large, is a H-1B dependent employer, or is seeking

\footnotetext{
${ }^{41}$ See DNS, supra, at 4, citing Dube et al., Employee Replacement Costs, IRLE Working Paper 201-10, (2010).

42 The H-1B for specialized workers such as computer programmers, the H-2A, for agricultural workers, and the H$2 \mathrm{~B}$, for seasonal workers.

${ }^{43}$ The OFLC currently uses the Standard Occupational Classification or SOC code.

${ }^{44}$ Contra this, employers are more likely to claim they are experiencing shortages when unemployment is higher. See Ben A. Rissing \& Emilio J. Castilla, Testing Attestations: U.S. Unemployment and Immigrant Work Authorizations, ILR Review, 69(5), 1081-1113 (2016).
} 
an expedited approval. ${ }^{45}$ The last step is for an employee to schedule an appointment with a U.S. embassy or consulate, and take the necessary actions to obtain a visa. There are substantial opportunity and logistical costs associated with each step in the process. To compare the readily quantifiable institutional frictions between visas, we standardize costs in Table 1 using an $\$ 120$ per hour estimate of billing rates for a paralegal $^{46}$ for all paperwork. ${ }^{47}$

Table 1 - Summary Costs of Institutional Frictions

\begin{tabular}{|c|c|c|c|c|c|c|c|}
\hline \multirow[t]{2}{*}{ Visa } & \multicolumn{2}{|c|}{$\begin{array}{c}\text { Step } 1 \text { - Obtain } \\
\text { LCA }\end{array}$} & \multicolumn{2}{|c|}{$\begin{array}{c}\text { Step } 2 \text { - Obtain USCIS } \\
\text { I-129 }\end{array}$} & \multicolumn{2}{|c|}{$\begin{array}{c}\text { Step } 3 \text { - Obtain } \\
\text { Visa }\end{array}$} & \multirow[t]{2}{*}{ Cost Estimate } \\
\hline & Fees & Time & Fees & Time & Fees & Time & \\
\hline $\mathrm{H}-2 \mathrm{~A}$ & - & 1 hour & $\$ 460$ & 4.26 hours & $\$ 160$ & $\begin{array}{l}1.25 \\
\text { hours }\end{array}$ & $\$ 1,401$ \\
\hline $\mathrm{H}-2 \mathrm{~B}$ & - & $\begin{array}{l}1.92 \\
\text { hours }\end{array}$ & $\$ 460$ & 4.26 hours & $\$ 160$ & $\begin{array}{l}1.25 \\
\text { hours }\end{array}$ & $\$ 1,512$ \\
\hline $\mathrm{H}-1 \mathrm{~B}$ & - & $\begin{array}{l}1.25 \\
\text { hours }\end{array}$ & $\begin{array}{l}\$ 460+ \\
\$ 750- \\
\$ 4,000 \text { in } \\
\text { fees }\end{array}$ & 5.26 hours & $\$ 160$ & $\begin{array}{l}1.25 \\
\text { hours }\end{array}$ & $\begin{array}{c}\$ 2,301- \\
\$ 6,301\end{array}$ \\
\hline
\end{tabular}

Table 1 demonstrates that guest worker programs incorporate additional paperwork burdens compared to the rest of the labor market. Along with the reforms of AC21, some regulations on job mobility were lessened, such as the earlier requirement that guest workers wait for government approval to switch jobs. As Sen. Hatch described: "The Committee further

\footnotetext{
${ }^{45}$ Under the H-1B Visa Reform Act of 2004, an employer with under 25 employees and certain conditions must pay an additional $\$ 750$, and an employer with 26 ore more employees must pay an additional $\$ 1,500$. An expedited visa costs \$1,000 additional. Under Pub. L. 111-230 (2010), firms with more than 50 employees and more than $50 \%$ of their workforce on visas must pay an additional fee of $\$ 2,000$. This was increased under Pub. L. 114-113 (2015) to \$4,000. This fee must also be paid at the time of change of status.

${ }^{46}$ We calculate the cost of the paperwork burden using the average regional billing rates of a paralegal in 2016. See, National Association of Legal Assistants, National Utilization \& Compensation Survey Report, (2016).

${ }^{47}$ The Department of Labor has 3 separate forms, for the H-2A, ETA 9142A, for the H-2B, ETA 9142B, for the H1B, ETA 9035. See: https://www.foreignlaborcert.doleta.gov/form.cfm. The USCIS form is the I-129: https://www.uscis.gov/forms/h-and-1-filing-fees-form-i-129-petition-nonimmigrant-worker. For the State Department form DS-160, see State Department: https://travel.state.gov/content/travel/en/us-visas/visa-informationresources/fees/fees-visa-services.html\#temp and https://travel.state.gov/content/dam/visas/PDF-other/DS160_Example.pdf
} 
facilitated this flexibility in S. 2045 by allowing an H-1B employee to change employers at the time a new employer files the initial paperwork, rather than requiring the employee to wait for the new H-1B application to be approved. ${ }^{, 48}$ Still, remaining institutional frictions limit the labor market through larger switching costs and a potentially thinner labor market.

For example, some visas are given for an initial period and can be extended once for the same duration. In the case of the $\mathrm{H}-1 \mathrm{~B}$, upon renewal of the initial three-year visa, there is a spike in quits due to guest workers seeking better firms. ${ }^{49}$ This is consistent with workers avoiding job search until after their visa renewal, and thus staying with bad employers because of these frictions. In other cases, visas are given either for a short period or an initial period determined on an individual basis. For the H-2A visa, for example, the maximum duration is one year, but the approved duration could be the harvest season for a particular region and crop. Such short periods could also restrict the number of employers willing to hire a guest worker.

\section{Abuses and Lawsuits}

To identify the visas of concern and the types of abuses seen in the programs, we searched for lawsuits and law review articles involving guest worker abuses. ${ }^{50}$ Across guest worker programs, abuse allegations range from conditions of indentured servitude to commonplace wage theft and poor working conditions. Guest workers are often subjected to fraudulent and coercive recruitment in their home country, followed by wage theft, safety violations, poor living conditions, intimidation and retaliation by an employer that is often no

\footnotetext{
${ }^{48}$ See Hatch, supra.

${ }^{49}$ See DNS, at 9.

${ }^{50}$ We iteratively searched Lexis-Nexis for terms "guest worker," both with and without labor and employment law filters, and "foreign worker," and by using Nexis headnotes that allow for filtering all cases under the label "Types of Nonimmigrant Visa." This search resulted 163 relevant federal lawsuits since 1990, the year of the last major legislative update of many of these nonimmigrant programs. In addition, 48 relevant law review articles written since 2013 were examined. Relevant cases and law articles were coded to learn about the types of abuse occurring in each program, as well as the number of issues in each program.
} 
more than a labor market intermediary. ${ }^{51}$ Several noteworthy articles include criticisms of the J-1 visa program that sponsors au pairs and domestic workers, ${ }^{52}$ the $\mathrm{H}-1 \mathrm{~B}$ program for computer professionals, ${ }^{53}$ the $\mathrm{H}-2 \mathrm{~A}$ program for agricultural workers, ${ }^{54}$ and the $\mathrm{H}-2 \mathrm{~B}$ program for temporary seasonal workers. ${ }^{55}$ For workers trapped in these situations, a lack of protection from retaliatory practices and incentives for reporting has left employers unaccountable. ${ }^{56}$

To examine complaints regarding guest worker programs, we coded the legal basis for complaints in lawsuits against employers of guest workers. For example, any complaint that alleged underpayment of promised wages was coded as a "wage and hour" complaint, and any complaint involving sexual harassment was coded "discrimination." We also coded fraud, trafficking, and antitrust claims. ${ }^{57}$ Figure 1 summarizes the visas and the specific complaints contained in guest worker related lawsuits since 1990. This illustrates a diverse set of abuses concentrated in a small number of guest worker visa programs. While law articles tend to address problems with multiple visas, most of the lawsuits are filed with respect to the H-1B, H-2A, or

\footnotetext{
${ }^{51}$ See Lucy Benz-Rogers, Relief for Guestworkers: Employer Perjury as a Qualifying Crime for U Visa Petitions, 42 Fordham Urb. L.J. 193 (2014); Jennifer Gordon, Regulating the Human Supply Chain, 102 Iowa L. Rev. 445 (2016).

${ }^{5}$ See Janie A. Chuang, The US Au Pair Program: Labor Exploitation and the Myth of Cultural Exchange. Harv. JL \& Gender, 36, 269 (2013).

53 See Matloff, supra.

${ }^{54}$ See Lisa Guerra, Modern-Day Servitude: A Look at the H-2A Program's Purposes, Regulations, and Realities, 29 Vt. L. Rev. 185 (2004).

${ }^{55}$ See Bryce W. Ashby, Indentured Guests-How the H-2A and H-2B Temporary Guest Worker Programs Create the Conditions for Indentured Servitude and Why Upfront Reimbursement for Guest Workers' Transportation, Visa, and Recruitment Costs is the Solution. U. Mem. L. Rev., 38, 893 (2007).

${ }^{56}$ See Elizabeth Lincoln, Accountability for Pesticide Poisoning of Undocumented Farmworkers, 24 Hastings W.N.W. J. Env. L. \& Pol'y 383 (2018).

${ }^{57}$ For coding purposes, discrimination claims include all complaints brought under Title VII of the Civil Rights Act, and relate to discrimination on the basis of national origin, race, and sex, including sexual harassment and hostile work environments. Fraud claims and conspiracy to commit fraud claims brought under the Racketeering Influenced and Corrupt Organizations (RICO) Act related to false employer claims made in documentation either provided to the workers at the time of recruitment, or to the government when acquiring visas. Trafficking claims related to violations of the Trafficking Victims Protection Act (TVPA), and in one case, the Thirteenth Amendment, which bans slavery and indentured servitude, including debt peonage. Trafficking claims often involve employers seizing workers' passports to prevent employees' ability to return home, as well as false imprisonment and curtailing workers' ability to move freely outside of a labor camp or worksite (including ambassadors' residences in several cases).
} 
the $\mathrm{H}-2 \mathrm{~B}$ program. This makes sense, as the $\mathrm{H}-2 \mathrm{~A}$ program for agricultural workers, the $\mathrm{H}-2 \mathrm{~B}$ program for non-agricultural workers, and the H-1B program for specialty occupations are among the largest guest worker programs. ${ }^{58}$

\section{Figure 1 - Federal Claims Brought in Guest Worker Cases 1990-2017}

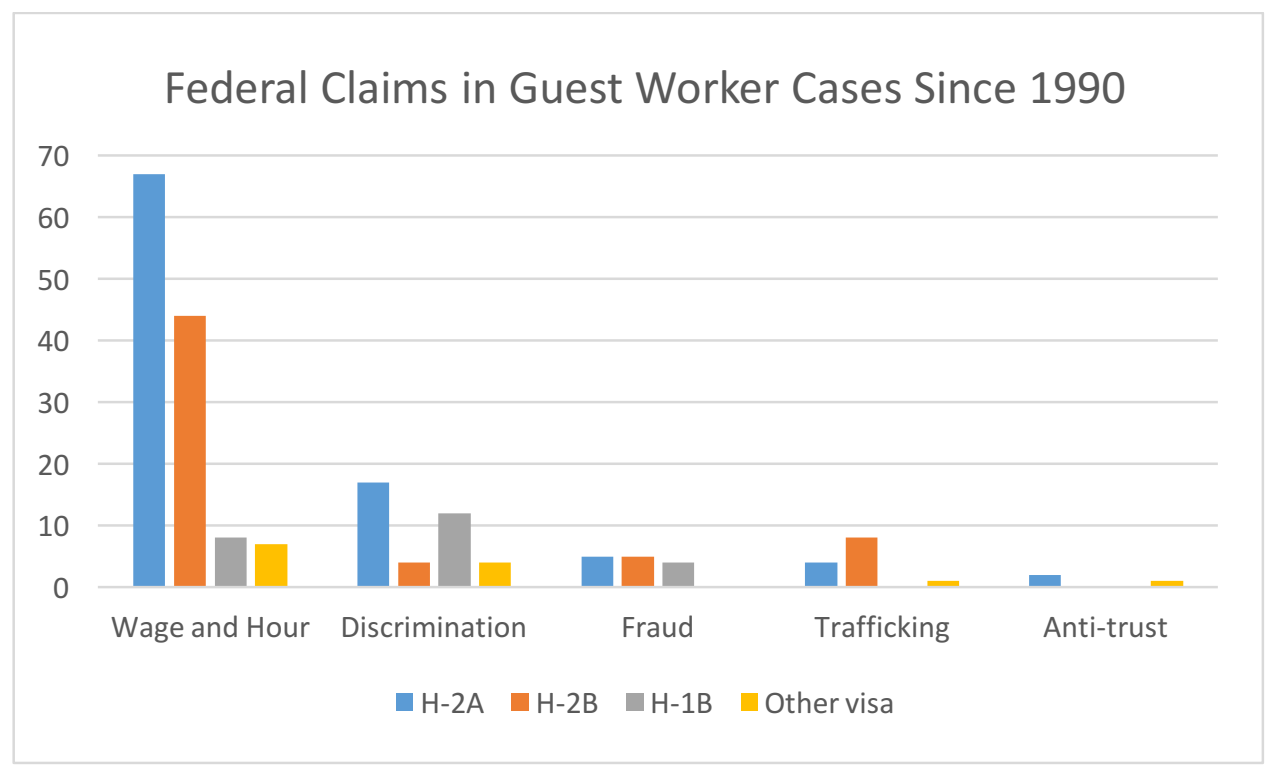

The number of allegations (193) depicted in Figure 1 is greater than the number of cases (163), as a single court matter often involves claims of violations of multiple laws. In reviewing complaints included in the lawsuits, the most common allegation involved wage and hour claims under the Fair Labor Standards Act or the Migrant and Agricultural Workers Protection Act. ${ }^{59}$

\footnotetext{
${ }^{58}$ See Costa \& Rosenbaum, supra. The J-1 program for exchange visitors and the F-1 program for foreign students who wish to work following degree completion are larger than the H programs, yet attract fewer lawsuits, perhaps because their emphasis is on cultural exchange rather than work, although this has attracted notable criticism (see, e.g. Chuang, supra).

${ }^{59}$ Worker protections in the guest worker programs include a requirement that employers pay guest workers a minimum rate. Wage and hour claims arise when workers are paid less than the minimum wage, less than the required wage (the prevailing or adverse effect wage rate, depending upon the program), less than a labor condition application stated, or when workers face illegal deductions for recruitment / travel costs, housing, or denial of pay stubs, timely pay, and overtime. After wage and hour violations, the most common complaints brought regarding guest worker programs involved discrimination, followed by fraud, trafficking, and lastly, antitrust.
} 
One hundred eleven of these complaints arose under the $\mathrm{H}-2 \mathrm{~A}$ and $\mathrm{H}-2 \mathrm{~B}$ programs. While antitrust cases brought by guest workers appear to be small in number, this may in part be due to the structure of the programs that require employers to pay guest workers at least a minimum rate. In Rios v. Marshall, 530 F. Supp. 351 1981, when migrant fruit workers alleged discriminatory wages, the Court ruled against them and granted limited antitrust immunity to fruit grower defendants because the DOL is authorized to regulate wage rates for H-2A workers. Two recent antitrust lawsuits brought by guest workers, and legal commentary, have invigorated the discussion of guest workers and antitrust concerns.

\section{Oligopsony and Antitrust Law}

Two recent lawsuits, one permitted to proceed and one rejected by the courts, include antitrust claims brought on behalf of guest workers. These lawsuits allege that two or more oligopsonistic employers colluded with one another in order to illegally suppress guest worker wages. In one recent antitrust lawsuit, Beltran v. InterExchange, Inc., 2018 U.S. Dist. LEXIS 23940, plaintiffs represent a class of all au pairs on J-1 visas. The suit claims that sixteen defendant companies, which represent $100 \%$ of the sponsors of au pairs, conspired to fix wages at an artificially low floor, to prevent wage competition. Plaintiffs allege that the companies committed price fixing and misrepresented actual wages of au pairs in recruitment materials and advertisements. In this case, plaintiffs hired an investigator who was told by representatives of the sponsors that they had agreed to keep au pair wages as low as possible. This "smoking gun" proved essential for the plaintiffs. While the court decided the evidence was "weak," the case was allowed to go forward due to the combination of circumstantial factors and the limited available evidence. 
In the second case, Llacua v. Western Range Ass'n, 2016 U.S. Dist. LEXIS 193120, the plaintiffs were five Peruvian sheepherders who were recruited on H-2A visas and paid the minimum DOL-set wage floor at five different ranches. The sheepherders sued the five ranchers, as well as the Western Range Association (WRA), and the Mountain Plains Agricultural Service (MPAS) under antitrust law. The ranchers had hired the WRA and the MPAS to represent them in recruiting and employing foreign-born sheepherders and offered standard wages to the workers. Despite the evidence that the ranches used a common agent to sponsor guest workers, because the plaintiffs offered no specific evidence of conspiracy to fix wages in the Llacua case, the Court held that "the conspiracy is not plausible if in light of common economic experience the alleged conduct is equally likely to result from independent action."

In order to succeed in an antitrust matter, plaintiffs must show evidence of a conspiracy "from an agreement," not merely from the "independent decisions" of individual businesses. ${ }^{60}$ Regardless of the legal bar for proving a case, both unlawful collusion and independent decisions can create a monopsonistic effect of depressing a worker's wages below their value to the firm. To protect citizens and guest workers, the $\mathrm{H}-1 \mathrm{~B}$ and $\mathrm{H}-2 \mathrm{~B}$ programs require employers to pay the prevailing wage in the specific occupation in which the worker is employed. Protections such as these prevailing wage requirements for workers might serve as an effective check on market power and enhance welfare, as a well-designed wage regulation in a monopsonistic labor market raises both employment levels and wages. However, for many years the regulations gave employers the right to select the survey, occupation and experience level. This may allow employers to still exercise their monopsony power by giving them the ability to define the

${ }^{60}$ See Bell Atl. Corp v. Twombly, 550 U.S. 544, 553, 127 S. Ct. 1955, 167 L. Ed. 2d 929, (2007). 
market. ${ }^{61,62}$ Thus, the degree to which employers are able to exercise this power is an empirical question, and our analysis will shed some light on this.

As a further example of potential actions that allow for the exercise of monopsony power without violating the law, Lee states in connection with monopsony power and the $\mathrm{H}-2 \mathrm{~A}$ and $\mathrm{H}-$ 2B program: "employers can essentially price-fix a suboptimal wage for these jobs so they will attract few U.S. workers." 63 Under the H-2A program, the wage floor is the Adverse Effect Wage Rate or the "“annual weighted average hourly wage rate' for field and livestock workers for the region obtained from the annual Farm Labor Survey conducted by the U.S. Department of Agriculture." Lee argues that because $50-70 \%$ of agricultural workers are undocumented, employers can suppress wages prior to survey administration by employing non-native workers to be included in the survey.

Beltran and Llacua illustrate how collusion among employers has been very difficult to prove in the absence of a "smoking gun." In contrast, enhanced antitrust scrutiny is merited and may be more effective when markets clearly display circumstantial evidence of monopsony power and a "smoking gun" is absent. This suggests an important role for Industrial Organization Economists and Labor Economists to examine such markets with quantitative methods to better identify places where anti-competitive outcomes may be occurring, and where antitrust oversight may be most important. In the following section, we perform such an analysis of three guest

\footnotetext{
${ }^{61}$ See Maria L. Ontiveros, H-1B Visas, Outsourcing and Body Shops: A Continuum of Exploitation for High Tech Workers, 38 Berkeley J. Emp. \& Lab. L. 1 (2017).

${ }^{62}$ While employers still face the choice of the level and occupation of their guest workers, the H-1B Visa Reform Act of 2004 provided a good faith compliance defense to employers that use the recognized industry standard wage survey to identify the prevailing wage. For this reason, the choice of survey now largely defaults to the use of the Bureau of Labor Statistics Occupational Employment Survey.

${ }^{63}$ See Jennifer J. Lee, U.S. Workers Need Not Apply: Challenging Low-Wage Guest Worker Programs, 28 Stan. L. \& Pol'y Rev 1 (2017).
} 
worker programs to determine if it would be possible to make a prima facie case that oligopsony is a cause for concern.

\section{EVIDENCE OF OLIGOPSONY AND FRICTIONS IN GUEST WORKER WAGES}

This section presents results from our analysis of the degree of imperfection in three guest worker visa programs. Given the abuses in guest worker programs, we seek to address two fundamental questions. First, we seek to establish whether guest worker labor markets are highly concentrated. If guest worker labor markets show no signs of concentration, then antitrust law has little relevance, and guest workers work in occupations and places where there is ample competition among employers for workers. If there is evidence of concentration, then it is necessary to pose a second question: could concentration lower guest worker wages? If concentration is unrelated to wages, then this suggests that firms cannot exercise their oligopsonistic power to set wages. In Section A below, we first describe the construction of the dataset used in the analysis in detail, then proceed in Sections B and C to the two questions posed above, and finally, in Section D, to estimate the relative importance of oligopsony and frictions as influences on guest worker wages.

\section{A. Data Construction}

As documented above, the $\mathrm{H}-1 \mathrm{~B}, \mathrm{H}-2 \mathrm{~A}$, and $\mathrm{H}-2 \mathrm{~B}$ visa programs attract the largest number of complaints and represent a large share of granted visas. From a process perspective, all three programs require that employers apply for a Labor Condition Application (LCA) from the Department of Labor (DOL) prior to petitioning for a visa. The LCA process creates a record of every application by an employer for a guest worker visa, and despite some limitations, can serve as a good proxy for firm-level demand for guest workers. 
For our analysis, we use annual LCA disclosure data from the DOL's Education and Training Administration Office of Foreign Labor Certification (OFLC) to analyze employerspecific wages and program-specific concentration ratios. The OFLC makes raw data publicly available from its website. ${ }^{64}$ The OFLC has responsibility over several of the largest nonimmigrant guest worker programs including the H-2A, H-2B, and H-1B. Data on H-1B workers with a college degree in "specialty occupations" is available for fiscal years 2001 to 2017, the H2B data for non-agricultural temporary workers is available from 2000 to 2017, and the H-2A program data for agricultural workers is available from 2006 to 2017.

The data requires extensive cleaning. We clean the data and create single files that consistently capture the following variables across programs and years as reported by the employer: employer name, dates (start and end), employer state ${ }^{65}$ and zip code, minimum legally mandated wage, lowest wage promised to be paid to employee, and job title and occupation of

\footnotetext{
${ }^{64}$ See https://www.foreignlaborcert.doleta.gov/performancedata.cfm and FLCDataCenter.com.

${ }^{65}$ Our baseline geographic definition of the labor market at the state level is generally broader than for other papers in this literature, though our population of workers is also different. One concern may be that even a state level definition of a labor market may be too broad for guest workers; if these individuals were willing to uproot their lives and move potentially thousands of miles from home in search of better job opportunities, it seems plausible that they might also be much more likely than native born workers to move within the United States to further improve their lot. While we do not have demographic data on the individual guest workers who may be filling the LCA data that we examine, we are able to provide some justification for our market definition with an analysis of survey data. We use the 2005-2017 American Community Survey, which contains individual level data on interstate mobility. Here, we employ observations for over 22 million individuals age 18 to 65 (inclusively) who lived in the United States the year before the survey. We find evidence that foreign born individuals are actually less mobile than native born workers overall, even after including a broad set of controls including a quadratic of age indicators for educational attainment level, marital status, and the year and state of the current residence for each observation. There is heterogeneity in these relative mobility patterns by level of education. When examining individuals with less than a high school education, raw annual interstate mobility rates are $1.25 \%$ for the foreign born, as compared to $1.88 \%$ for native born individuals, with the mobility difference being statistically significantly lower for the foreign born when including the above-mentioned controls. The reverse is true for college educated workers, with raw mobility rates being $3.27 \%$ for the overall population, and $3.34 \%$ and $3.25 \%$ for the foreign- and native-born populations, respectively. Once including the above controls, we find a statistically significant 0.3 percentage point higher rate of mobility among the foreign born which corresponds to these individuals being about $10 \%$ more likely to move over the overall baseline. Generally, the fact that over $96 \%$ of even college educated workers remain in the same state from one year to the next helps to provide some justification for considering this to be a relevant market. Because zip code data is available, in some specifications for H-1B workers, we also consider a narrower definitions of the geographic labor market, namely commuting zones. See infra, at 78.
} 
worker. Crucially, we only observe data on potential jobs in the form of certified LCAs; we do not know whether all of these jobs were filled (or even posted). However, to some extent the nature of this data mirrors best practices in this literature: it is the existence of new potential job options, and the corresponding degree of concentration of these jobs among potential new employers, which likely best describes market concentration from the perspective of a worker seeking to improve their lot, rather than the distribution of existing jobs. ${ }^{66}$

In our raw data, occupational coding is based on two different classification methods. The Dictionary of Occupation Titles (DOT) is used for occupational coding in the years 20012009. After 2009, occupations are coded primarily using 2010 Standard Occupational Classification (SOC) codes. For consistency in occupational measurement, we crosswalk DOT 3digit occupations to 2-digit SOC codes. ${ }^{67}$ The relationship between the 3-digit DOT level and the 2-digit SOC level is not a 1:1 mapping. To obtain the most consistent mapping, we allocate 3digit DOT codes to a 2-digit SOC if a 2-digit code was the predominant 1:1 mapping at the 6digit level. ${ }^{68}$ For example, if there are three unique 3-digit (6-digit) DOT codes and two of the three mapped to a 2-digit SOC code of 17, then all three are coded as 17.

The occupations of guest workers vary significantly across programs. We examine the 22 civilian occupations as defined by the SOC Codes "Major Group" (two-digit) definitions. This level of aggregation is justified by low rates of mobility between occupations at this level. Only around $8 \%$ of non-citizen workers who underwent a change in employment status also

\footnotetext{
${ }^{66}$ See discussion infra, at footnotes 74-75.

${ }^{67} \mathrm{We}$ crosswalk DOT occupational codes to SOC occupational codes using a crosswalk supplied by O*NET (https://www.onetcenter.org/crosswalks.html).

${ }^{68}$ DOT coding has the following form, XXX.XXX-XXX. A 3-digit designation is the first three digits of an occupation code. The SOC has the following coding form, XX-XXXX.XX. A 2-digit aggregation is denoted by all occupation codes that share the same first two digits. Aggregation of SOC codes at the 2-digit level is also known as aggregating occupations at the "Major Group" level.
} 
transitioned between different occupations under this definition annually. ${ }^{69}$ Furthermore, the top five and top seven occupations account for over $90 \%$ of certified LCAs for $\mathrm{H}-1 \mathrm{~B}$ and $\mathrm{H}-2 \mathrm{~B}$ workers, respectively. We present the relative frequency of the most common occupations for each of these visa programs in Table 2. The lack of overlap between these occupations underscores the different nature of these programs. In addition, it is worthwhile to note that guest workers are much more concentrated in a narrow set of occupations relative to the general population, as would be expected given that guest workers visas are awarded in only specific occupations. Note that given the nature of the H-2A program, we code all certified LCAs in this program to Farming, Fishing and Forestry Occupations (45).

Table 2 - Top Occupations in H-1B and H-2B Data

\begin{tabular}{|l|l|l|l|}
\hline \multicolumn{2}{|c|}{ H-1B } & \multicolumn{2}{c|}{ H-2B } \\
\hline Occupation and SOC Code & Percent & Occupation and SOC Code & Percent \\
\hline Computer and Mathematical (15) & $35 \%$ & $\begin{array}{l}\text { Building and Grounds Cleaning } \\
\text { and Maintenance (37) }\end{array}$ & $44 \%$ \\
\hline Architecture and Engineering (17) & $15 \%$ & Production (51) & $12 \%$ \\
\hline $\begin{array}{l}\text { Business and Financial Operations } \\
(13)\end{array}$ & $13 \%$ & Construction and Extraction (47) & $10 \%$ \\
\hline $\begin{array}{l}\text { Management (11) } \\
\text { Life, Physical, and Social Science } \\
\text { (19) }\end{array}$ & $9 \%$ & $\begin{array}{l}\text { Food Preparation and Serving } \\
\text { Related (35) }\end{array}$ & $9 \%$ \\
\hline $\begin{array}{l}\text { Healthcare Practitioners and } \\
\text { Technical (29) }\end{array}$ & $8 \%$ & Farming, Fishing and Forestry (45) & $6 \%$ \\
\hline $\begin{array}{l}\text { Education, Training, and Library } \\
(25)\end{array}$ & $5 \%$ & Personal Care and Service (39) & $5 \%$ \\
\hline
\end{tabular}

\footnotetext{
${ }^{69}$ We use 2006-2016 monthly data for non-citizens aged between 18 and 65 (inclusive), and code current and previous occupations for workers who experienced a break in employment during the period of study. See Sarah Flood et al. Integrated Public Use Microdata Series, Current Population Survey: Version 6.0 [dataset]. Minneapolis, MN: IPUMS (2018). https://doi.org/10.18128/D030.V6.0
} 
Despite the difficulty working with LCA data, a number of previously published studies have used this data. ${ }^{70}$ As stated above, one disadvantage of the data is that not all approved applications correspond to actual hiring. Such data is publicly available from United States Citizenship and Immigration Services (USCIS). However, USCIS data also has limitations: occupation data is missing and is only available for a limited number of years, and with the number of workers hired often censored. ${ }^{71}$ Our preference for the LCA data stems primarily from the fact that it comes with administrative data on the occupation, which is an important part of the definition of the relevant market.

There are several decisions made in creating the LCA data that require the exercise of judgment and the use of caution in interpretation. In cleaning the raw data, we drop a number of observations due to inconsistencies that make the data difficult to import. We discard all applications rejected by the OFLC, thus restricting our use to only applications that are certified. After these steps, we are able to retain $94 \%$ of the observations in the raw $\mathrm{H}-1 \mathrm{~B}$ data, $96 \%$ of the raw observations in the $\mathrm{H}-2 \mathrm{~A}$ data, and $78 \%$ of the raw observations in the $\mathrm{H}-2 \mathrm{~B}$ data. We also address the problem of typographical errors and reduce bias due to outliers in the wage data by winsorizing the dataset in the following ways: we replace the top and bottom $5 \%$ of wage values in the $\mathrm{H}-1 \mathrm{~B}, \mathrm{H}-2 \mathrm{~A}$ and $\mathrm{H}-2 \mathrm{~B}$ data within years with the $95^{\text {th }}$ and $5^{\text {th }}$ percentile, respectively. We also winsorize the number of guest workers sponsored by a given firm at the $99^{\text {th }}$ and $1^{\text {st }}$

\footnotetext{
${ }^{70}$ See e.g., Madeline Zavodny. The H-1B Program and its Effects on Information Technology Workers. Economic Review-Federal Reserve Bank of Atlanta, 88(3), 33-44, (2003). William R. Kerr \& William F. Lincoln, The Supply Side of Innovation: H-1B Visa Reforms and US Ethnic Invention, Journal of Labor Economics, 28(3), 473-508, (2010). Gaurav Khanna \& Munseob Lee, High-Skill Immigration, Innovation, and Creative Destruction. In Ganguli et al., supra.

${ }^{71}$ In its report on guest worker programs, GAO, supra, the GAO recommended DOL and USCIS share data to better identify potential abusers of the program.
} 
percentile. ${ }^{72}$ We inflate all wage data to 2018 prices using the Consumer Price Index. We then manually inspect and correct firm names for at least the largest 5\% of firms in each program. In doing so, we reduced the chances that a firm entered with various spellings will be inappropriately captured more than once in the data.

Further interpretive caution is in order. First, weighted results are meant to represent the average worker's experience of the labor market, but in the case of intermediary firms, the weighted results, in particular, may be skewed by a difference between the observed employer of record's location and the location of the employee. ${ }^{73}$ To address this, we calculated the ratio of the largest firm (in terms of employment of guest workers) to the median firm in each market and dropped the most skewed one percent of markets. ${ }^{74}$ As the preliminary step in the process of hiring guest workers, it is possible that an employer either obtains more permissions than necessary or decides to cease the process at a later stage. Ex-ante, it is not clear whether this data would show evidence of more or less market concentration than equivalent data on the number of workers actually hired; this would depend upon how the distribution of unfilled jobs varies with a firm's size in this labor market. Therefore, an HHI obtained from the LCA data may better represent the degree of competitiveness in a labor market: the key characteristic of labor market competition from the perspective of the worker looking for a new job is the number of outside

\footnotetext{
${ }^{72}$ Winsorization replaces rather than removes potential outliers with a maximum or minimum value, and thus reduces bias in estimates toward the extremes. See Webber, supra for another use of winsorization to address similar challenges.

${ }^{73}$ For example, the weighted results at the commuting zone level for the H-1B program appeared to be driven by a small number of commuting zones with a large number of workers. We found this was due to a few cases in which a single firm reported sponsoring an extremely high number of guest workers while using their zip code as the reported work location. Such firms could be readily identified as international labor market intermediaries, see, Peter Norlander \& Arup Varma, H-1B and L-1 Visa Sponsored Guest Workers in the USA: An Analysis of the Strategic Impact of Indian and Other Firms, Thunderbird International Business Review, (forthcoming).

${ }^{74}$ This had little or no impact on the state-level analysis, as the most skewed markets were in nearly all cases at the commuting zone level.
} 
options which are available. Other works use similar approaches when examining concentration and wages. $^{75}$

\section{B. Are Guest Worker Labor Markets Oligopsonistic?}

The Department of Justice (DOJ) applies a standard methodology to analyzing the facts regarding the potential antitrust implications of a merger. ${ }^{76}$ We follow Azar et al. in using these guidelines to study labor markets and perform the first in-depth examination of concentration in the guest worker programs, as well as one of a handful of studies of how concentration, at the occupational level, correlates with wages. ${ }^{77}$ We report in Table 3 summary statistics for each guest worker program, including the mean and standard deviation for the HHI, number of firms, and wage including both unweighted and weighted averages. From this table, it is possible to see that in both the $\mathrm{H}-2 \mathrm{~B}$ and the $\mathrm{H}-1 \mathrm{~B}$ programs, the average market (or the unweighted) $\mathrm{HHI}$ is greater than the DOJ's concentration threshold, and that the average worker (weighted) also faces a market that meets the DOJ's threshold. It is also noteworthy that the average number of firms in a market suggests a higher level of competition than does the HHI, consistent with a market structure of one or two dominant firms and a competitive fringe of a large number of small firms. We are able to construct this measure for far more markets for the H-2B visa than the H-1A visa (in large part on account of the H-2B visa serving multiple two-digit occupations). The H-1B visa provides even more data, especially when we extend our analysis to the

\footnotetext{
${ }_{76}^{75}$ See, Azar et al., supra.

${ }^{76}$ These definitions of concentration are given in Horizontal Merger Guidelines, supra. Previous definitions of Moderate Concentrated and Highly Concentrated were 1000 and 1800, respectively in the 1982, 1984, 1992 and 1997 versions of the guidelines. See, Department of Justice, AntiTrust Division, Merger Enforcement, https://www.justice.gov/atr/merger-enforcement.

${ }^{77}$ See, Azar et al., supra; Pedro S. Martins, Making Their Own Weather? Estimating Employer Labour-Market Power And Its Wage Effects, CGR Working Paper 95 (2018); Alan Kwan \& Yukun Liu, Labor Market Power and Firm Financial Flexibility, SSRN Working Paper (2018).
} 
commuting zone level. H-1B workers are generally much higher paid than workers under either of the H-2 programs.

We present our calculations of HHIs for various labor markets in Figure 2. The Figure is arranged into four columns, which display data (from left to right) on the $\mathrm{H}-2 \mathrm{~A}, \mathrm{H}-2 \mathrm{~B}$, and $\mathrm{H}-1 \mathrm{~B}$ visa programs. For the H-1B program, on which we have significantly more data, we present the results of analysis at both the state and commuting zone level. ${ }^{78}$ The top row in the figure presents average HHI values, while the bottom row displays data on the share of markets that would meet a threshold of concentration (1500 or above, according to DOJ standards). We present results using a state-level analysis of a labor market. To the best of our knowledge, no papers exploring market concentration and wages in the recent literature have used any measures broader than state. Thus, if our measures of concentration are prone to bias, they are likely underestimating the degree of concentration.

\section{Table 3 - Descriptive Statistics}

\begin{tabular}{|c|c|c|c|c|c|c|}
\hline & & \multicolumn{2}{|c|}{ Unweighted } & \multicolumn{2}{|c|}{ Weighted } & \multirow[b]{2}{*}{$\mathrm{N}$} \\
\hline & & Mean & Std. Dev. & Mean & Std. Dev. & \\
\hline \multirow{3}{*}{$\begin{array}{c}\mathrm{H}-2 \mathrm{~A}, \\
\text { State }\end{array}$} & HHI & 1368 & 1880 & 649 & 851 & 601 \\
\hline & Wage & $\$ 22,603.19$ & $\$ 2,959.59$ & $\$ 22,233.42$ & $\$ 2,641.25$ & 601 \\
\hline & Number of Firms & 123 & 163 & 299 & 263 & 601 \\
\hline \multirow{3}{*}{$\begin{array}{c}\mathrm{H}-2 \mathrm{~B}, \\
\text { State }\end{array}$} & $\mathrm{HHI}$ & 5379 & 3612 & 1505 & 2151 & 7127 \\
\hline & Wage & $\$ 29,161.58$ & $\$ 18,194.98$ & $\$ 27,328.06$ & $\$ 15,067.12$ & 7127 \\
\hline & Number of Firms & 12 & 31 & 82 & 93 & 7127 \\
\hline \multirow{3}{*}{$\begin{array}{c}\mathrm{H}-1 \mathrm{~B}, \\
\text { State }\end{array}$} & $\mathrm{HHI}$ & 3112 & 3369 & 1846 & 2309 & 11614 \\
\hline & Wage & $\$ 66,202.21$ & $\$ 19,215.02$ & $\$ 77,488.13$ & $\$ 11,550.98$ & 11614 \\
\hline & Number of Firms & 132 & 407 & 1795 & 1765 & 11614 \\
\hline \multirow{2}{*}{$\begin{array}{c}\mathrm{H}-1 \mathrm{~B} \\
\mathrm{CZ}\end{array}$} & $\mathrm{HHI}$ & 5802 & 3637 & 1467 & 2104 & 56802 \\
\hline & Wage & $\$ 68,977.62$ & $\$ 26,395.94$ & $\$ 75,494.52$ & $\$ 15,148.29$ & 56802 \\
\hline
\end{tabular}

\footnotetext{
${ }^{78}$ Commuting zones are interrelated geographic areas with respect to labor markets. Commuting zones combine county boundaries that representing geographical markets between employers and employees.
} 
Figure 2 - Employer Concentration Levels (HHI) for H-2A, H-2B, and H-1B Visas

H-2A
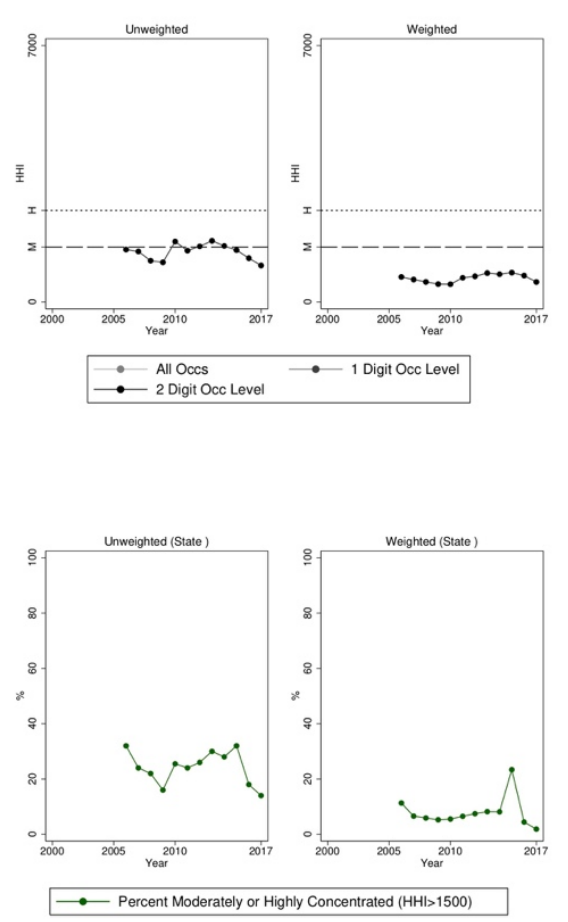

H-2B

H-1B State

Average HHIs
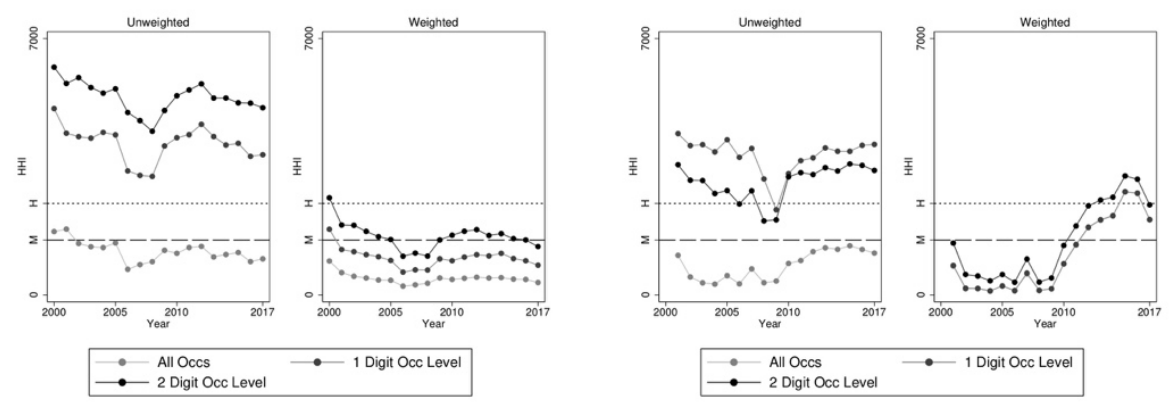

Concentration Percentages
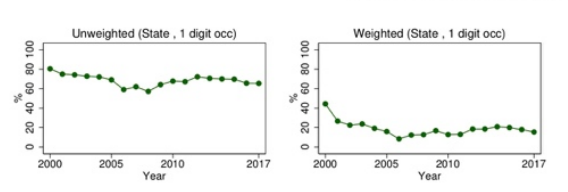

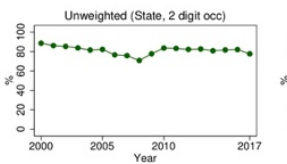

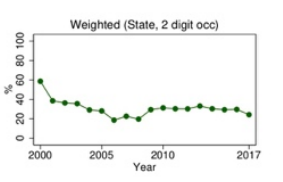

$\longrightarrow$ Percent Moderately or Highly Concentrated (HHI $>1500)$
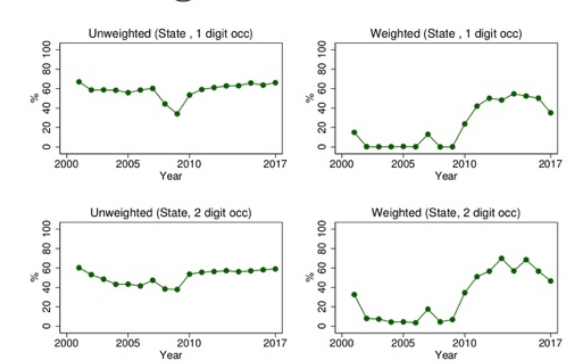

$\longrightarrow$ Percent Moderately or Highly Concentrated (HHI 1500$)$
H-1B CZ
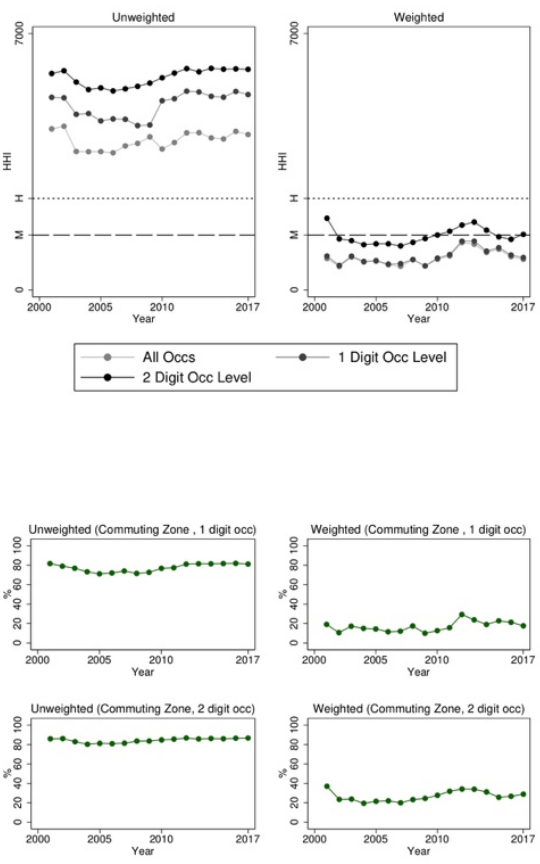

$\longrightarrow$ Percent Moderately or Highly Concentrated (HH\>1500) 
In the top left panel of Figure 2, we examine concentration in the market for H-2A workers. For workers on this visa, we consider all farm work to fall under one specific two-digit occupational code. The results suggest that the average market is near the threshold for concentration. In the panel to the right, we weight these estimates such that the HHI represents the level of concentration faced by the average worker (proxied for by the number of approved LCA jobs in that category), rather than the level of concentration in the average market. Here, we see that the average worker does not face such concentration in their labor market.

Examining the figure for average HHIs for the H-2B program, in the second leftmost panel of the figure we see that the average market is generally below the threshold for concentration when we treat all jobs as perfect substitutes ("All Occs"). On the other hand, when we segment labor markets based on the 1-digit "High-Level Aggregation" (5 civilian occupations), or 2-digit "Major Group Level” (22 civilian occupations) aggregations, the HHI is typically above 2500, the cutoff for "highly concentrated." The weighted average reveals HHIs close to the concentration threshold for our 2-digit analysis. We find similar results when examining the $\mathrm{H}$ 2B program at the state-level, and starker differences between weighted and un-weighted estimates in our commuting zone analysis.

In the bottom row of the figures, we turn to an examination of the share of markets (left panel) or jobs (right panel) that are in concentrated labor markets. These numbers are again quite low for the H-2A visas. Here, we dispense with analysis treating all jobs as perfect substitutes and instead focus on only the 1-digit and 2-digit occupation levels for the $\mathrm{H}-2 \mathrm{~B}$ and $\mathrm{H}-1 \mathrm{~B}$ visas. 
Using either definition, we observe that over half of all $\mathrm{H}-2 \mathrm{~B}$ and $\mathrm{H}-1 \mathrm{~B}$ markets are characterized by an $\mathrm{HHI}$ representing at least moderate degrees of concentration. ${ }^{79}$

Before summing up this analysis, it is worthwhile to note that even if the typical dollar spent by a consumer on a final good is not spent in a concentrated market, this does not suggest that there is no role for antitrust policy. Rather, antitrust policy in output markets concentrates on those markets in which there is significant concentration because of the effects this has on other markets. Thus, our estimates suggest that even though a typical worker may not face a moderate or high concentration of employers, there may still be some role for antitrust policy in particular markets. Even if the experience of a typical worker is that of employment in a well-functioning labor market, some of the labor markets face heavy concentration from the vantage point of output market merger scrutiny standards.

As such, these results do suggest a role for increased antitrust scrutiny of particular markets, if not all markets. The intensity of such scrutiny is at the end of the day a function of the definition of the market. Further study of the degree of mobility for these workers between occupations and between states or commuting zones (as well as to other non-H-1B sponsoring employers) could shed further light on the relevant definition of a market. In the next section, we turn our attention to an exploration of what forms increased scrutiny of concentrated markets may take.

\section{Does Oligopsony Lower Wages?}

We now turn to our next piece of analysis: an examination of the relationship between wages and the HHI values in the markets that we have examined. Recall that our data contains

\footnotetext{
${ }^{79}$ In Appendix A Figures 1-6, we show how these numbers break down by "Moderate" or "High" Concentration for $\mathrm{H}-1 \mathrm{~B}$ and $\mathrm{H}-2 \mathrm{~B}$ visas.
} 
information on the approved minimum wages to be paid for a certified LCA application. Table 4 presents estimates from regressions of the average log wage in a labor market (2-digit occupation, state or commuting zone) on a cubic of the HHI in that labor market. Controls include year, geographic (state or commuting zone) and occupation (H-1B and H-2B estimations only) fixed effects. All standard errors are clustered at the geographic level. The table presents the average $\mathrm{HHI}$ (weighted and unweighted), and the corresponding marginal effect of additional labor market concentration (with the HHI scaled between 0 and 1) and standard error on this estimate. We also present a "Pure Monopsony Effect" displaying how a move from perfect competition to pure monopsony, along with the standard error on this estimate. In addition, we display the p-value from a test of joint significance on each of the polynomial terms, along with the number of observations in the regression. 
Table 4 - Regression Analysis

\begin{tabular}{|c|c|c|c|c|c|c|c|c|}
\hline & \multicolumn{2}{|c|}{ H-2A State } & \multicolumn{2}{|c|}{ H-2B State } & \multicolumn{2}{|c|}{ H-1B State } & \multicolumn{2}{|c|}{$\mathrm{H}-1 \mathrm{~B} \mathrm{CZ}$} \\
\hline HHI Bar & $\begin{array}{c}\text { Unweighted } \\
1.3678\end{array}$ & $\begin{array}{c}\text { Weighted } \\
1.3678\end{array}$ & $\begin{array}{c}\text { Unweighted } \\
0.5379\end{array}$ & $\begin{array}{l}\text { Weighted } \\
0.5379\end{array}$ & $\begin{array}{c}\text { Unweighted } \\
0.3112\end{array}$ & $\begin{array}{l}\text { Weighted } \\
0.3112\end{array}$ & $\begin{array}{l}\text { Unweighted } \\
0.5802\end{array}$ & $\begin{array}{c}\text { Weighted } \\
0.5802\end{array}$ \\
\hline $\begin{array}{c}\text { Marginal Effect at HHI } \\
\text { Bar }\end{array}$ & $\begin{array}{l}-0.0049 \\
(0.0228)\end{array}$ & $\begin{array}{c}-0.007 \\
(0.0218)\end{array}$ & $\begin{array}{c}-0.206 \\
(0.1298)\end{array}$ & $\begin{array}{l}-0.6051 \\
(0.1614)\end{array}$ & $\begin{array}{c}-0.264 \\
(0.1066)\end{array}$ & $\begin{array}{l}-0.4624 \\
(0.1464)\end{array}$ & $\begin{array}{l}-0.2607 \\
(0.0531)\end{array}$ & $\begin{array}{c}0.0273 \\
(0.1654)\end{array}$ \\
\hline HHI W-Bar & 0.649 & 0.649 & 0.1505 & 0.1505 & 0.1846 & 0.1846 & 0.1467 & 0.1467 \\
\hline $\begin{array}{c}\text { Marginal Effect at HHI } \\
\text { W-Bar }\end{array}$ & $\begin{array}{l}-0.0086 \\
(0.0284)\end{array}$ & $\begin{array}{c}0.038 \\
(0.0208)\end{array}$ & $\begin{array}{l}-0.2078 \\
(0.1492)\end{array}$ & $\begin{array}{l}-0.4523 \\
(0.1723)\end{array}$ & $\begin{array}{c}-0.306 \\
(0.1108)\end{array}$ & $\begin{array}{l}-0.4719 \\
(0.1231)\end{array}$ & $\begin{array}{l}-0.3547 \\
(0.0655)\end{array}$ & $\begin{array}{c}0.0662 \\
(0.1531)\end{array}$ \\
\hline Pure Monopsony Effect & $\begin{array}{c}0.033 \\
(0.0858)\end{array}$ & $\begin{array}{c}0.4513 \\
(0.4729)\end{array}$ & $\begin{array}{l}-0.0687 \\
(0.0229)\end{array}$ & $\begin{array}{l}-0.1275 \\
(0.0327)\end{array}$ & $\begin{array}{c}-0.0902 \\
(0.0226)\end{array}$ & $\begin{array}{l}-0.0689 \\
(0.0361)\end{array}$ & $\begin{array}{c}-0.1336 \\
(0.0119)\end{array}$ & $\begin{array}{l}-0.0662 \\
(0.0393)\end{array}$ \\
\hline $\begin{array}{c}\text { P-Value on F on Cubic } \\
\mathrm{N}\end{array}$ & $\begin{array}{c}0.686 \\
601\end{array}$ & $\begin{array}{c}0.2018 \\
601\end{array}$ & $\begin{array}{c}0.0177 \\
7127\end{array}$ & $\begin{array}{c}0.0001 \\
7127\end{array}$ & $\begin{array}{l}0.0003 \\
11614\end{array}$ & $\begin{array}{c}0 \\
11614\end{array}$ & $\begin{array}{c}0 \\
56802\end{array}$ & $\begin{array}{c}0.0229 \\
56802\end{array}$ \\
\hline
\end{tabular}

This table presents a state level estimation of the effect of HHI on wage with 2-digit occupation (for H-1B and H-2B; H-2A contains only one occupation) controls, and a battery of year, occupation, and state fixed effects. HHI Bar represents the average concentration in an occupation and state level labor market, and HHI W-Bar represents the average concentration faced by a guest worker (HHI W-Bar is weighted by the number of employees requested in a certified Labor Condition Application). Unweighted and Weighted columns indicate whether or not the regression is weighted based on the number of guest workers. Standard Errors (in parentheses) are clustered at the State or Commuting Zone level. 
The results in the first two columns show very little evidence of a relationship between wages and market concentration for the $\mathrm{H}-2 \mathrm{~A}$ visa, though it should be noted that we observe only one occupation for the H-2A visa, and thus have only 601 observations. The next two columns present results of a similar analysis conducted on the $\mathrm{H}-2 \mathrm{~B}$ visa, which corresponds to a number of different occupations as seen in Table 2. Here we find some evidence of an oligopsony effect on wages, as shown by p-values from the F-test on the cubic function of the HHI that allows us to reject a null hypothesis of joint insignificance. Specifically, we find that a move from perfect competition to pure monopsony is associated with a decline in wages of between 7 and 13 percent. In addition, our four estimates of the marginal effect of more concentration (at the average $\mathrm{HHI}$ ) on wages are all negative, and significant in two cases. We find stronger evidence of an oligopsony effect with the H-1B visa at the state level. Here we reject the $\mathrm{F}$ test for joint insignificance of the cubic terms in both weighted and unweighted regressions. The pure monopsony effects are both negative and significant, and range between 7 and 9 percent. In addition, our four estimates of the marginal effect of more concentration (at the average HHI) on wages are all negative and significant. ${ }^{80}$ Finally, we examine evidence for the $\mathrm{H}-1 \mathrm{~B}$ visa at the commuting zone level, finding stronger evidence in the unweighted regressions compared to the weighted regressions. We reject the $\mathrm{F}$ test in both cases but only find significant wage effects in the unweighted regressions, consistent with the largest markets being outliers as discussed earlier in the section.

\footnotetext{
${ }^{80}$ For our state-level analysis, we experiment with interacted fixed effects (i.e. fixed effects at the occupational crossed with state level, occupation crossed with year level, and state cross with year level). These results are displayed in Appendix B - Tables 9 and 10. As can be seen in the 6th through 8th columns, the results generated by these models are qualitatively similar, though smaller when using occupation and geographic interactions for fixed effects. To ease computational burden, we conduct our commuting zone analysis without these interacted fixed effects.
} 
We further examine the above results in Figure 3, where we plot the estimated cubic functions from the regression results reported in Table 3. The vertical lines displayed in each figure denote the 25 th and 75 th percentile of market concentration. The left panel of the figure displays results from our unweighted regression, while the right panel displays the weighted results. The figure allows us to identify the non-linear relationship between concentration and wages more easily. In the H-2A panel in Figure 3, we see that a lack of precision, likely on account of the smaller amount of data available for this visa program, prohibits us from making any clear conclusions about a relationship between $\mathrm{HHI}$ and wages regarding this visa.

\section{Figure 3 - Oligopsony on Wages}

H-2A

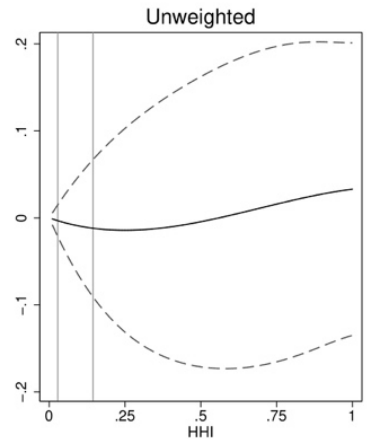

$$
\begin{aligned}
& ----- \text { 95\% Confidence Interval (H) } \quad-----95 \% \text { Confidence Interval (L) } \\
& - \text { HHI Log-Wage Function }
\end{aligned}
$$

H-2B
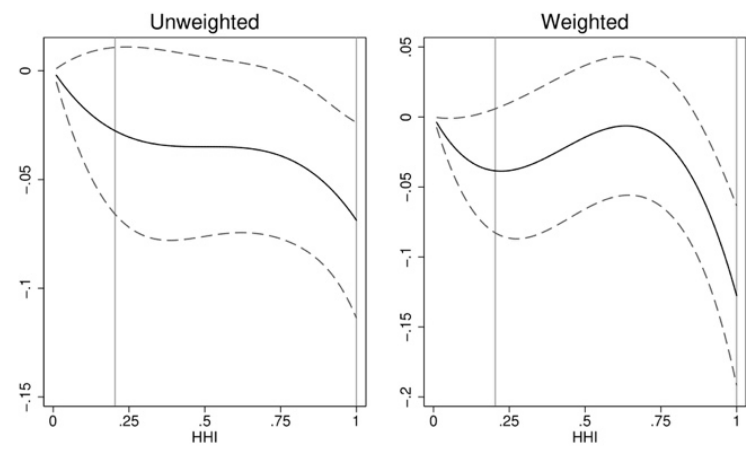

- - - - 95\% Confidence Interval (H) HHI Log-Wage Function

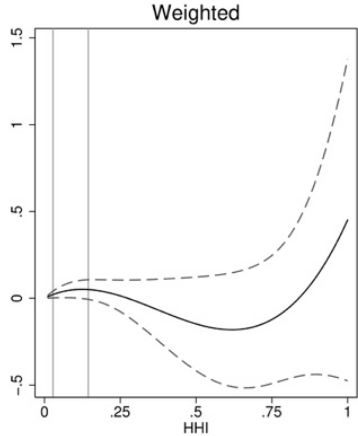
$-----95 \%$ Confidence Interval (L)
H-1B
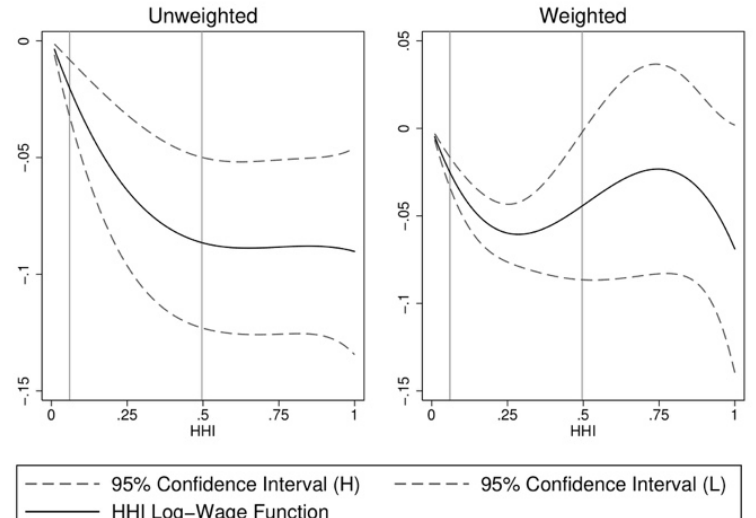

H-1B CZ
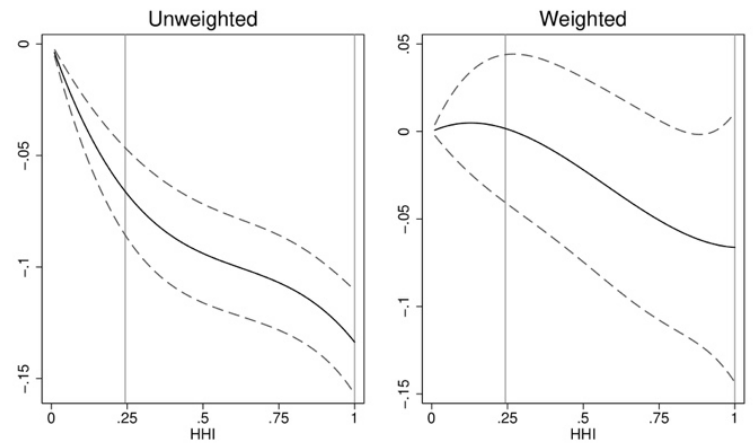

- - - - 95\% Confidence Interval $(\mathrm{H})$ HHI Log-Wage Function 
The bottom left panel on the H-2B visa displays some evidence of a negative correlation between wages and concentration for this visa, consistent with the results presented in Table 3 . The right two panels display results on the H-1B visa for the state level (top right) and commuting zone level (bottom right) analysis. In our unweighted estimates, we observe a negative but diminishing effect with the commuting zone estimates which appear, in general, to be more precisely estimated. The weighted estimates display similar evidence consistent with more concentration leading to lower wages, though these models are less precisely estimated than their unweighted counterparts.

To answer the question regarding the link between oligopsony and wages posed at the start of this section, we find consistent evidence that oligopsony is correlated with lower wages. Whether concentration and the use of oligopsony power causes lower wages requires further research with greater experimental or quasi-experimental analysis. However, given the data analysis conducted here, in combination with other economic evidence and theoretical modeling, it is possible to provide estimates of the role that frictions and oligopsony have in decreasing guest worker wages.

\section{Modeling the Role of Frictions and Oligopsony on Wages}

As we have discussed, labor markets can depart from perfect competition for two distinct reasons: market concentration and market frictions (both natural and institutional). The results presented in Table 3 and Figure 3 demonstrate evidence consistent with oligopsonistic market pressures: as market concentration increases, wages decrease. In Table 1 we documented the existence of institutional frictions that add to the cost of mobility and would theoretically be expected to decrease worker mobility. 
In order to best understand how well this labor market functions, as well as how potential policy reforms could improve the functioning of this market, it is worthwhile to attempt to understand the relative importance of these two anti-competitive forces in the labor market. To undertake such an analysis, we turn to a model proposed by Naidu $\&$ Posner ${ }^{81}$ which expresses the elasticity of labor supply to an individual firm as a function of both labor market concentration as well as a monopsonistically competitive elasticity. The latter term expresses the degree of imperfect competition that would exist even when an infinite number of firms were competing for the same workers, and thus the corresponding HHI were zero. ${ }^{82}$

In Figure 4 we present results from a simulation based on the model of Naidu \& Posner, and compare them to our empirical results displaying the relationship between market concentration and wages. ${ }^{83}$ We use results from DNS on the elasticity of labor supply to the firm for guest workers in computer services occupations. ${ }^{84}$ We use our estimates of the HHI for workers in this industry in the years covered by the DNS data. ${ }^{85}$ With these two parameters, we can estimate the "competitive elasticity" for any given value of the aggregate elasticity of supply to the labor market. Naidu \& Posner consider two values of the aggregate elasticity: 2.8 and .78.

\footnotetext{
${ }^{81}$ Naidu \& Posner, supra.

${ }^{82}$ Specifically, they show that eta $=1 /(($ h/eta_agg $)+(1 /$ eta_comp $))$, where eta represents the elasticity of labor supply that an individual firm faces, $\mathrm{h}$ is HHI (indexed between 0 and 1 ), eta_agg is the elasticity of labor supply to the entire market, and eta_comp is the elasticity of labor supply to an individual firm even in the presence of competition between many different firms. This can be easily seen by setting $\mathrm{h}=0$ and seeing that this implies that eta $=$ eta_comp

${ }^{83} \mathrm{We}$ choose to use our estimates for the entire set of $\mathrm{H}-1 \mathrm{~B}$ occupations that we examine, rather than to run a new set of estimates limited only to computer professions given the importance of including occupational fixed effects. ${ }^{84}$ The DNS results are obtained from estimates on data from 2003 to 2011 which come from both H-1B and L-1 visas. Here, we calculate the elasticity of labor supply to the firm as 1.74 , multiplying the estimated quit elasticity found in DNS (-.872) at the average rate of unemployment in the data (7.89\%) by -2 , as per Manning, supra. We choose to treat the estimated return to India elasticity as irrelevant for this calculation as we believe that the vast majority of such returns are representative of involuntary separations, rather than voluntary quits for better employment opportunities. When we consider these to be voluntary quits, our results suggest a larger elasticity of labor supply to the firm and that firms would have the ability to markdown wages by less than $10 \%$ with no concentration and at an aggregate labor supply elasticity of 0.78 .

${ }^{85}$ We choose to use the HHI faced by the average worker in this occupation, rather than the HHI in the average market, as the DNS results are implicitly weighted towards the elasticity for the average worker.
} 
We consider values of the aggregate elasticity between 0 and 2.8, in increments of 0.01 . We exclude values of the competitive elasticity which are either negative or smaller than the aggregate elasticity, or which imply a competitive elasticity larger than the average elasticity from DNS.

Figure 4 displays how wages decrease, as compared to the monopsonistically competitive wage, as concentration increases. Our empirical results, corresponding to the unweighted regression results for the $\mathrm{H}-1 \mathrm{~B}$ visa at the commuting zone level shown previously in Figure 3, are displayed in dashed lines, while the simulated results are displayed using solid lines. The lighter solid lines correspond to smaller assumed values of the elasticity of labor supply to the market, while the darker lines correspond to higher assumed values of this parameter. In the legend, we display the assumed aggregate supply elasticity and corresponding implied competitive elasticity for our smallest and largest assumed aggregate elasticity values that produce valid estimates of the competitive elasticity.

What is clear from Figure 4 is that all of our simulations yield implied wage effects of market concentration which are stronger than what was estimated in our data. As mentioned above, Naidu \& Posner consider two aggregate elasticity estimates from prior work: 2.8 and 0.78. We find that 2.8 is not a feasible elasticity given our restrictions, and therefore consider the results at 0.78 . This aggregate elasticity implies a monopsonistically competitive elasticity of 2.3 . This further implies that a worker in a monopsonistically competitive market is paid $70 \%$ of their worth to the firm, suggesting a significant anti-competitive role for frictions in this market. In a pure monopsony (with an implied elasticity of 0.58 ) the worker is paid only $37 \%$ of their marginal revenue product. Thus, we would expect wages under monopsony to be $47 \%$ lower 
than under monopsonistic competition. In contrast, our empirical results imply that pure monopsony firms only reduce wages by about $13 \%$ compared to a market with no concentration.

This suggests that firms are not able to use all of their market power. In the right panel, we display these results when scaled to the average wage for $\mathrm{H}-1 \mathrm{~B}$ guest workers in the years 2003-2011. A horizontal line at $\$ 60,000$ displays the minimum prevailing wage for $\mathrm{H}-1 \mathrm{~B}$ dependent firms that wish to remain exempt from certain regulations. ${ }^{86}$ The empirical results obtained from the influence of HHI on wages suggests that the regulatory process of approving firms' wages and a requirement that firms must pay the prevailing wage (or $\$ 60,000$ if $\mathrm{H}-1 \mathrm{~B}$ dependent), may have an effect of preventing this exercise of market power. Given a median prevailing wage of $\$ 66,304$ in this data, in the absence of such regulations, the implied power of firms under the model suggests wages could be $\$ 10,000$ to $\$ 40,000$ lower than at present depending upon assumptions regarding the competitiveness of the aggregate labor market.

\section{Figure 4 - Predicted and Simulated Change in Wages Under Monopsonistic}

\section{Competition and Pure Monopsony}

Quits-Weighted HHI (\%)

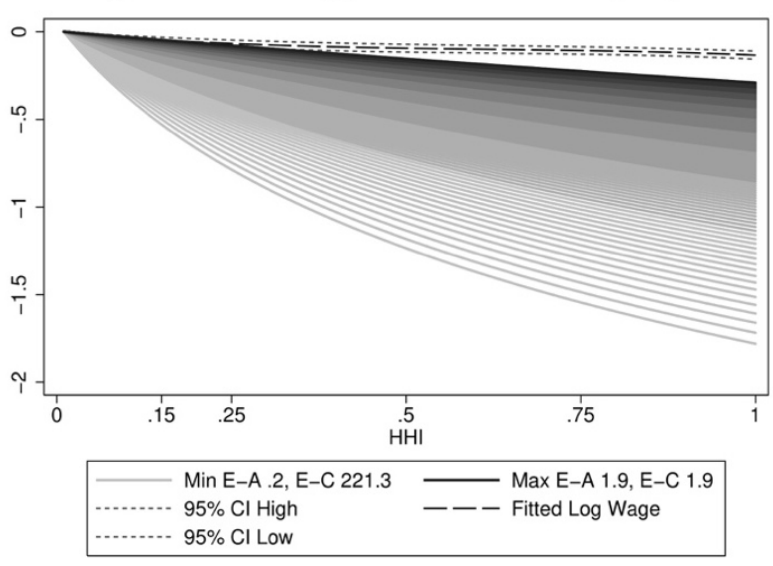

Real Wage

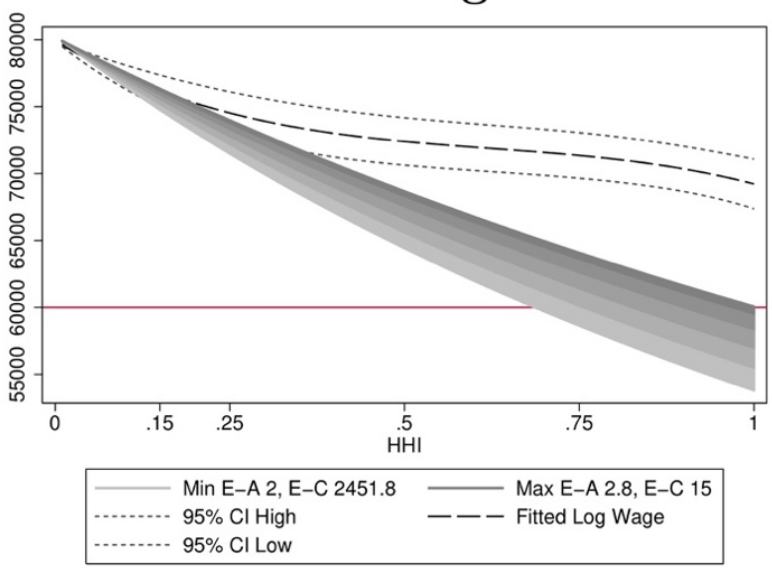

\footnotetext{
${ }^{86}$ An H-1B dependent employer, defined as one that has greater than $15 \%$ of their workforce on $\mathrm{H}-1 \mathrm{~B}$ visas, may be exempted from additional regulatory burdens by paying the worker the higher of the prevailing wage or $\$ 60,000$. See Department of Labor, Employment Law Guide, https:/webapps.dol.gov/elaws/elg/h1b.htm.
} 


\section{DISCUSSION AND POLICY IMPLICATIONS}

In this paper, we contribute to the growing literature on employer concentration as a source of imperfect competition in labor markets, as well as to a large literature on the abuses that occur in guest worker programs. We first document the frequency and nature of federal lawsuits filed by migrants on guest worker visas and find that cases involving antitrust claims are rare. We propose that a monopsonistic labor market may better explain these abuses than a competitive labor market. In a review of recent literature on monopsonistic models, we illustrate that labor markets may deviate from perfect competition for two basic reasons. With frictions to mobility, many firms may compete for workers, but the costs of mobility will reduce turnover and yield a labor market characterized by monopsonistic competition. The market structure of guest worker programs, characterized as they are by institutional frictions to job mobility, is consistent with mobility costs leading to monopsonistic competition. A second way a market deviates from perfect competition is if the market becomes oligopsonistic on account of too many jobs being concentrated among too few firms. An oligopsonistic market for many guest workers is also consistent with the level of HHIs that we calculate. These facts imply firms that employ guest workers have wage setting power, especially in more concentrated labor markets.

To our knowledge, ours is the first study to test the prediction that oligopsony lowers wages in the market for guest workers. Using LCA data, we find strong evidence in favor of a negative and statistically significant relationship between market concentration and wages paid to guest workers. Some caveats, discussed in detail infra., II.A., are suggested for the interpretation of our results. To summarize: limitations to the data, especially for certain visas, choices made while cleaning the data, and statistical modeling choices all bound the breadth of 
our conclusions. For this reason, we report full results and additional robustness checks in Appendix A - Figures and Appendix B - Tables.

Having found evidence of oligopsony, the relative importance of institutional and natural frictions compared to oligopsony as a source of monopsony power is important to determine. We provide some evidence of this by adopting the recent framework of Naidu \& Posner. We calibrate their model with levels of labor market concentration in the market for H-1B computer professionals calculated here, along with earlier estimates of labor supply to the firm from DNS. This exercise suggests that both frictions and concentration play an important role in determining wages. The simulation results, however, generally predict a greater decline in wages from increased market concentration than we find in our empirical results. This apparent inconsistency may be explained by the fact that the Department of Labor reviews proposed wages of $\mathrm{H}-1 \mathrm{~B}$ workers, as well as effectively imposing a minimum wage of $\$ 60,000$ for the largest employers, thus curtailing much of the oligopsonistic power that firms would otherwise possess. At the same time, workers' immobility may still serve as an explanation for the abuses that occur in guest worker programs. Further, a high floor on wages could place additional pressure on firms in competitive output industries to speed up production, reduce safety spending, or provide substandard accommodations.

These results may have important implications for policymakers. The above findings suggest that current policies are somewhat curbing the power of firms. Nevertheless, it may be prudent for the OFLC (which certifies labor condition applications) to incorporate concentrationbased guidelines when determining the degree of scrutiny to apply to a proposed wage in an application. If a lone employer recruits in a commuting zone for a given occupation, such an employer might have the power to influence the wage survey instrument used to determine the 
prevailing wage. At the same time, it may also make sense for regulators to apply less scrutiny when examining applications from labor markets with markers of a high degree of competition and job mobility within the U.S. In addition, it would make sense for visa programs not covered by the LCA program, such as the J-1 and other cultural exchange programs, to be covered by a prevailing wage certification process. Flawed as it is, the LCA program's wage floor appears to prevent worse exploitation. In other words, antitrust policy need not be carried out by those with the power to block mergers or prosecute anticompetitive behavior alone.

Policymakers might also reconsider legislatively constructed frictions to the mobility of guest workers, and revisions to immigration regulations that constrain the job mobility of guest workers. For example, guest worker program design that was cognizant of monopsony power would reduce the fees and regulatory burdens required for a worker to move between jobs. Such changes could increase wages to workers as well as the overall value provided by these markets to society. Given that these programs are typically constructed to be self-funding based upon fees, exploring other sources of revenue, for example, a small payroll tax on these workers, may be of use. Such a tax, while imposing a burden on the employer, would not impose a substantial fixed cost to recruiting an employed guest worker whose visa is sponsored by another employer. More generally, our results provide some insight into how to reign in market power in a labor market plagued by frictions and some degree of concentration. As Manning's 2003 framework for estimating labor market imperfections has helped to bring back to prominence the 1933 model of Joan Robinson, the attention of academics, public intellectuals, policymakers, and politicians alike has turned towards the monopsonistic view of labor markets. As this bourgeoning literature has expanded into an analysis of the causes and consequences of this market structure, the last two years have witnessed a blossoming of studies on the relationship 
between labor market concentration and wages. As the methods through which economists scrutinize the competitiveness of input markets continues to evolve, ultimately, the methods will hopefully approach a degree of sophistication that can be as practically useful as the scrutiny applied to the competitiveness of output markets.

Someday, many of the same basic notions and approaches of antitrust policy could be implemented in a similar manner towards input markets to properly scrutinize mergers, identify anti-competitive behavior, and determine damages to workers who have been harmed by such behavior. Unquestionably, future quantitative research is needed to advance in this direction. Thus, obtaining a better understanding of the functioning of guest worker labor markets may not only inform policymakers interested in these particular labor markets, but also lead to a better understanding of the function (or dysfunction) of labor markets in general. 


\section{Appendix A - Figures}

Figure 1: H-1B State Concentration, Unweighted

\section{Share of Markets Concentrated \\ State, Unweighted}
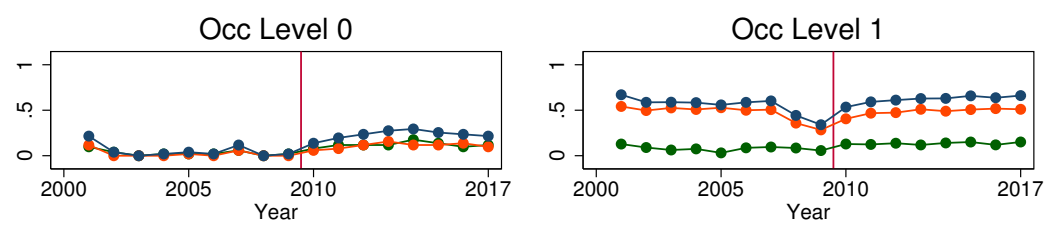

Occ Level 2

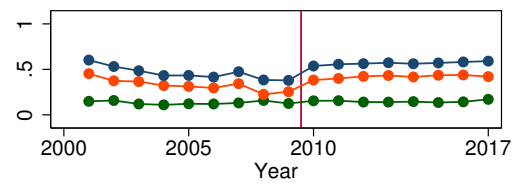

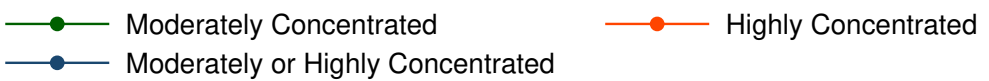

Note a structural break in occupational coding took place in 2010. Based on merger guidelines:

1500-2500 for moderate concentration, over 2500 for high concentration. See https://www.justice.gov/atr/herfi 
Figure 2: H-1B State Concentration, Weighted

\section{Share of Markets Concentrated \\ State, Weighted}
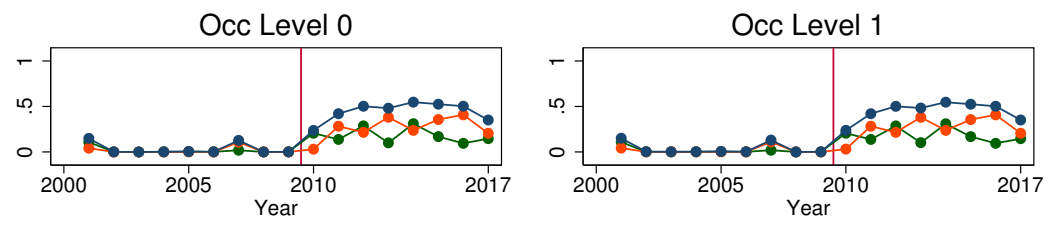

Occ Level 2

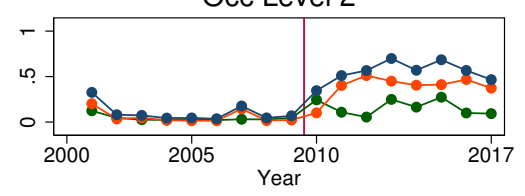

$\longrightarrow$ Moderately Concentrated
$\longrightarrow$ Moderately or Highly Concentrated

Note a structural break in occupational coding took place in 2010. Based on merger quidelines:

1500-2500 for moderate concentration, over 2500 for high concentration. See https://www.justice.gov/atr/herfi 
Figure 3: H-1B Commuting Zone Concentration, Unweighted

\section{Share of Markets Concentrated \\ Commuting Zone, Unweighted}
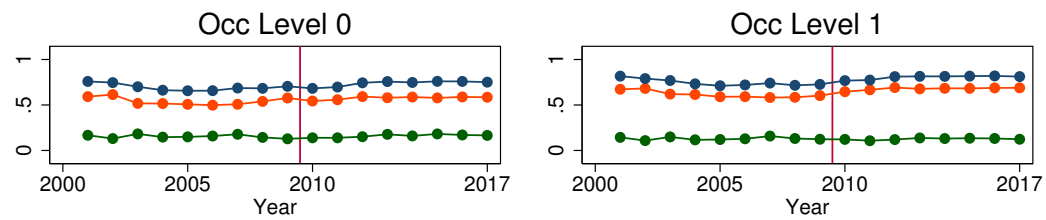

Occ Level 2
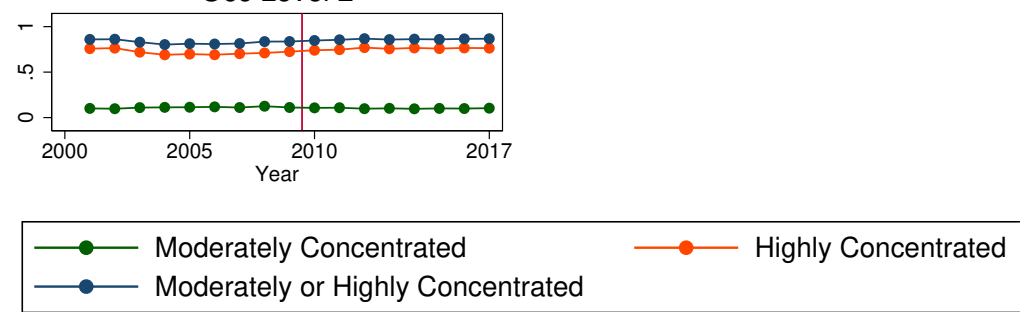

Note a structural break in occupational coding took place in 2010. Based on merger quidelines: 1500-2500 for moderate concentration, over 2500 for high concentration. See https://www.justice.gov/atr/herfi

Figure 4: H-1B Commuting Zone Concentration, Weighted

\section{Share of Markets Concentrated Commuting Zone, Weighted}
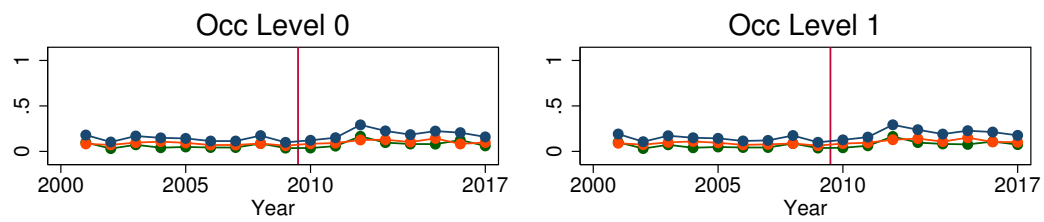

Occ Level 2

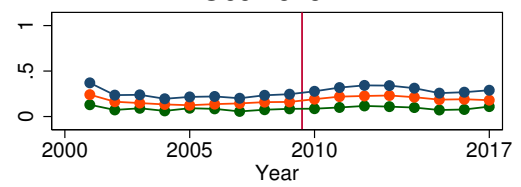

$\longrightarrow$ Moderately Concentrated $\quad \longrightarrow$ Highly Concentrated

Note a structural break in occupational coding took place in 2010. Based on merger guidelines: 1500-2500 for moderate concentration, over 2500 for high concentration. See https://www.justice.gov/atr/herfi 
Figure 5: H-2B State Concentration, Unweighted

\section{Share of Markets Concentrated State, Unweighted}
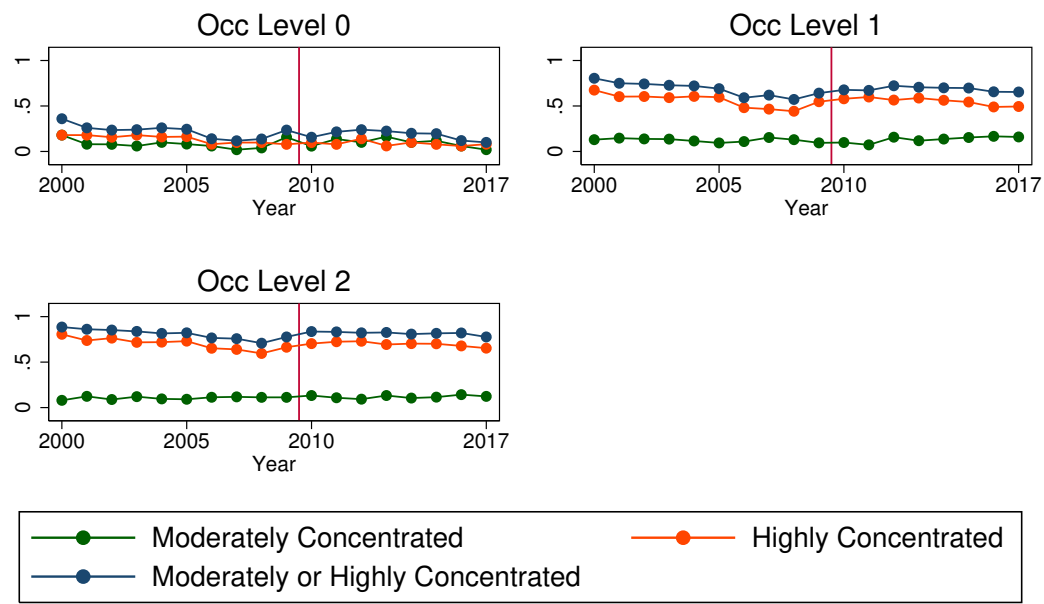

Note a structural break in occupational coding took place in 2010. Based on merger guidelines: 1500-2500 for moderate concentration, over 2500 for high concentration. See https://www.justice.gov/atr/herfi

Figure 6: H-2B State Concentration, Weighted

\section{Share of Markets Concentrated State, Weighted}
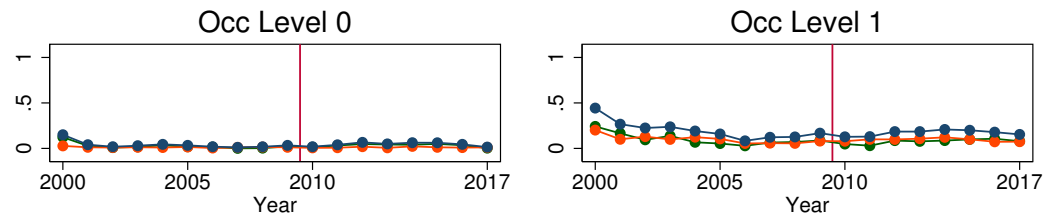

Occ Level 2

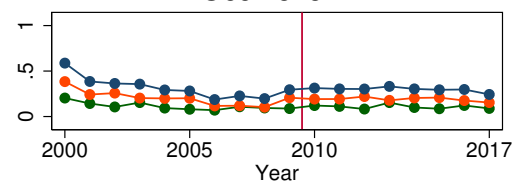

$\longrightarrow$ Moderately Concentrated $\quad \longrightarrow$ Highly Concentrated

Note a structural break in occupational coding took place in 2010. Based on merger guidelines: 1500-2500 for moderate concentration, over 2500 for high concentration. See https://www.justice.gov/atr/herfi 


\section{Robustness Figures}

Figure 7: Linear Estimates of the Effect of Concentration on Wages

H-2A
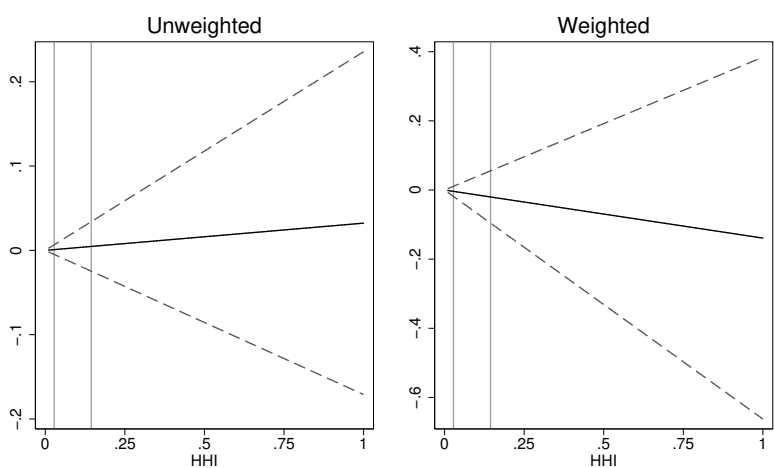

95\% Confidence Interval $(\mathrm{H})$ HHI Log-Wage Function

\section{$\mathrm{H}-2 \mathrm{~B}$}
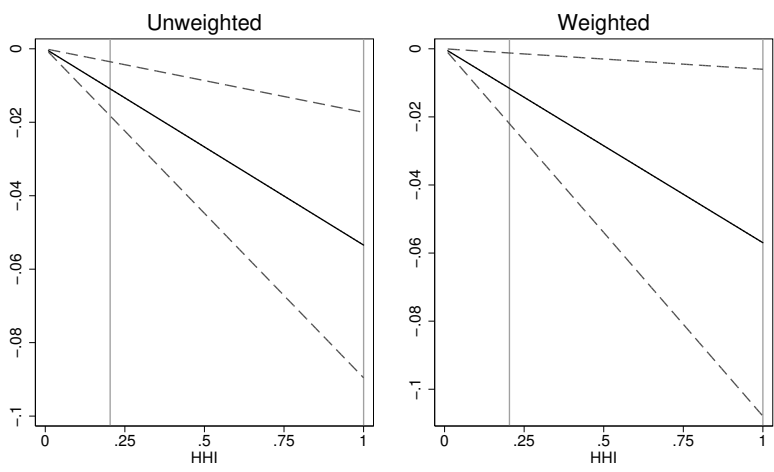

- - - - 95\% Confidence Interval (H) - - - - 95\% Confidence Interval (L) HHI Log-Wage Function
H-1B
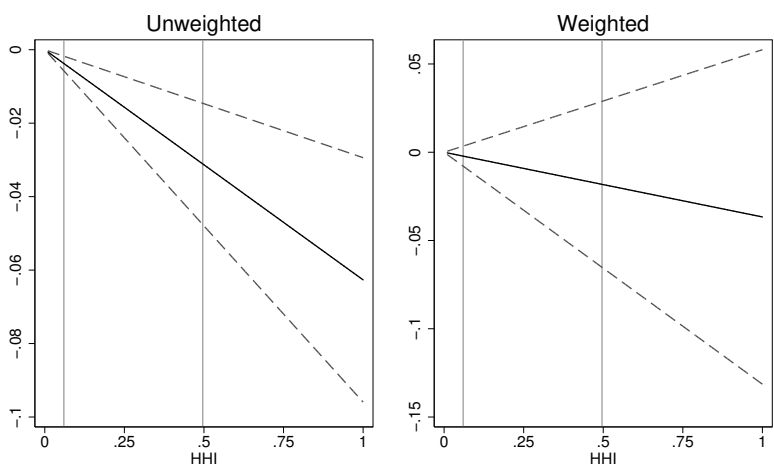

$95 \%$ Confidence Interval $(\mathrm{H})$ HHI Log-Wage Function

\section{H-1B CZ}
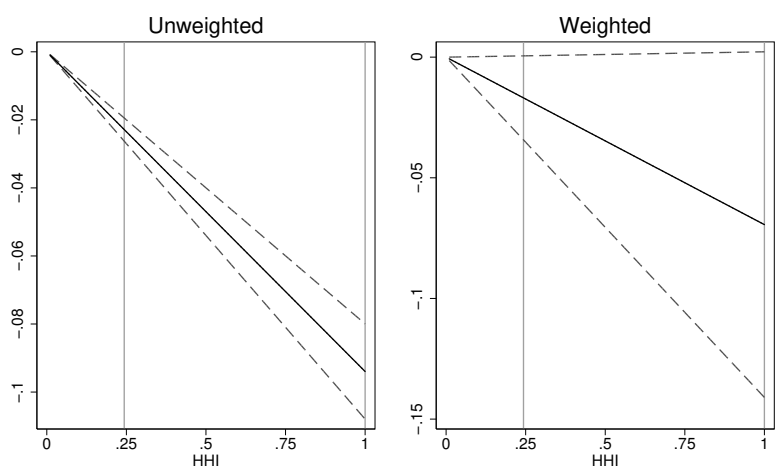

- - - - 95\% Confidence Interval $(\mathrm{H}) \quad$ - - - - 95\% Confidence Interval (L) HHI Log-Wage Function 
Figure 8: H-1B: Removing CZs with Monopsony
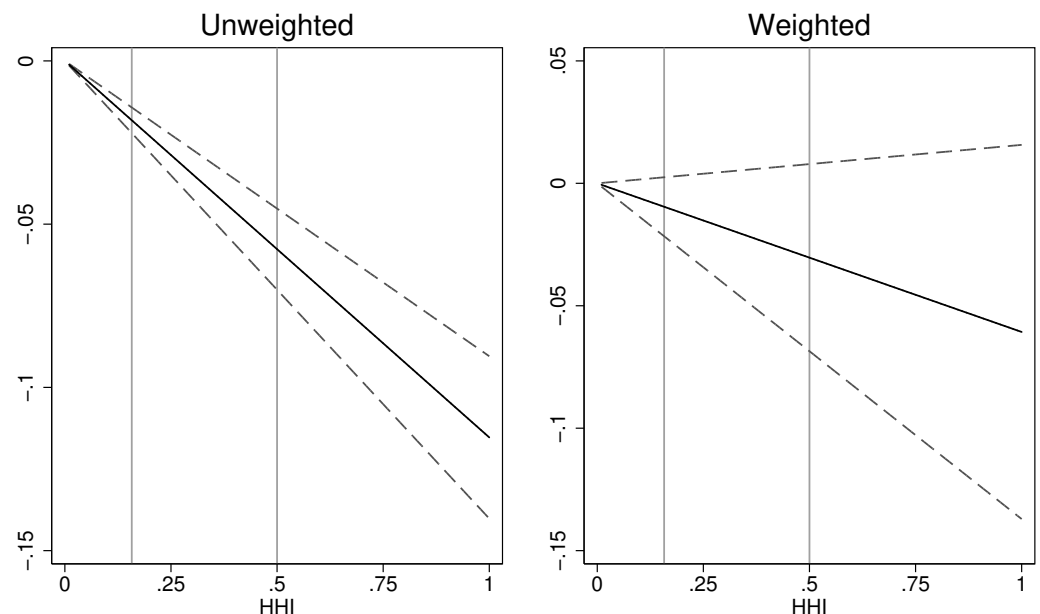

$-----95 \%$ Confidence Interval $(\mathrm{H}) \quad-----95 \%$ Confidence Interval $(\mathrm{L})$
$-\mathrm{HHI}$ Log-Wage Function
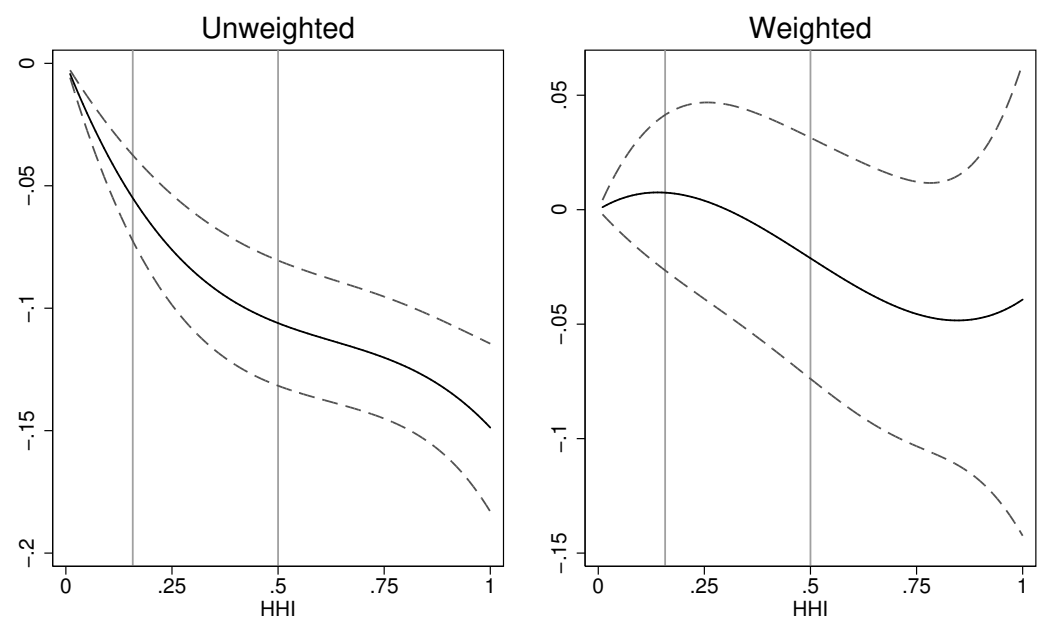

95\% Confidence Interval $(\mathrm{H})$

- - - - 95\% Confidence Interval (L) HHI Log-Wage Function 

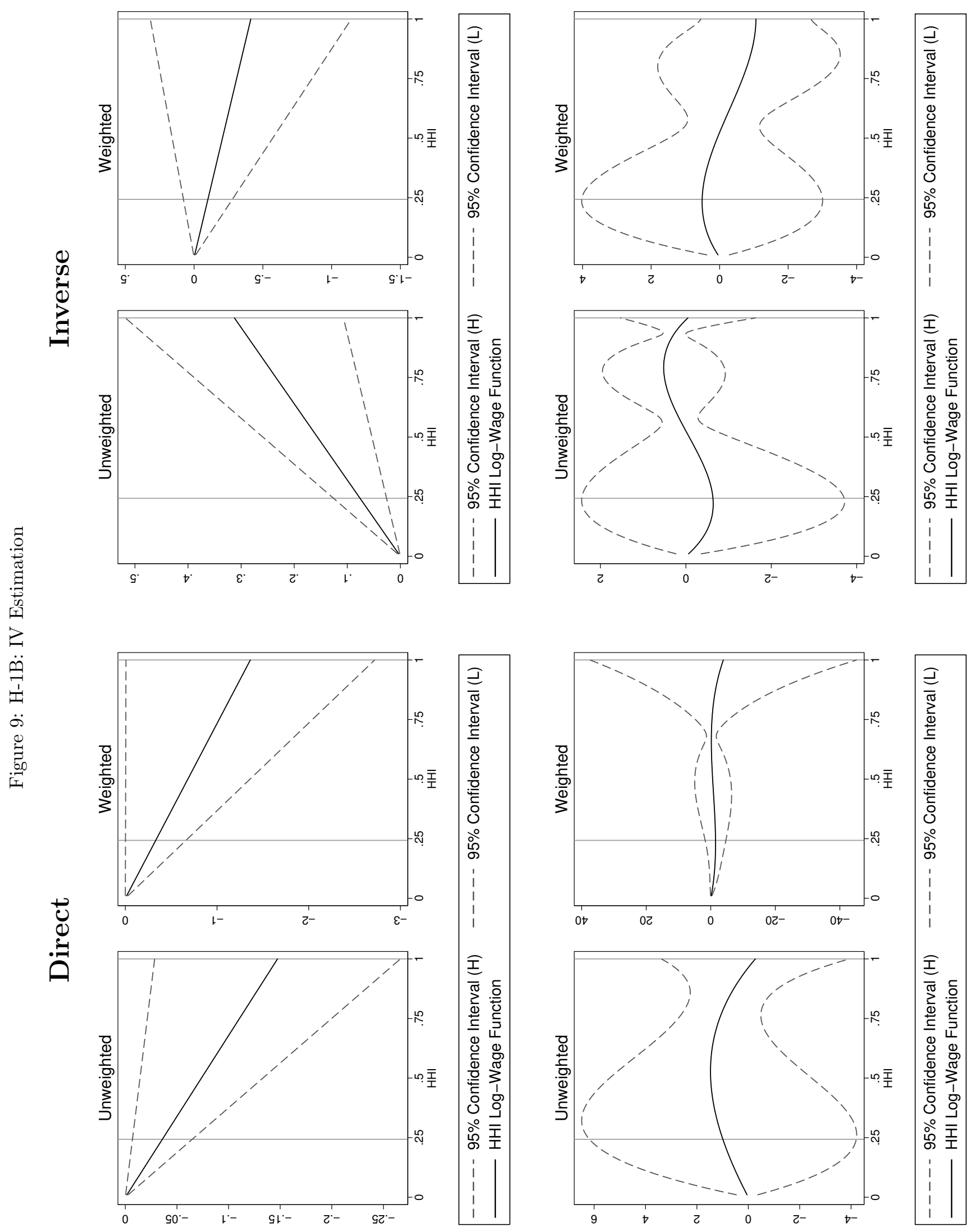


\section{Quits-Weighted HHI}

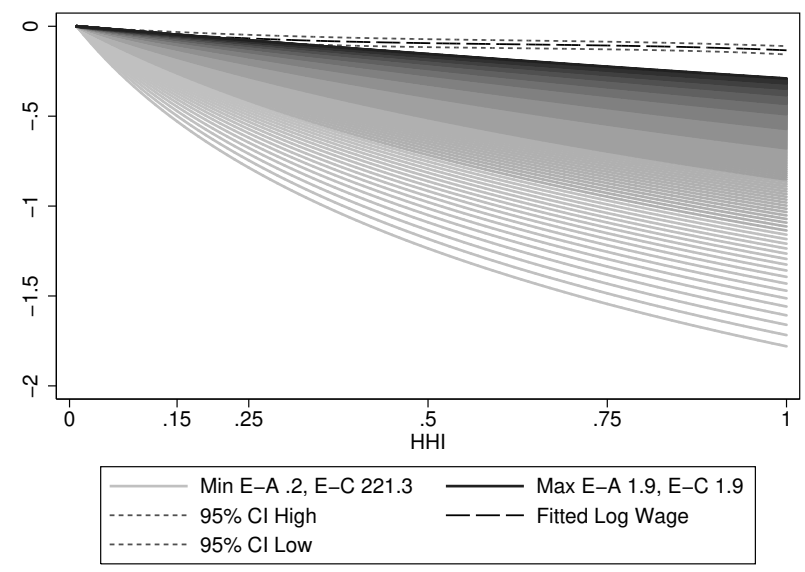

\section{Quits-Unweighted HHI}

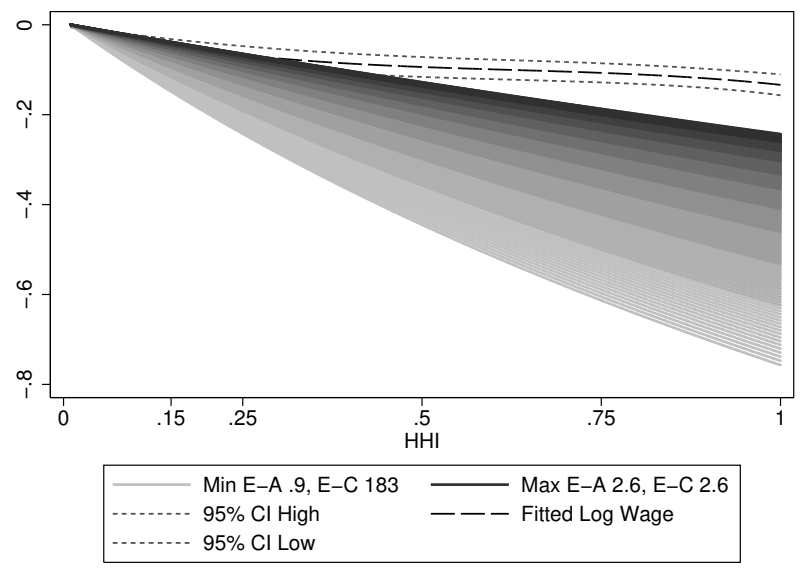

All-Weighted HHI

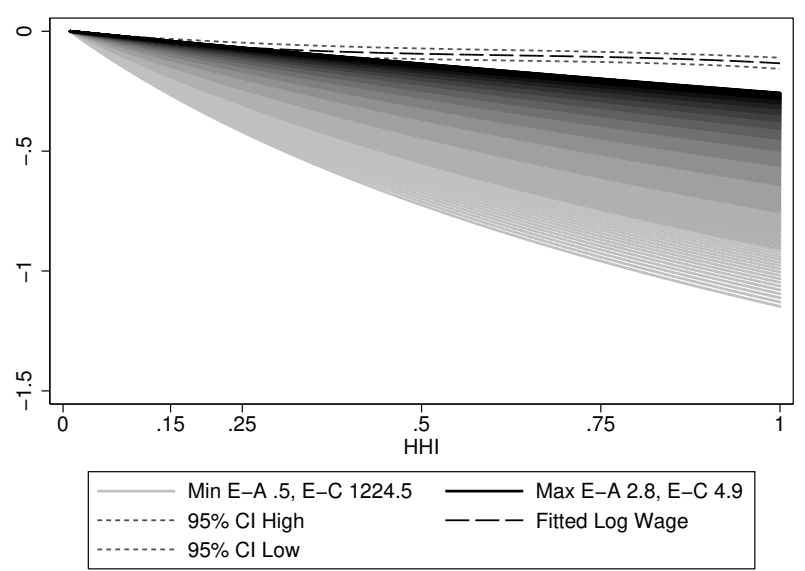

All-Unweighted HHI

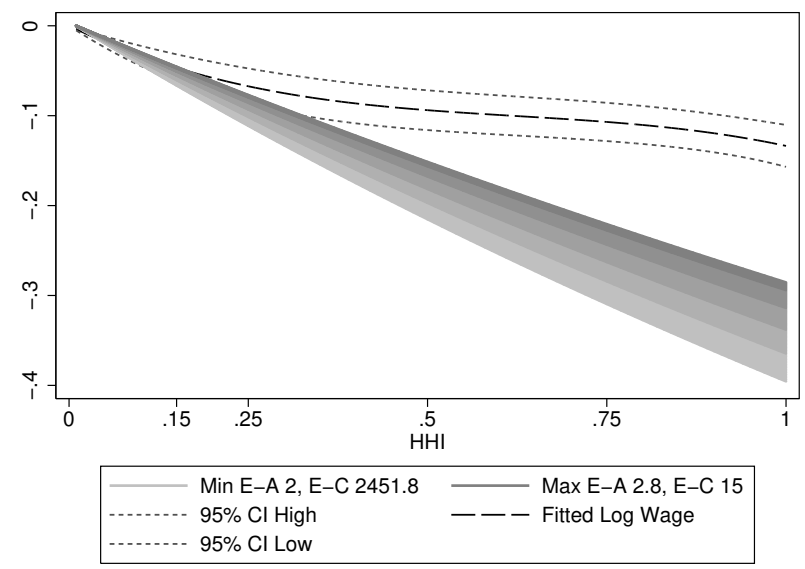




\section{Appendix B - Tables}

Table 1: H-1B: Census Region Linear Analysis Regression of Log Wage on HHI, Unweighted

\begin{tabular}{ccccccc}
\hline & & 1 & 2 & 3 & 4 & 5 \\
\hline \hline \multirow{3}{*}{ Occ 0} & HHI & 0.6741 & -0.7632 & -0.627 &. &. \\
& & $(0.1543)$ & $(0.3801)$ & $(0.1207)$ &. &. \\
& $\mathrm{N}$ & 68 & 68 & 68 &. &. \\
\hline \multirow{3}{*}{ Occ 1 } & $\mathrm{HHI}$ & -0.5472 & -0.5587 & -0.5894 & -0.0543 & -0.0662 \\
& & $(0.0708)$ & $(0.069)$ & $(0.0671)$ & $(0.0633)$ & $(0.0695)$ \\
& $\mathrm{N}$ & 322 & 322 & 322 & 322 & 322 \\
\hline \multirow{3}{*}{ Occ 2 } & $\mathrm{HHI}$ & -0.2773 & -0.2767 & -0.2882 & -0.0076 & -0.0232 \\
& & $(0.0346)$ & $(0.0349)$ & $(0.0346)$ & $(0.0434)$ & $(0.0448)$ \\
& $\mathrm{N}$ & 1311 & 1311 & 1311 & 1311 & 1311 \\
\hline & Fixed & & & & & \\
& Effects & & & & $\mathrm{X}$ & $\mathrm{X}$ \\
& Year & & & $\mathrm{X}$ & $\mathrm{X}$ & $\mathrm{X}$ \\
\hline \hline
\end{tabular}

This table presents a region level unweighted estimation of the effect of HHI on wage with 0,1 , and 2-digit occupation controls. Moving from left to right, a battery of fixed effect controls are added to the regression, as indicated in the bottom panel. Standard Errors (in parentheses) are robust. 
Table 2: H-1B: Census Region Cubic Analysis Regression of Log Wage on HHI, Unweighted

\begin{tabular}{|c|c|c|c|c|c|c|}
\hline & & 1 & 2 & 3 & 4 & 5 \\
\hline \multirow{10}{*}{ OCC 0} & HHI Bar & 0.032 & 0.032 & 0.032 & 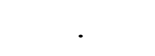 & . \\
\hline & Marginal Effect at HHI Bar & 37.7161 & -7.8303 & 5.2459 & . & . \\
\hline & & $(13.0391)$ & $(15.6376)$ & $(5.2125)$ & . & . \\
\hline & HHI W-Bar & 0.0496 & 0.0496 & 0.0496 & . & . \\
\hline & $\begin{array}{c}\text { Marginal Effect at HHI W- } \\
\text { Bar }\end{array}$ & 55.3233 & -10.078 & 8.1902 & . & . \\
\hline & & $(19.2522)$ & $(22.9107)$ & $(7.6115)$ & . & . \\
\hline & Total Effect & 309.2255 & -36.8755 & 51.5961 & . & . \\
\hline & & $(108.9647)$ & $(127.6489)$ & $(42.0708)$ & e & . \\
\hline & P-value on $\mathrm{F}$ on Cubic & 0 & 0.0776 & 0 & . & . \\
\hline & $\mathrm{N}$ & 68 & 68 & 68 & . & . \\
\hline \multirow{10}{*}{ OCC 1} & HHI Bar & 0.0998 & 0.0998 & 0.0998 & 0.0998 & 0.0998 \\
\hline & Marginal Effect at HHI Bar & -1.7156 & -1.8795 & -2.0539 & 0.0646 & -0.0468 \\
\hline & & $(0.3064)$ & $(0.3123)$ & $(0.3014)$ & $(0.3042)$ & $(0.2943)$ \\
\hline & HHI W-Bar & 0.0501 & 0.0501 & 0.0501 & 0.0501 & 0.0501 \\
\hline & $\begin{array}{c}\text { Marginal Effect at HHI W- } \\
\text { Bar }\end{array}$ & -1.7213 & -1.8818 & -2.0438 & 0.0814 & -0.0132 \\
\hline & & $(0.3039)$ & $(0.3099)$ & $(0.2987)$ & $(0.3031)$ & $(0.2958)$ \\
\hline & Total Effect & -0.4604 & -0.474 & -0.5586 & -0.1185 & -0.197 \\
\hline & & $(0.0327)$ & $(0.0444)$ & $(0.0505)$ & $(0.0593)$ & $(0.0528)$ \\
\hline & P-value on F on Cubic & 0 & 0 & 0 & 0.1655 & 0.0019 \\
\hline & $\mathrm{N}$ & 322 & 322 & 322 & 322 & 322 \\
\hline \multirow{10}{*}{ OCC 2} & HHI Bar & 0.149 & 0.149 & 0.149 & 0.149 & 0.149 \\
\hline & Marginal Effect at HHI Bar & -1.0561 & -1.1688 & -1.179 & 0.4983 & 0.4573 \\
\hline & & $(0.1853)$ & $(0.1894)$ & $(0.188)$ & $(0.1707)$ & $(0.1713)$ \\
\hline & HHI W-Bar & 0.0747 & 0.0747 & 0.0747 & 0.0747 & 0.0747 \\
\hline & $\begin{array}{c}\text { Marginal Effect at HHI W- } \\
\text { Bar }\end{array}$ & -1.1164 & -1.2339 & -1.2433 & 0.4972 & 0.4575 \\
\hline & & $(0.1787)$ & $(0.1827)$ & $(0.1815)$ & $(0.1645)$ & $(0.1651)$ \\
\hline & Total Fixed Effects & -0.2231 & -0.2231 & -0.2358 & 0.0311 & 0.0144 \\
\hline & & $(0.0435)$ & $(0.0438)$ & $(0.0434)$ & $(0.0499)$ & $(0.051)$ \\
\hline & P-value on $\mathrm{F}$ on Cubic & 0 & 0 & 0 & 0.0211 & 0.0342 \\
\hline & $\mathrm{N}$ & 1311 & 1311 & 1311 & 1311 & 1311 \\
\hline \multicolumn{7}{|c|}{ Fixed Effects } \\
\hline & Year & & $\mathrm{X}$ & $\mathrm{X}$ & $\mathrm{X}$ & $\mathrm{X}$ \\
\hline & Occ & & & & $\mathrm{X}$ & $\mathrm{X}$ \\
\hline & Region & & & $\mathrm{X}$ & & $\mathrm{X}$ \\
\hline
\end{tabular}

This table presents a region level unweighted estimation of the effect of HHI on wage with 0,1 , and 2 digit occupation controls. HHI Bar represents the average concentration in an occupation and region level labor market, and HHI W-Bar represents the average concentration faced by a labor market (HHI W-Bar is weighted by the number of employees requested in a certified LCA). Moving from left to right, a battery of fixed effect controls are added to the regression, as indicated in the bottom panel. Standard Errors (in parentheses) are robust. 
Table 3: H-1B: Linear Regional Level Analysis, Weighted

\begin{tabular}{ccccccc}
\hline & & 1 & 2 & 3 & 4 & 5 \\
\hline \hline \multirow{3}{*}{ Occ 0} & HHI & 0.4817 & -0.808 & -0.608 & $\cdot$ &. \\
& & $(0.1627)$ & $(0.3681)$ & $(0.1281)$ &. &. \\
& $\mathrm{N}$ & 68 & 68 & 68 &. &. \\
\hline \multirow{3}{*}{ Occ 1 } & $\mathrm{HHI}$ & 0.4126 & -0.781 & -0.623 & -0.75 & -0.56 \\
& & $(0.1628)$ & $(0.2825)$ & $(0.0854)$ & $(0.2973)$ & $(0.1003)$ \\
& $\mathrm{N}$ & 322 & 322 & 322 & 322 & 322 \\
\hline \multirow{3}{*}{ Occ 2 } & $\mathrm{HHI}$ & 0.1802 & -0.201 & -0.06 & -0.185 & -0.019 \\
& & $(0.0686)$ & $(0.1036)$ & $(0.0662)$ & $(0.1195)$ & $(0.0691)$ \\
& $\mathrm{N}$ & 1311 & 1311 & 1311 & 1311 & 1311 \\
\hline & Fixed & & & & & \\
& Effects & & $\mathrm{X}$ & $\mathrm{X}$ & $\mathrm{X}$ & $\mathrm{X}$ \\
& Year & & & & $\mathrm{X}$ & $\mathrm{X}$ \\
& Occ & & & $\mathrm{X}$ & & $\mathrm{X}$ \\
\hline \hline
\end{tabular}

This table presents a region level weighted estimation of the effect of HHI on wage with 0,1 , and 2 digit occupation controls. Moving from left to right, a battery of fixed effect controls are added to the regression, as indicated in the bottom panel. Standard Errors (in parentheses) are robust. 
Table 4: H-1B: Census Region Cubic Analysis Regression of Log Wage on HHI, Weighted

\begin{tabular}{|c|c|c|c|c|c|c|}
\hline & & 1 & 2 & 3 & 4 & 5 \\
\hline \multirow{10}{*}{ OCC 0} & HHI Bar & 0.032 & 0.032 & 0.032 & & . \\
\hline & Marginal Effect at HHI Bar & 39.457 & -9.1044 & 6.1316 & . & . \\
\hline & & $(15.3561)$ & $(14.8287)$ & $(6.1426)$ & . & . \\
\hline & HHI W-Bar & 0.0496 & 0.0496 & 0.0496 & . & . \\
\hline & $\begin{array}{c}\text { Marginal Effect at HHI W- } \\
\text { Bar }\end{array}$ & 57.9215 & -11.553 & 9.4426 & . & . \\
\hline & & $(22.5494)$ & $(21.7001)$ & $(8.8953)$ & . & . \\
\hline & Total Effect & 324.033 & -39.654 & 57.86 & . & . \\
\hline & & $(125.71)$ & $(120.437)$ & $(47.953)$ & . & . \\
\hline & P-value on F on Cubic & 0 & 0.0072 & 0 & . & . \\
\hline & $\mathrm{N}$ & 68 & 68 & 68 & 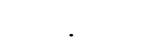 & . \\
\hline \multirow{10}{*}{ OCC 1} & HHI Bar & 0.0998 & 0.0998 & 0.0998 & 0.0998 & 0.0998 \\
\hline & Marginal Effect at HHI Bar & 0.8357 & -4.4094 & -1.078 & -4.522 & -1.136 \\
\hline & & $(0.9986)$ & $(1.2092)$ & $(0.4066)$ & $(1.2089)$ & $(0.4125)$ \\
\hline & HHI W-Bar & 0.0501 & 0.0501 & 0.0501 & 0.0501 & 0.0501 \\
\hline & $\begin{array}{c}\text { Marginal Effect at HHI W- } \\
\text { Bar }\end{array}$ & 0.8801 & -3.9005 & -1.011 & -4.042 & -1.103 \\
\hline & & $(0.8385)$ & $(1.0505)$ & $(0.3418)$ & $(1.0504)$ & $(0.3464)$ \\
\hline & Total Effect & -0.5315 & -0.7142 & -0.643 & -0.283 & -0.24 \\
\hline & & $(0.0583)$ & $(0.0797)$ & $(0.025)$ & $(0.0777)$ & $(0.0285)$ \\
\hline & P-value on $\mathrm{F}$ on Cubic & 0 & 0 & 0 & 0.0001 & 0 \\
\hline & $\mathrm{N}$ & 322 & 322 & 322 & 322 & 322 \\
\hline \multirow{14}{*}{ OCC 2} & HHI Bar & 0.149 & 0.149 & 0.149 & 0.149 & 0.149 \\
\hline & Marginal Effect at HHI Bar & 0.2107 & -1.1711 & -0.675 & -1.489 & -0.93 \\
\hline & & $(0.3343)$ & $(0.2929)$ & $(0.2077)$ & $(0.3584)$ & $(0.1929)$ \\
\hline & HHI W-Bar & 0.0747 & 0.0747 & 0.0747 & 0.0747 & 0.0747 \\
\hline & $\begin{array}{c}\text { Marginal Effect at HHI W- } \\
\text { Bar }\end{array}$ & 0.3053 & -1.0459 & -0.532 & -1.373 & -0.821 \\
\hline & & $(0.272)$ & $(0.2788)$ & $(0.1824)$ & $(0.3278)$ & $(0.1696)$ \\
\hline & Total Effect & -0.2422 & -0.4917 & -0.508 & -0.336 & -0.272 \\
\hline & & $(0.2969)$ & $(0.1086)$ & $(0.1355)$ & $(0.1933)$ & $(0.1141)$ \\
\hline & P-value on $\mathrm{F}$ on Cubic & 0.0456 & 0 & 0.0007 & 0.0002 & 0 \\
\hline & $\mathrm{N}$ & 1311 & 1311 & 1311 & 1311 & 1311 \\
\hline & \multicolumn{6}{|l|}{ Fixed Effects } \\
\hline & Year & & $\mathrm{X}$ & $\mathrm{X}$ & $\mathrm{X}$ & $\mathrm{X}$ \\
\hline & Occ & & & & $\mathrm{X}$ & $\mathrm{X}$ \\
\hline & Region & & & $\mathrm{X}$ & & $\mathrm{X}$ \\
\hline
\end{tabular}

This table presents a region level weighted estimation of the effect of HHI on wage with 0,1 , and 2 digit occupation controls. HHI Bar represents the average concentration in an occupation and region level labor market, and HHI WBar represents the average concentration faced by a guest worker (HHI W-Bar is weighted by the number of employees requested in a certified LCA). Moving from left to right, a battery of fixed effect controls are added to the regression, as indicated in the bottom panel. Standard Errors (in parentheses) are robust. 
Table 5: H-1B: Census Division Linear Analysis Regression of Log Wage on HHI, Unweighted

\begin{tabular}{|c|c|c|c|c|c|c|}
\hline & & 1 & 2 & 3 & 4 & 5 \\
\hline \multirow{3}{*}{ Occ 0} & HHI & 0.1572 & -0.225 & -0.202 & & \\
\hline & & $(0.0696)$ & $(0.0601)$ & $(0.0313)$ & . & . \\
\hline & $\mathrm{N}$ & 153 & 153 & 153 & . & \\
\hline \multirow{3}{*}{ Occ 1} & HHI & -0.3261 & -0.317 & -0.336 & -0.019 & 0.0202 \\
\hline & & $(0.0491)$ & $(0.0485)$ & $(0.0471)$ & $(0.0518)$ & $(0.052)$ \\
\hline & $\mathrm{N}$ & 705 & 705 & 705 & 705 & 705 \\
\hline \multirow[t]{2}{*}{ Occ 2} & HHI & $\begin{array}{l}-0.2717 \\
(0.0179)\end{array}$ & $\begin{array}{l}-0.274 \\
(0.018)\end{array}$ & $\begin{array}{c}-0.275 \\
(0.0181)\end{array}$ & $\begin{array}{c}-0.034 \\
(0.0236)\end{array}$ & $\begin{array}{c}-0.007 \\
(0.0249)\end{array}$ \\
\hline & $\mathrm{N}$ & 2755 & 2755 & 2755 & 2755 & 2755 \\
\hline \multicolumn{7}{|c|}{$\begin{array}{l}\text { Fixed } \\
\text { Effects }\end{array}$} \\
\hline & Year & & X & X & $\begin{array}{l}X \\
\text { Y }\end{array}$ & $\mathrm{X}$ \\
\hline & Division & & & X & & X \\
\hline
\end{tabular}

This table presents a division level unweighted estimation of the effect of HHI on wage with 0,1 , and 2 digit occupation controls. Moving from left to right, a battery of fixed effect controls are added to the regression, as indicated in the bottom panel. Standard Errors (in parentheses) are robust. 
Table 6: H-1B: Census Division Cubic Analysis Regression of Log Wage on HHI, Unweighted

\begin{tabular}{|c|c|c|c|c|c|c|}
\hline & & 1 & 2 & 3 & 4 & 5 \\
\hline \multirow{10}{*}{ OCC 0} & HHI Bar & 0.0393 & 0.0393 & 0.0393 & . & . \\
\hline & Marginal Effect at HHI Bar & 1.7478 & -2.043 & -0.624 & . & . \\
\hline & & $(0.8695)$ & $(0.8371)$ & $(0.5287)$ & . & . \\
\hline & HHI W-Bar & 0.0689 & 0.0689 & 0.0689 & . & . \\
\hline & $\begin{array}{c}\text { Marginal Effect at HHI W- } \\
\text { Bar }\end{array}$ & 2.2679 & -2.724 & -0.75 & . & . \\
\hline & & $(1.2283)$ & $(1.168)$ & $(0.7221)$ & . & . \\
\hline & Total Effect & 4.8016 & -6.499 & -1.33 & . & . \\
\hline & & $(3.3917)$ & $(3.1332)$ & $(1.8136)$ & . & . \\
\hline & P-value on F on Cubic & 0.0071 & 0.001 & 0 & . & . \\
\hline & $\mathrm{N}$ & 153 & 153 & 153 & . & . \\
\hline \multirow{10}{*}{ OCC 1} & HHI Bar & 0.1808 & 0.1808 & 0.1808 & 0.1808 & 0.1808 \\
\hline & Marginal Effect at HHI Bar & -1.237 & -1.347 & -1.446 & 0.1353 & 0.186 \\
\hline & & $(0.2203)$ & $(0.2225)$ & $(0.2137)$ & $(0.2311)$ & $(0.2249)$ \\
\hline & HHI W-Bar & 0.0695 & 0.0695 & 0.0695 & 0.0695 & 0.0695 \\
\hline & $\begin{array}{c}\text { Marginal Effect at HHI W- } \\
\text { Bar }\end{array}$ & -1.394 & -1.495 & -1.597 & 0.0701 & 0.1253 \\
\hline & & $(0.2054)$ & $(0.2077)$ & $(0.1988)$ & $(0.2185)$ & $(0.2134)$ \\
\hline & Total Effect & -0.223 & -0.23 & -0.252 & 0.0344 & 0.0698 \\
\hline & & $(0.0711)$ & $(0.0708)$ & $(0.0683)$ & $(0.072)$ & $(0.0707)$ \\
\hline & P-value on F on Cubic & 0 & 0 & 0 & 0.1367 & 0.3966 \\
\hline & $\mathrm{N}$ & 705 & 705 & 705 & 705 & 705 \\
\hline \multirow{10}{*}{ OCC 2} & HHI Bar & 0.2091 & 0.2091 & 0.2091 & 0.2091 & 0.2091 \\
\hline & Marginal Effect at HHI Bar & -1.131 & -1.241 & -1.22 & -0.176 & 0.0185 \\
\hline & & $(0.1364)$ & $(0.1364)$ & $(0.1359)$ & $(0.122)$ & $(0.1224)$ \\
\hline & HHI W-Bar & 0.1005 & 0.1005 & 0.1005 & 0.1005 & 0.1005 \\
\hline & $\begin{array}{c}\text { Marginal Effect at HHI W- } \\
\text { Bar }\end{array}$ & -1.22 & -1.34 & -1.319 & -0.198 & 0.0048 \\
\hline & & $(0.1331)$ & $(0.1332)$ & $(0.1329)$ & $(0.1183)$ & $(0.1193)$ \\
\hline & Total Effect & -0.269 & -0.275 & -0.276 & -0.046 & -0.007 \\
\hline & & $(0.0208)$ & $(0.0209)$ & $(0.021)$ & $(0.025)$ & $(0.0262)$ \\
\hline & P-value on F on Cubic & 0 & 0 & 0 & 0.0121 & 0.6814 \\
\hline & $\mathrm{N}$ & 2755 & 2755 & 2755 & 2755 & 2755 \\
\hline \multicolumn{7}{|c|}{ Fixed Effects } \\
\hline & Year & & $\mathrm{X}$ & $\mathrm{X}$ & $\mathrm{X}$ & $\mathrm{X}$ \\
\hline & Occ & & & & $\mathrm{X}$ & $\mathrm{X}$ \\
\hline & Division & & & $\mathrm{X}$ & & $\mathrm{X}$ \\
\hline
\end{tabular}

This table presents a division level unweighted estimation of the effect of HHI on wage with 0,1 , and 2 digit occupation controls. HHI Bar represents the average concentration in an occupation and division level labor market, and HHI W-Bar represents the average concentration faced by labor market (HHI WBar is weighted by the number of employees requested in a certified LCA). Moving from left to right, a battery of fixed effect controls are added to the regression, as indicated in the bottom panel. Standard Errors (in parentheses) are robust. 
Table 7: H-1B: Census Division Linear Analysis Regression of Log Wage on HHI, Weighted

\begin{tabular}{ccccccc}
\hline & & 1 & 2 & 3 & 4 & 5 \\
\hline \hline \multirow{3}{*}{ Occ 0} & HHI & 0.1113 & -0.4319 & -0.251 & $\cdot$ &. \\
& & $(0.1022)$ & $(0.1306)$ & $(0.0449)$ &. &. \\
& $\mathrm{N}$ & 153 & 153 & 153 &. &. \\
\hline \multirow{3}{*}{ Occ 1 } & $\mathrm{HHI}$ & 0.0898 & -0.439 & -0.2726 & -0.4264 & -0.2508 \\
& & $(0.0981)$ & $(0.1177)$ & $(0.0409)$ & $(0.1194)$ & $(0.0395)$ \\
& $\mathrm{N}$ & 705 & 705 & 705 & 705 & 705 \\
\hline \multirow{5}{*}{ Occ 2 } & HHI & 0.0117 & -0.2434 & -0.1093 & -0.2468 & -0.1118 \\
& & $(0.0473)$ & $(0.0594)$ & $(0.0371)$ & $(0.0597)$ & $(0.0366)$ \\
& $\mathrm{N}$ & 2755 & 2755 & 2755 & 2755 & 2755 \\
\hline & Fixed & & & & & \\
& Effects & & & & & $\mathrm{X}$ \\
& Year & & & $\mathrm{X}$ & $\mathrm{X}$ & $\mathrm{X}$ \\
& Occ & & & $\mathrm{X}$ & & $\mathrm{X}$ \\
\hline \hline
\end{tabular}

This table presents a division level unweighted estimation of the effect of $\mathrm{HHI}$ on wage with 0,1 , and 2 digit occupation controls. Moving from left to right, a battery of fixed effect controls are added to the regression, as indicated in the bottom panel. Standard Errors (in parentheses) are robust. 
Table 8: H-1B: Census Division Cubic Analysis Regression of Log Wage on HHI, Weighted

\begin{tabular}{|c|c|c|c|c|c|c|}
\hline & & 1 & 2 & 3 & 4 & 5 \\
\hline \multirow{10}{*}{ OCC 0} & HHI Bar & 0.0393 & 0.0393 & 0.0393 & 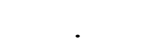 & 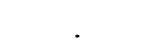 \\
\hline & Marginal Effect at HHI Bar & 2.0653 & -3.132 & -0.343 & . & . \\
\hline & & $(1.1712)$ & $(1.2666)$ & $(0.5173)$ & . & . \\
\hline & HHI W-Bar & 0.0689 & 0.0689 & 0.0689 & . & . \\
\hline & $\begin{array}{c}\text { Marginal Effect at HHI W- } \\
\text { Bar }\end{array}$ & 2.6679 & -3.995 & -0.312 & . & . \\
\hline & & $(1.6455)$ & $(1.7247)$ & $(0.7052)$ & . & . \\
\hline & Total Effect & 5.4611 & -8.289 & 0.0978 & . & . \\
\hline & & $(4.4369)$ & $(4.336)$ & $(1.7627)$ & . & . \\
\hline & P-value on $\mathrm{F}$ on Cubic & 0.0272 & 0.0005 & 0 & . & . \\
\hline & $\mathrm{N}$ & 153 & 153 & 153 & . & . \\
\hline \multirow{10}{*}{ OCC 1} & HHI Bar & 0.1808 & 0.1808 & 0.1808 & 0.1808 & 0.1808 \\
\hline & Marginal Effect at HHI Bar & 0.4187 & -1.245 & -0.667 & -0.964 & -0.372 \\
\hline & & $(0.3115)$ & $(0.3444)$ & $(0.1232)$ & $(0.3494)$ & $(0.1254)$ \\
\hline & HHI W-Bar & 0.0695 & 0.0695 & 0.0695 & 0.0695 & 0.0695 \\
\hline & $\begin{array}{c}\text { Marginal Effect at HHI W- } \\
\text { Bar }\end{array}$ & 0.5374 & -1.079 & -0.543 & -0.946 & -0.403 \\
\hline & & $(0.2709)$ & $(0.319)$ & $(0.1144)$ & $(0.322)$ & $(0.115)$ \\
\hline & Total Effect & -0.457 & -0.669 & -0.511 & -0.3 & -0.118 \\
\hline & & $(0.1222)$ & $(0.1414)$ & $(0.0271)$ & $(0.1426)$ & $(0.0328)$ \\
\hline & $\mathrm{P}$-value on $\mathrm{F}$ on Cubic & 0 & 0 & 0 & 0.0004 & 0 \\
\hline & $\mathrm{N}$ & 705 & 705 & 705 & 705 & 705 \\
\hline \multirow{10}{*}{ OCC 2} & HHI Bar & 0.2091 & 0.2091 & 0.2091 & 0.2091 & 0.2091 \\
\hline & Marginal Effect at HHI Bar & 0.2339 & -0.995 & -0.59 & -0.896 & -0.49 \\
\hline & & $(0.3662)$ & $(0.2225)$ & $(0.1558)$ & $(0.298)$ & $(0.1765)$ \\
\hline & HHI W-Bar & 0.1005 & 0.1005 & 0.1005 & 0.1005 & 0.1005 \\
\hline & $\begin{array}{c}\text { Marginal Effect at HHI W- } \\
\text { Bar }\end{array}$ & 0.2893 & -0.864 & -0.448 & -0.863 & -0.458 \\
\hline & & $(0.2699)$ & $(0.2009)$ & $(0.1316)$ & $(0.2471)$ & $(0.136)$ \\
\hline & Total Effect & -0.16 & -0.526 & -0.436 & -0.292 & -0.175 \\
\hline & & $(0.2882)$ & $(0.1197)$ & $(0.1017)$ & $(0.1994)$ & $(0.1503)$ \\
\hline & P-value on F on Cubic & 0.2204 & 0 & 0 & 0 & 0.0001 \\
\hline & $\mathrm{N}$ & 2755 & 2755 & 2755 & 2755 & 2755 \\
\hline \multicolumn{7}{|c|}{ Fixed Effects } \\
\hline & Year & & $\mathrm{X}$ & $\mathrm{X}$ & $\mathrm{X}$ & $\mathrm{X}$ \\
\hline & Occ & & & & $\mathrm{X}$ & $\mathrm{X}$ \\
\hline & Division & & & $\mathrm{X}$ & & $X$ \\
\hline
\end{tabular}

This table presents a division level unweighted estimation of the effect of HHI on wage with 0,1 , and 2 digit occupation controls. HHI Bar represents the average concentration in an occupation and division level labor market, and HHI W-Bar represents the average concentration faced by a guest worker (HHI W-Bar is weighted by the number of employees requested in a certified LCA). Moving from left to right, a battery of fixed effect controls are added to the regression, as indicated in the bottom panel. Standard Errors (in parentheses) are robust. 
Table 9: H-1B: Census State Linear Analysis Regression of Log Wage on HHI, Unweighted

\begin{tabular}{|c|c|c|c|c|c|c|c|c|c|}
\hline & & 1 & 2 & 3 & 4 & 5 & 6 & 7 & 8 \\
\hline & $\mathrm{HHI}$ & 0.1624 & -0.0107 & -0.0761 & . & . & . & . & $\cdot$ \\
\hline \multirow[t]{2}{*}{ Occ 0} & & $(0.0662)$ & $(0.074)$ & $(0.0691)$ & . & . & . & . & . \\
\hline & $\mathrm{N}$ & 867 & 867 & 867 & . & . & . & . & . \\
\hline \multirow{3}{*}{ Occ 1} & HHI & -0.2618 & -0.262 & -0.286 & -0.0795 & -0.0423 & -0.0114 & -0.0488 & -0.0487 \\
\hline & & $(0.0204)$ & $(0.0206)$ & (0.019) & $(0.0252)$ & $(0.0255)$ & $(0.0295)$ & $(0.0246)$ & $(0.0323)$ \\
\hline & $\mathrm{N}$ & 2917 & 2917 & 2917 & 2917 & 2917 & 2917 & 2917 & 2917 \\
\hline \multirow{2}{*}{ Occ 2} & $\mathrm{HHI}$ & $\begin{array}{l}-0.2616 \\
00134)\end{array}$ & $\begin{array}{l}-0.2732 \\
(0.0131)\end{array}$ & $\begin{array}{l}-0.2793 \\
(00126)\end{array}$ & $\begin{array}{l}-0.1095 \\
(00199)\end{array}$ & $\begin{array}{r}-0.0627 \\
(0.017)\end{array}$ & $\begin{array}{c}-0.02 \\
(0.0197)\end{array}$ & $\begin{array}{c}-0.0688 \\
(00151)\end{array}$ & $\begin{array}{r}-0.0705 \\
(0.0173)\end{array}$ \\
\hline & $\mathrm{N}$ & 11614 & 11614 & 11614 & 11614 & 11614 & 11614 & 11614 & 11614 \\
\hline \multicolumn{10}{|c|}{ Fixed Effects } \\
\hline & Year & & $\mathrm{X}$ & $\mathrm{X}$ & $\mathrm{X}$ & $\mathrm{X}$ & $\mathrm{X}$ & $\mathrm{X}$ & $\mathrm{X}$ \\
\hline & Occ & & & & $\mathrm{X}$ & $\mathrm{X}$ & $\mathrm{X}$ & $\mathrm{X}$ & $X$ \\
\hline & State & & & $\mathrm{X}$ & & $\mathrm{X}$ & $\mathrm{X}$ & $\mathrm{X}$ & $\mathrm{X}$ \\
\hline & OccXGeo & & & & & & $\mathrm{X}$ & & \\
\hline & OccXYear & & & & & & & $X$ & \\
\hline & GeoXYear & & & & & & & & $X$ \\
\hline
\end{tabular}

This table presents a state level unweighted estimation of the effect of HHI on wage with 0,1 , and 2 digit occupation controls. Moving from left to right, a battery of fixed effect controls are added to the regression, as indicated in the bottom panel. Standard Errors (in parentheses) are clustered at the state level. 
Table 10: H-1B: Census State Cubic Analysis Regression of Log Wage on HHI, Unweighted

\begin{tabular}{|c|c|c|c|c|c|c|c|c|c|}
\hline & & 1 & 2 & 3 & 4 & 5 & 6 & 7 & 8 \\
\hline \multirow{10}{*}{$\begin{array}{c}\text { OCC } \\
0\end{array}$} & HHI Bar & 0.0807 & 0.0807 & 0.0807 & . & . & . & . & . \\
\hline & Marginal Effect at HHI Bar & 0.7493 & -0.116 & -0.2234 & . & . & . & . & . \\
\hline & & $(0.4156)$ & $(0.4881)$ & $(0.2741)$ & . & . & . & . & . \\
\hline & HHI W-Bar & 0.1411 & 0.1411 & 0.1411 & . & . & . & . & . \\
\hline & Marginal Effect at HHI W-Bar & 0.8537 & -0.0909 & -0.1741 & . & . & . & . & . \\
\hline & & $(0.4674)$ & $(0.5456)$ & $(0.3269)$ & . & . & . & . & . \\
\hline & Total Effect & 0.5493 & 0.0887 & 0.1106 & . & . & . & . & . \\
\hline & & $(0.2583)$ & $(0.2811)$ & $(0.2095)$ & . & . & . & . & . \\
\hline & $\mathrm{P}$-value on $\mathrm{F}$ on Cubic & 0.0033 & 0.7978 & 0.0685 & . & . & . & . & . \\
\hline & $\mathrm{N}$ & 867 & 867 & 867 & . & . & . & . & . \\
\hline \multirow{10}{*}{$\begin{array}{c}\text { OCC } \\
1\end{array}$} & HHI Bar & 0.3865 & 0.3865 & 0.3865 & 0.3865 & 0.3865 & 0.3865 & 0.3865 & 0.3865 \\
\hline & Marginal Effect at HHI Bar & -0.6714 & -0.7645 & -0.8579 & -0.1106 & -0.0055 & -0.0379 & -0.0805 & 0.0976 \\
\hline & & $(0.1943)$ & $(0.1887)$ & $(0.1745)$ & $(0.1732)$ & $(0.1592)$ & $(0.1628)$ & $(0.1615)$ & $(0.2131)$ \\
\hline & HHI W-Bar & 0.1421 & 0.1421 & 0.1421 & 0.1421 & 0.1421 & 0.1421 & 0.1421 & 0.1421 \\
\hline & Marginal Effect at HHI W-Bar & -0.8604 & -0.9646 & -1.0769 & -0.1448 & -0.0376 & -0.0492 & -0.1117 & 0.0686 \\
\hline & & $(0.1885)$ & $(0.1818)$ & $(0.1691)$ & $(0.1754)$ & $(0.1655)$ & $(0.1717)$ & $(0.17)$ & $(0.2209)$ \\
\hline & Total Effect & -0.2953 & -0.3027 & -0.3327 & -0.0882 & -0.0477 & -0.017 & -0.0607 & -0.0433 \\
\hline & & $(0.0212)$ & $(0.0217)$ & $(0.0185)$ & $(0.0311)$ & $(0.0322)$ & $(0.0323)$ & $(0.0341)$ & $(0.0393)$ \\
\hline & P-value on $\mathrm{F}$ on Cubic & 0 & 0 & 0 & 0.0288 & 0.3651 & 0.9583 & 0.257 & 0.4249 \\
\hline & $\mathrm{N}$ & 2917 & 2917 & 2917 & 2917 & 2917 & 2917 & 2917 & 2917 \\
\hline \multirow{15}{*}{$\begin{array}{c}\mathrm{OCC} \\
2\end{array}$} & HHI Bar & 0.3112 & 0.3112 & 0.3112 & 0.3112 & 0.3112 & 0.3112 & 0.3112 & 0.3112 \\
\hline & Marginal Effect at HHI Bar & -0.767 & -0.8215 & -1.034 & -0.431 & -0.264 & -0.1982 & -0.2136 & -0.2829 \\
\hline & & $(0.116)$ & $(0.1073)$ & $(0.0984)$ & $(0.1045)$ & $(0.1066)$ & $(0.1029)$ & $(0.1076)$ & 0.1155 \\
\hline & HHI W-Bar & 0.1846 & 0.1846 & 0.1846 & 0.1846 & 0.1846 & 0.1846 & 0.1846 & 0.1846 \\
\hline & Marginal Effect at HHI W-Bar & -0.8433 & -0.9075 & -1.1359 & -0.4831 & -0.306 & -0.2336 & -0.2473 & -0.3251 \\
\hline & & $(0.1183)$ & $(0.1094)$ & $(0.1002)$ & $(0.1079)$ & $(0.1108)$ & $(0.1058)$ & $(0.1125)$ & $(0.12)$ \\
\hline & Total Effect & -0.2921 & -0.3073 & -0.3339 & -0.1331 & -0.0902 & -0.045 & -0.0911 & -0.0988 \\
\hline & & $(0.0155)$ & $(0.0154)$ & $(0.0145)$ & $(0.0226)$ & $(0.0226)$ & $(0.0246)$ & $(0.0219)$ & $(0.0234)$ \\
\hline & $\mathrm{P}$-value on $\mathrm{F}$ on Cubic & 0 & 0 & 0 & 0 & 0.0003 & 0.0185 & 0.0003 & 0.0002 \\
\hline & $\mathrm{N}$ & 11614 & 11614 & 11614 & 11614 & 11614 & 11614 & 11614 & 11614 \\
\hline & Fixed Effects & & & & & & & & \\
\hline & Year & & $\mathrm{X}$ & $X$ & $X$ & $\mathrm{X}$ & $X$ & $X$ & $X$ \\
\hline & Occ & & & & $X$ & $X$ & $X$ & $X$ & $X$ \\
\hline & State & & & $X$ & & $X$ & $X$ & $X$ & $X$ \\
\hline & Interactions & & & & & & OccXGeo & OccXYear & GeoXYear \\
\hline
\end{tabular}

This table presents a state level unweighted estimation of the effect of $\mathrm{HHI}$ on wage with 0,1 , and 2 digit occupation controls. HHI Bar represents the average concentration in an occupation and state level labor market, and HHI W-Bar represents the average concentration faced by a labor market (HHI W-Bar is weighted by the number of employees requested in a certified LCA). Moving from left to right, a battery of fixed effect controls are added to the regression, as indicated in the bottom panel. Standard Errors (in parentheses) are clustered at the state level. 
Table 11: H-1B: Census State Linear Analysis Regression of Log Wage on HHI, Weighted

\begin{tabular}{|c|c|c|c|c|c|c|c|c|c|}
\hline & & 1 & 2 & 3 & 4 & 5 & 6 & 7 & 8 \\
\hline \multirow{3}{*}{ Occ 0} & HHI & 0.1002 & -0.0501 & -0.0087 & . & . & . & . & . \\
\hline & & $(0.0909)$ & $(0.1252)$ & $(0.0674)$ & . & . & . & . & . \\
\hline & $\mathrm{N}$ & 867 & 867 & 867 & . & . & . & . & . \\
\hline \multirow{3}{*}{ Occ 1} & HHI & 0.0949 & -0.0556 & -0.0225 & -0.0522 & -0.0125 & -0.0108 & -0.0069 & -0.119 \\
\hline & & $(0.0919)$ & $(0.1242)$ & $(0.0666)$ & $(0.1232)$ & $(0.0641)$ & $(0.0672)$ & $(0.0656)$ & $(0.0861)$ \\
\hline & $\mathrm{N}$ & 2917 & 2917 & 2917 & 2917 & 2917 & 2917 & 2917 & 2917 \\
\hline \multirow{3}{*}{ Occ 2} & HHI & 0.0447 & -0.0752 & -0.0381 & -0.0696 & -0.0367 & -0.0079 & -0.0476 & -0.0414 \\
\hline & & $(0.0862)$ & $(0.098)$ & $(0.042)$ & $(0.094)$ & $(0.0483)$ & $(0.0569)$ & $(0.0467)$ & $(0.05)$ \\
\hline & $\mathrm{N}$ & 11614 & 11614 & 11614 & 11614 & 11614 & 11614 & 11614 & 11614 \\
\hline \multicolumn{10}{|c|}{ Fixed Effects } \\
\hline & Year & & $\mathrm{X}$ & $X$ & $\mathrm{X}$ & $X$ & $\mathrm{X}$ & $X$ & $X$ \\
\hline & Occ & & & & $X$ & $X$ & $\mathrm{X}$ & $X$ & $X$ \\
\hline & State & & & $X$ & & $X$ & $\mathrm{X}$ & $\mathrm{X}$ & $\mathrm{X}$ \\
\hline & OccXGeo & & & & & & $X$ & & \\
\hline & OccXYear & & & & & & & $\mathrm{X}$ & \\
\hline & GeoXYear & & & & & & & & $\mathrm{X}$ \\
\hline
\end{tabular}

This table presents a state level weighted estimation of the effect of HHI on wage with 0,1 , and 2 digit occupation controls. Moving from left to right, a battery of fixed effect controls are added to the regression, as indicated in the bottom panel. Standard Errors (in parentheses) are clustered at the state level. 
Table 12: H-1B: Census State Cubic Analysis Regression of Log Wage on HHI, Weighted

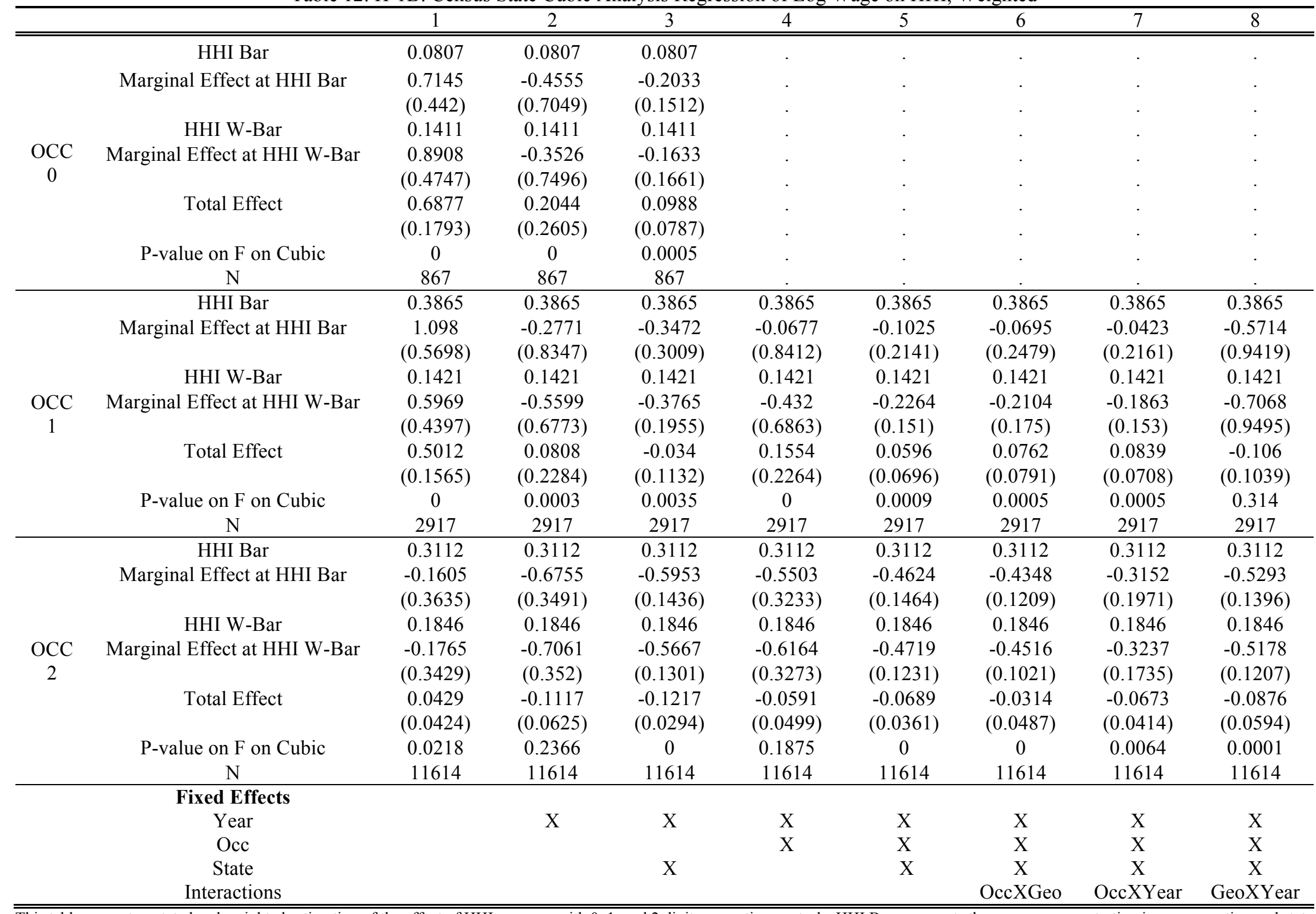

This table presents a state level weighted estimation of the effect of HHI on wage with 0,1 , and 2 digit occupation controls. HHI Bar represents the average concentration in an occupation and state level labor market, and HHI W-Bar represents the average concentration faced by a guest worker (HHI W-Bar is weighted by the number of employees requested in a certified LCA). Moving from left to right, a battery of fixed effect controls are added to the regression, as indicated in the bottom panel. Standard Errors (in parentheses) are clustered at the state level. 
Table 13: H-1B: Census Commuting Zone Linear Analysis Regression of Log Wage on HHI, Unweighted

\begin{tabular}{ccccccc}
\hline & & 1 & 2 & 3 & 4 & 5 \\
\hline \hline \multirow{2}{*}{ Occ 0} & HHI & -0.1736 & -0.1793 & -0.1388 &. &. \\
& & $(0.0173)$ & $(0.0174)$ & $(0.0218)$ &. &. \\
& $\mathrm{N}$ & 10150 & 10150 & 10150 &. &. \\
\hline \multirow{3}{*}{ Occ 1} & HHI & -0.2474 & -0.2515 & -0.2738 & -0.1626 & -0.1146 \\
& & $(0.0121)$ & $(0.0122)$ & $(0.0102)$ & $(0.0136)$ & $(0.0142)$ \\
& $\mathrm{N}$ & 14640 & 14640 & 14640 & 14640 & 14640 \\
\hline \multirow{3}{*}{ Occ 2 } & HHI & -0.1918 & -0.1982 & -0.3021 & -0.1445 & -0.094 \\
& & $(0.0081)$ & $(0.0081)$ & $(0.0078)$ & $(0.0074)$ & $(0.0071)$ \\
& $\mathrm{N}$ & 56802 & 56802 & 56802 & 56802 & 56802 \\
\hline & Fixed & & & & & \\
& Effects & & & & & $\mathrm{X}$ \\
& Year & & & $\mathrm{X}$ & $\mathrm{X}$ & $\mathrm{X}$ \\
& Occ & & & $\mathrm{X}$ & & $\mathrm{X}$ \\
\hline \hline
\end{tabular}

This table presents a commuting zone level unweighted estimation of the effect of HHI on wage with 0,1 , and 2 digit occupation controls. HHI Bar represents the average concentration in an occupation and commuting zone level labor market. Moving from left to right, a battery of fixed effect controls are added to the regression, as indicated in the bottom panel. Standard Errors (in parentheses) are clustered at the commuting zone level. 
Table 14: H-1B: Census Commuting Zone Cubic Analysis Regression of Log Wage on HHI, Unweighted

\begin{tabular}{|c|c|c|c|c|c|c|}
\hline & & 1 & 2 & 3 & 4 & 5 \\
\hline \multirow{10}{*}{$\begin{array}{c}\text { OCC } \\
0\end{array}$} & HHI Bar & 0.4078 & 0.4078 & 0.4078 & . & . \\
\hline & \multirow[t]{2}{*}{ Marginal Effect at HHI Bar } & 0.2571 & 0.2101 & -0.1071 & . & . \\
\hline & & $(0.1221)$ & $(0.1221)$ & $(0.12)$ & . & . \\
\hline & HHI W-Bar & 0.085 & 0.085 & 0.085 & $\cdot$ & . \\
\hline & \multirow[t]{2}{*}{ Marginal Effect at HHI W-Bar } & 0.3518 & 0.2912 & -0.0979 & . & . \\
\hline & & $(0.1319)$ & $(0.1319)$ & $(0.132)$ & & . \\
\hline & \multirow[t]{2}{*}{ Total Effect } & -0.1265 & -0.1368 & -0.1331 & . & . \\
\hline & & 0.0201 & 0.0204 & 0.0259 & & . \\
\hline & P-value on F on Cubic & 0 & 0 & 0 & & . \\
\hline & $\mathrm{N}$ & 10150 & 10150 & 10150 & & \\
\hline \multirow{10}{*}{$\begin{array}{c}\text { OCC } \\
1\end{array}$} & HHI Bar & 0.5066 & 0.5066 & 0.5066 & 0.5066 & 0.5066 \\
\hline & Marginal Effect at HHI Bar & -0.1041 & -0.1378 & -0.6892 & 0.1463 & -0.0491 \\
\hline & & $(0.1085)$ & $(0.1078)$ & $(0.0981)$ & $(0.1084)$ & $(0.1005)$ \\
\hline & HHI W-Bar & 0.0886 & 0.0886 & 0.0886 & 0.0886 & 0.0886 \\
\hline & \multirow[t]{2}{*}{ Marginal Effect at HHI W-Bar } & 0.006 & -0.0409 & -0.8273 & 0.2022 & -0.0195 \\
\hline & & $(0.1247)$ & $(0.124)$ & $(0.1099)$ & $(0.1213)$ & $(0.1147)$ \\
\hline & \multirow[t]{2}{*}{ Total Effect } & -0.2206 & -0.2289 & -0.3278 & -0.1282 & -0.1015 \\
\hline & & $(0.0155)$ & $(0.0157)$ & $(0.0136)$ & $(0.0175)$ & $(0.0205)$ \\
\hline & P-value on F on Cubic & 0 & 0 & 0 & 0 & 0 \\
\hline & $\mathrm{N}$ & 14640 & 14640 & 14640 & 14640 & 14640 \\
\hline \multirow{14}{*}{$\begin{array}{c}\text { OCC } \\
2\end{array}$} & HHI Bar & 0.5802 & 0.5802 & 0.5802 & 0.5802 & 0.5802 \\
\hline & Marginal Effect at HHI Bar & -0.427 & -0.43 & -0.7972 & -0.3696 & -0.2607 \\
\hline & & $(0.0783)$ & $(0.0769)$ & $(0.063)$ & $(0.0643)$ & $(0.0531)$ \\
\hline & HHI W-Bar & 0.1467 & 0.1467 & 0.1467 & 0.1467 & 0.1467 \\
\hline & Marginal Effect at HHI W-Bar & -0.3975 & -0.411 & -0.9836 & -0.4519 & -0.3547 \\
\hline & \multirow{3}{*}{ Total Effect } & $(0.0965)$ & $(0.0949)$ & $(0.075)$ & $(0.0796)$ & $(0.0655)$ \\
\hline & & -0.2061 & -0.214 & -0.3848 & -0.1783 & -0.1336 \\
\hline & & $(0.0144)$ & $(0.0143)$ & $(0.012)$ & $(0.0129)$ & $(0.0119)$ \\
\hline & P-value on F on Cubic & 0 & 0 & 0 & 0 & 0 \\
\hline & $\mathrm{N}$ & 56802 & 56802 & 56802 & 56802 & 56802 \\
\hline & \multicolumn{6}{|l|}{ Fixed Effects } \\
\hline & Year & & $\mathrm{X}$ & $\mathrm{X}$ & $\mathrm{X}$ & $\mathrm{X}$ \\
\hline & Occ & & & & $\mathrm{X}$ & $\mathrm{X}$ \\
\hline & $\mathrm{CZ}$ & & & $\mathrm{X}$ & & $\mathrm{X}$ \\
\hline
\end{tabular}

This table presents a commuting zone level unweighted estimation of the effect of HHI on wage with 0,1 , and 2 digit occupation controls. HHI Bar represents the average concentration in an occupation and commuting zone level labor market, and HHI W-Bar represents the average concentration faced by a labor market (HHI W-Bar is weighted by the number of employees requested in a certified LCA). Moving from left to right, a battery of fixed effect controls are added to the regression, as indicated in the bottom panel. Standard Errors (in parentheses) are clustered at the commuting zone level. 
Table 15: H-1B: Census Commuting Zone Linear Analysis Regression of Log Wage on HHI, Weighted

\begin{tabular}{|c|c|c|c|c|c|c|}
\hline & & (1) & (2) & (3) & (4) & (5) \\
\hline \multirow{3}{*}{ Occ 0} & HHI & -0.0882 & -0.1049 & -0.112 & . & . \\
\hline & & $(0.0518)$ & $(0.0444)$ & $(0.0463)$ & . & . \\
\hline & $\mathrm{N}$ & 10150 & 10150 & 10150 & . & . \\
\hline \multirow{3}{*}{ Occ 1} & HHI & -0.1032 & -0.1226 & -0.2293 & -0.0963 & -0.0764 \\
\hline & & $(0.0483)$ & $(0.0416)$ & $(0.0485)$ & $(0.0417)$ & $(0.0428)$ \\
\hline & $\mathrm{N}$ & 14640 & 14640 & 14640 & 14640 & 14640 \\
\hline \multirow[t]{6}{*}{ Occ 2} & HHI & $\begin{array}{c}-0.1302 \\
(0.0443)\end{array}$ & $\begin{array}{l}-0.1428 \\
(0.0424)\end{array}$ & $\begin{array}{l}-0.1654 \\
(0.039)\end{array}$ & $\begin{array}{l}-0.1091 \\
(0.0375)\end{array}$ & $\begin{array}{c}-0.0694 \\
(0.0365)\end{array}$ \\
\hline & $\mathrm{N}$ & 56802 & 56802 & 56802 & 56802 & 56802 \\
\hline & $\begin{array}{c}\text { Fixed } \\
\text { Effects }\end{array}$ & & & & & \\
\hline & Year & & $\mathrm{X}$ & $\mathrm{X}$ & $\mathrm{X}$ & $\mathrm{X}$ \\
\hline & Occ & & & & $X$ & $X$ \\
\hline & $\mathrm{CZ}$ & & & $X$ & & $X$ \\
\hline
\end{tabular}

This table presents a commuting zone level weighted estimation of the effect of HHI on wage with 0,1 , and 2 digit occupation controls. Moving from left to right, a battery of fixed effect controls are added to the regression, as indicated in the bottom panel. Standard Errors (in parentheses) are clustered at the commuting zone level. 
Table 16: H-1B: Census Commuting Zone Cubic Analysis Regression of Log Wage on HHI, Weighted

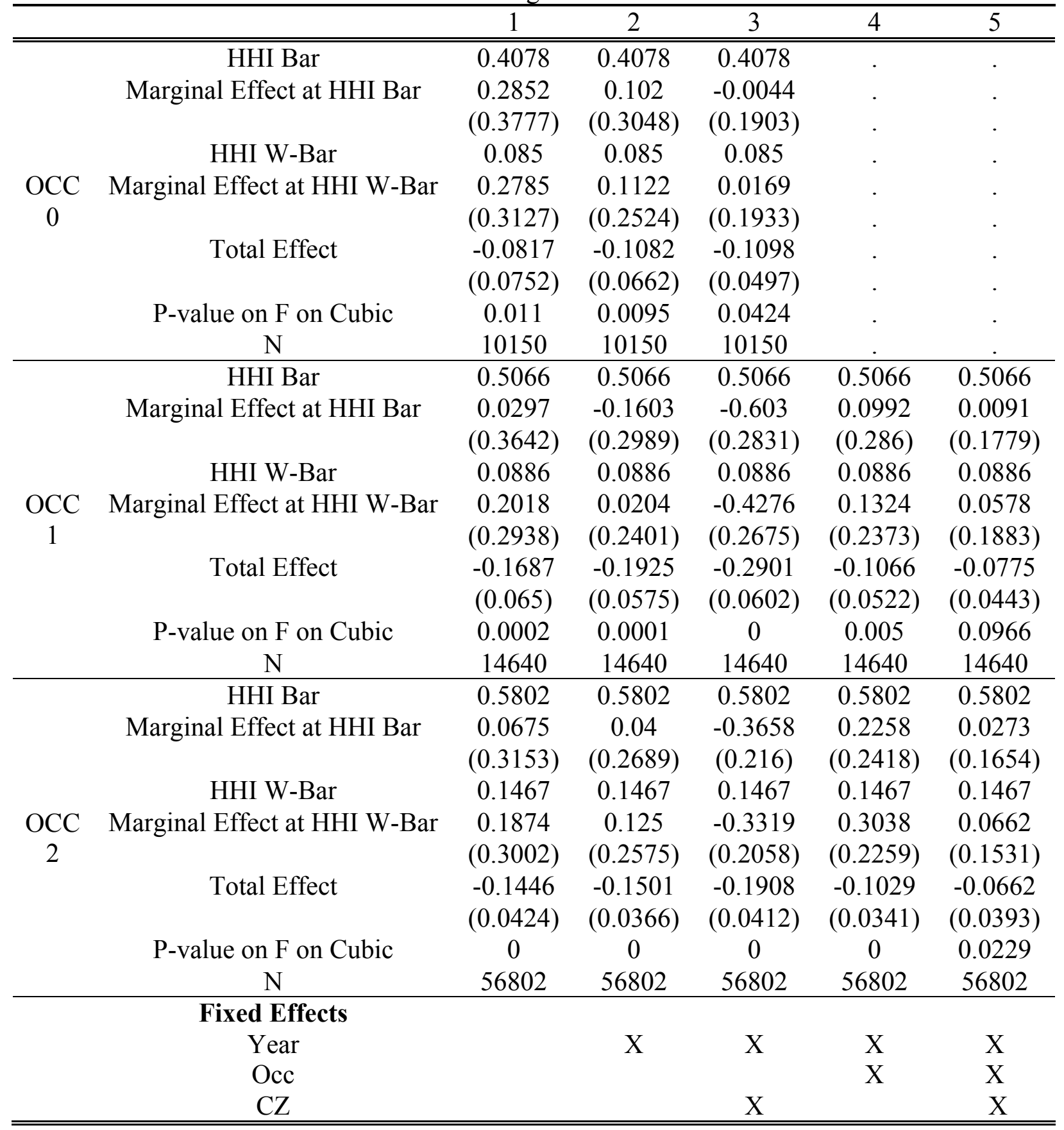

This table presents a commuting zone level weighted estimation of the effect of HHI on wage with 0,1 , and 2 digit occupation controls. HHI Bar represents the average concentration in an occupation and commuting zone level labor market, and HHI W-Bar represents the average concentration faced by a guest worker (HHI W-Bar is weighted by the number of employees requested in a certified LCA). Moving from left to right, a battery of fixed effect controls are added to the regression, as indicated in the bottom panel. Standard Errors (in parentheses) are clustered at the commuting zone level. 
Table 17: H-2B: Census Region Linear Analysis Regression of Log Wage on HHI, Unweighted

\begin{tabular}{|c|c|c|c|c|c|c|}
\hline & & 1 & 2 & 3 & 4 & 5 \\
\hline & HHI & 0.8851 & 3.8759 & 1.1589 & . & . \\
\hline \multirow{2}{*}{ Occ 0} & & (4.3374) & $(3.4660)$ & $(4.3842)$ & . & . \\
\hline & $\mathrm{N}$ & 72 & 72 & 72 & . & . \\
\hline & HHI & 0.2248 & 0.2930 & 0.3891 & -0.2843 & -0.2104 \\
\hline \multirow[t]{2}{*}{ Occ 1} & & $(0.1278)$ & $(0.1017)$ & $(0.1100)$ & $(0.0874)$ & $(0.1025)$ \\
\hline & $\mathrm{N}$ & 360 & 360 & 360 & 360 & 360 \\
\hline \multirow[t]{6}{*}{ Occ 2} & HHI & $\begin{array}{c}0.2580 \\
(0.0400)\end{array}$ & $\begin{array}{c}0.2589 \\
(0.0391)\end{array}$ & $\begin{array}{c}0.2758 \\
(0.0387)\end{array}$ & $\begin{array}{l}-0.2054 \\
(0.0498)\end{array}$ & $\begin{array}{c}-.2010 \\
(0.0519)\end{array}$ \\
\hline & $\mathrm{N}$ & 1075 & 1075 & 1075 & 1075 & 1075 \\
\hline & $\begin{array}{c}\text { Fixed } \\
\text { Effects }\end{array}$ & & & & & \\
\hline & Year & & $\mathrm{X}$ & $\mathrm{X}$ & $\mathrm{X}$ & $\mathrm{X}$ \\
\hline & Occ & & & & $\mathrm{X}$ & X \\
\hline & Region & & & $X$ & & $\mathrm{X}$ \\
\hline
\end{tabular}

This table presents a region level unweighted estimation of the effect of HHI on wage with 0,1 , and 2 digit occupation controls. Moving from left to right, a battery of fixed effect controls are added to the regression, as indicated in the bottom panel. Standard Errors (in parentheses) are robust. 
Table 18: H-2B: Census Region Cubic Analysis Regression of Log Wage on HHI, Unweighted

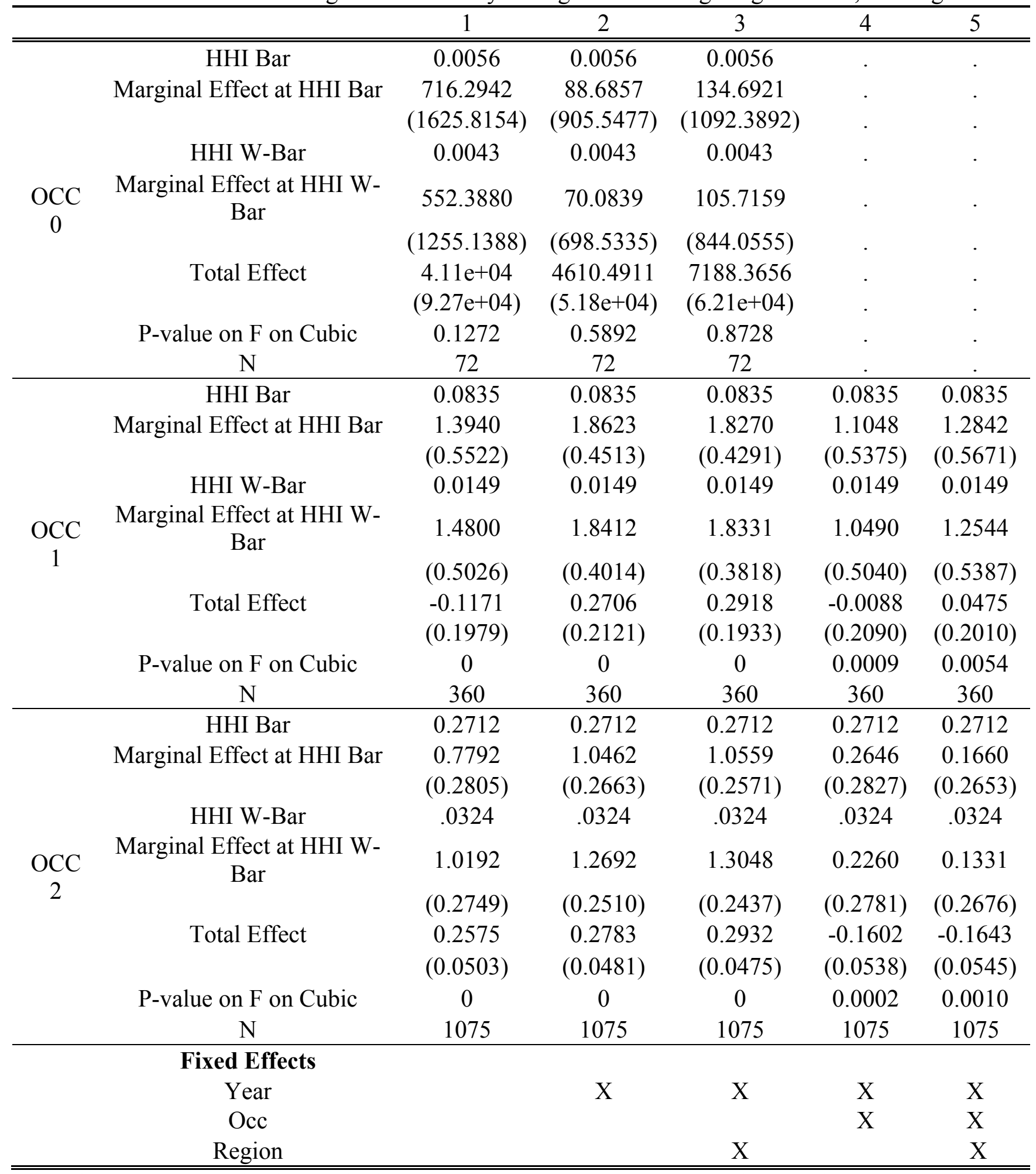

This table presents a region level unweighted estimation of the effect of HHI on wage with 0,1 , and 2 digit occupation controls. HHI Bar represents the average concentration in an occupation and region level labor market, and HHI W-Bar represents the average concentration faced by a labor market (HHI W-Bar is weighted by the number of employees requested in a certified LCA). Moving from left to right, a battery of fixed effect controls are added to the regression, as indicated in the bottom panel. Standard Errors (in parentheses) are robust. 
Table 19: H-2B: Linear Regional Level Analysis, Weighted

\begin{tabular}{|c|c|c|c|c|c|c|}
\hline & & 1 & 2 & 3 & 4 & 5 \\
\hline & HHI & 2.6625 & 9.4058 & 3.3352 & $\cdot$ & ${ }^{\circ}$ \\
\hline \multirow[t]{2}{*}{ Occ 0} & & $(6.9634)$ & $(2.7633)$ & $(4.4694)$ & . & . \\
\hline & $\mathrm{N}$ & 72 & 72 & 72 & . & . \\
\hline \multirow{3}{*}{ Occ 1} & HHI & 0.9766 & 1.2409 & 1.1036 & 0.3480 & 0.2253 \\
\hline & & $(0.3152)$ & $(0.2303)$ & $(0.2168)$ & $(0.219)$ & $(0.1869)$ \\
\hline & $\mathrm{N}$ & 360 & 360 & 360 & 360 & 360 \\
\hline \multirow{3}{*}{ Occ 2} & HHI & 0.4053 & 0.6046 & 0.5388 & 0.0504 & -0.0513 \\
\hline & & $(0.1402)$ & $(0.0796)$ & $(0.0789)$ & $(0.080)$ & $(0.0795)$ \\
\hline & $\mathrm{N}$ & 1075 & 1075 & 1075 & 1075 & 1075 \\
\hline \multicolumn{7}{|c|}{ Fixed } \\
\hline & Year & & $X$ & $X$ & X & $X$ \\
\hline & Occ & & & & $X$ & $X$ \\
\hline & Region & & & $X$ & & $X$ \\
\hline
\end{tabular}

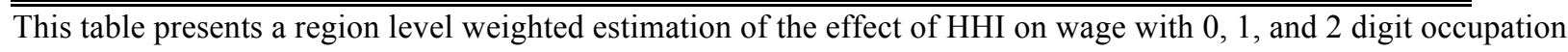
controls. Moving from left to right, a battery of fixed effect controls are added to the regression, as indicated in the bottom panel. Standard Errors (in parentheses) are robust. 
Table 20: H-2B: Census Region Cubic Analysis Regression of Log Wage on HHI, Weighted

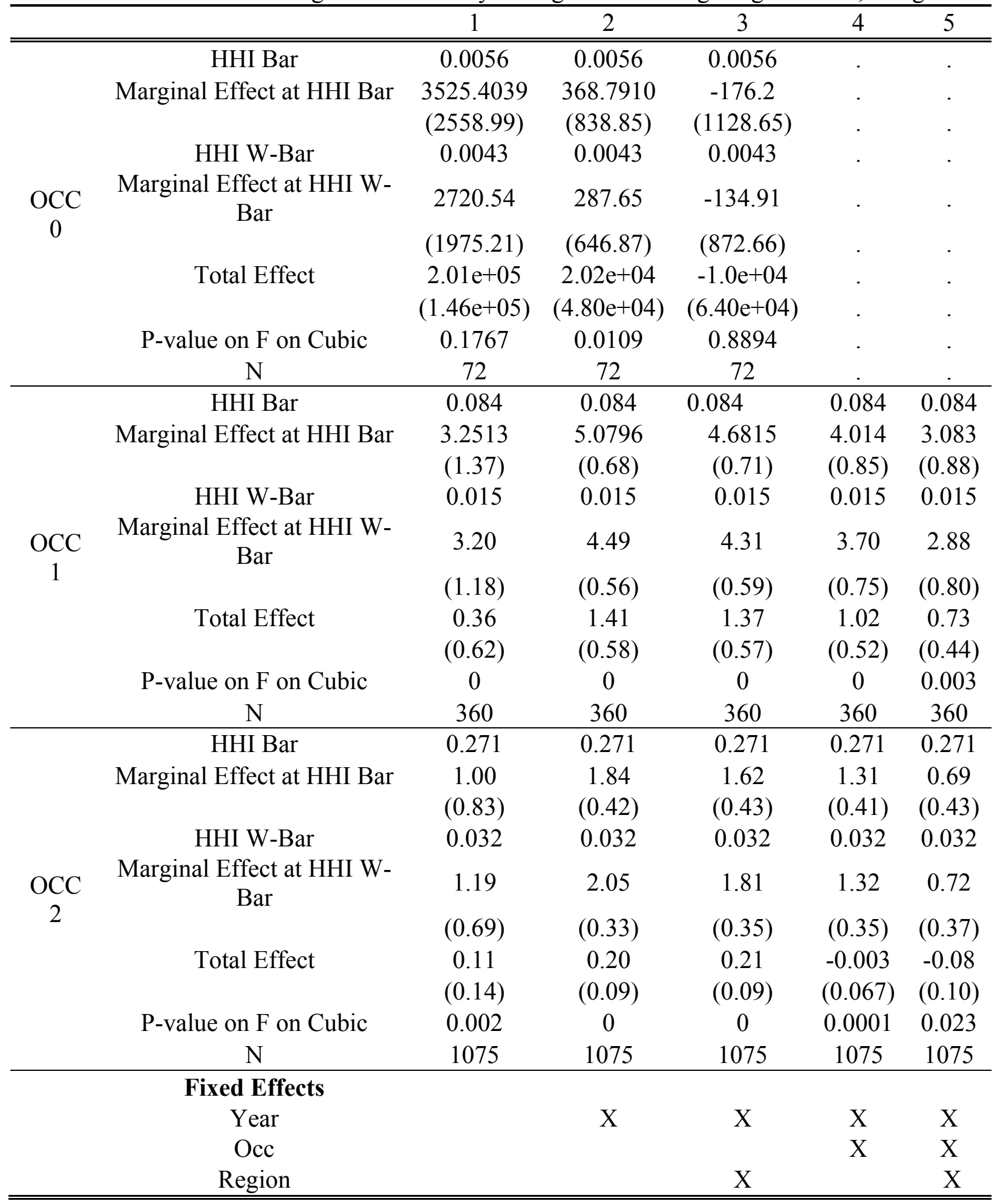

This table presents a region level weighted estimation of the effect of HHI on wage with 0,1 , and 2 digit occupation controls. HHI Bar represents the average concentration in an occupation and region level labor market, and HHI WBar represents the average concentration faced by a guest worker (HHI W-Bar is weighted by the number of employees requested in a certified LCA). Moving from left to right, a battery of fixed effect controls are added to the regression, as indicated in the bottom panel. Standard Errors (in parentheses) are robust. 
Table 21: H-2B: Census Division Linear Analysis Regression of Log Wage on HHI, Unweighted

\begin{tabular}{ccccccc}
\hline & & 1 & 2 & 3 & 4 & 5 \\
\hline \hline \multirow{3}{*}{ Occ 0} & HHI & 1.21 & 3.14 & 2.55 &. &. \\
& & $(1.58)$ & $(1.31)$ & $(2.02)$ &. &. \\
& $\mathrm{N}$ & 162 & 162 & 162 &. &. \\
\hline \multirow{3}{*}{ Occ 1} & $\mathrm{HHI}$ & 0.08 & 0.11 & 0.17 & -0.11 & -0.04 \\
& & $(0.05)$ & $(0.05)$ & $(0.05)$ & $(0.06)$ & $(0.06)$ \\
& $\mathrm{N}$ & 798 & 798 & 798 & 798 & 798 \\
\hline \multirow{3}{*}{ Occ 2 } & $\mathrm{HHI}$ & 0.23 & 0.23 & 0.24 & -0.06 & -0.05 \\
& & $(0.02)$ & $(0.02)$ & $(0.02)$ & $(0.03)$ & $(0.03)$ \\
& $\mathrm{N}$ & 2130 & 2130 & 2130 & 2130 & 2130 \\
\hline & Fixed & & & & & \\
& Effects & & & & & $\mathrm{X}$ \\
& Year & & $\mathrm{X}$ & $\mathrm{X}$ & $\mathrm{X}$ & $\mathrm{X}$ \\
& Occ & & & $\mathrm{X}$ & & $\mathrm{X}$ \\
\hline \hline
\end{tabular}

This table presents a division level unweighted estimation of the effect of HHI on wage with 0,1 , and 2 digit occupation controls. Moving from left to right, a battery of fixed effect controls are added to the regression, as indicated in the bottom panel. Standard Errors (in parentheses) are robust. 
Table 22: H-2B: Census Division Cubic Analysis Regression of Log Wage on HHI, Unweighted

\begin{tabular}{|c|c|c|c|c|c|c|}
\hline & & 1 & 2 & 3 & 4 & 5 \\
\hline \multirow{10}{*}{ OCC 0} & HHI Bar & 0.013 & 0.013 & 0.013 & . & . \\
\hline & Marginal Effect at HHI Bar & 81.77 & -93.82 & -123.85 & . & . \\
\hline & & $(450.29)$ & $(373.22)$ & $(360.00)$ & . & . \\
\hline & HHI W-Bar & 0.009 & 0.009 & 0.009 & . & . \\
\hline & Marginal Effect at HHI W-Bar & 55.16 & -66.86 & -87.89 & . & . \\
\hline & & $(315.19)$ & $(260.23)$ & $(251.57)$ & . & . \\
\hline & Total Effect & 2225.07 & $-2 \mathrm{e}+03$ & $-3 e+03$ & . & . \\
\hline & & $1.10 \mathrm{e}+04$ & 9219.92 & 8836.69 & . & . \\
\hline & P-value on F on Cubic & 0.20 & 0.02 & 0.39 & . & . \\
\hline & $\mathrm{N}$ & 162 & 162 & 162 & . & . \\
\hline \multirow{10}{*}{ OCC 1} & HHI Bar & 0.1674 & 0.1674 & 0.1674 & 0.1674 & 0.1674 \\
\hline & Marginal Effect at HHI Bar & 1.29 & 1.53 & 1.44 & 1.22 & 1.23 \\
\hline & & $(0.33)$ & $(0.30)$ & $(0.03)$ & $(0.03)$ & $(0.03)$ \\
\hline & HHI W-Bar & 0.03 & 0.03 & 0.03 & 0.03 & 0.03 \\
\hline & Marginal Effect at HHI W-Bar & 1.45 & 1.68 & 1.57 & 1.29 & 1.30 \\
\hline & & $(0.31)$ & $(0.27)$ & $(0.26)$ & $(0.32)$ & $(0.33)$ \\
\hline & Total Effect & 0.03 & 0.08 & 0.14 & 0.01 & 0.09 \\
\hline & & $(0.07)$ & $(0.08)$ & $(0.08)$ & $(0.09)$ & $(0.09)$ \\
\hline & P-value on F on Cubic & 0 & 0 & 0 & 0 & 0.0002 \\
\hline & $\mathrm{N}$ & 798 & 798 & 798 & 798 & 798 \\
\hline \multirow{10}{*}{ OCC 2} & HHI Bar & 0.3508 & 0.3508 & 0.3508 & 0.3508 & 0.3508 \\
\hline & Marginal Effect at HHI Bar & 0.72 & 0.77 & 0.79 & 0.20 & 0.10 \\
\hline & & $(0.21)$ & $(0.20)$ & $(0.20)$ & $(0.20)$ & $(0.20)$ \\
\hline & HHI W-Bar & 0.058 & 0.058 & 0.058 & 0.058 & 0.058 \\
\hline & Marginal Effect at HHI W-Bar & 0.82 & 0.89 & 0.89 & 0.21 & 0.06 \\
\hline & & $(0.21)$ & $(0.20)$ & $(0.19)$ & $(0.20)$ & $(0.20)$ \\
\hline & Total Effect & 0.26 & 0.27 & 0.29 & -0.04 & -0.04 \\
\hline & & $(0.03)$ & $(0.03)$ & $(0.03)$ & $(0.03)$ & $(0.03)$ \\
\hline & P-value on F on Cubic & 0 & 0 & 0 & 0.12 & 0.20 \\
\hline & $\mathrm{N}$ & 2130 & 2130 & 2130 & 2130 & 2130 \\
\hline \multicolumn{7}{|c|}{ Fixed Effects } \\
\hline & Year & & $\mathrm{X}$ & $\mathrm{X}$ & $\mathrm{X}$ & $\mathrm{X}$ \\
\hline & Occ & & & & $\mathrm{X}$ & $\mathrm{X}$ \\
\hline & Division & & & $\mathrm{X}$ & & $\mathrm{X}$ \\
\hline
\end{tabular}

This table presents a division level unweighted estimation of the effect of HHI on wage with 0,1 , and 2 digit occupation controls. HHI Bar represents the average concentration in an occupation and division level labor market, and HHI W-Bar represents the average concentration faced by labor market (HHI W-Bar is weighted by the number of employees requested in a certified LCA). Moving from left to right, a battery of fixed effect controls are added to the regression, as indicated in the bottom panel. Standard Errors (in parentheses) are robust. 
Table 23: H-2B: Census Division Linear Analysis Regression of Log Wage on HHI, Weighted

\begin{tabular}{ccccccc}
\hline & & 1 & 2 & 3 & 4 & 5 \\
\hline \hline \multirow{3}{*}{ Occ 0} & HHI & 0.05 & 2.51 & 1.36 &. &. \\
& & $(2.64)$ & $(1.38)$ & $(2.12)$ &. &. \\
& $\mathrm{N}$ & 162 & 162 & 162 &. &. \\
\hline \multirow{3}{*}{ Occ 1} & $\mathrm{HHI}$ & 0.59 & 0.76 & 0.72 & 0.23 & 0.19 \\
& & $(0.16)$ & $(0.10)$ & $(0.10)$ & $(0.11)$ & $(0.12)$ \\
& $\mathrm{N}$ & 798 & 798 & 798 & 798 & 798 \\
\hline \multirow{3}{*}{ Occ 2} & $\mathrm{HHI}$ & 0.24 & 0.38 & 0.35 & 0.03 & -0.02 \\
& & $(0.08)$ & $(0.05)$ & $(0.05)$ & $(0.05)$ & $(0.05)$ \\
& $\mathrm{N}$ & 2130 & 2130 & 2130 & 2130 & 2130 \\
\hline & Fixed & & & & & \\
& Effects & & & & & $\mathrm{X}$ \\
& Year & & & $\mathrm{X}$ & $\mathrm{X}$ & $\mathrm{X}$ \\
& Occ & & & $\mathrm{X}$ & & $\mathrm{X}$ \\
\hline \hline
\end{tabular}

$\overline{\text { This table presents a division level unweighted estimation of the effect of HHI on wage with } 0,1 \text {, and } 2}$ digit occupation controls. Moving from left to right, a battery of fixed effect controls are added to the regression, as indicated in the bottom panel. Standard Errors (in parentheses) are clustered robust. 
Table 24: H-2B: Census Division Cubic Analysis Regression of Log Wage on HHI, Weighted

\begin{tabular}{|c|c|c|c|c|c|c|}
\hline & & 1 & 2 & 3 & 4 & 5 \\
\hline \multirow{10}{*}{ OCC 0} & HHI Bar & 0.013 & 0.013 & 0.013 & . & . \\
\hline & Marginal Effect at HHI Bar & 437.05 & 394.57 & 142.32 & . & . \\
\hline & & $(894.56)$ & $(410.28)$ & $(484.34)$ & . & . \\
\hline & HHI W-Bar & 0.009 & 0.009 & 0.009 & . & . \\
\hline & Marginal Effect at HHI W-Bar & 304.69 & 275.59 & 99.49 & . & . \\
\hline & & $(625.08)$ & $(286.12)$ & $(338.59)$ & . & . \\
\hline & Total Effect & $1.08 \mathrm{e}+04$ & 9712.07 & 3497.29 & . & . \\
\hline & & $(2.2 \mathrm{e}+04)$ & $(1 . e+04)$ & $(1.2 \mathrm{e}+04)$ & . & . \\
\hline & P-value on F on Cubic & 0.95 & 0.35 & 0.95 & . & . \\
\hline & $\mathrm{N}$ & 162 & 162 & 162 & . & . \\
\hline \multirow{10}{*}{ OCC 1} & HHI Bar & 0.167 & 0.167 & 0.167 & 0.167 & 0.167 \\
\hline & Marginal Effect at HHI Bar & 0.95 & 2.50 & 2.90 & 1.79 & 1.91 \\
\hline & & $(0.87)$ & $(0.44)$ & $(0.44)$ & $(0.46)$ & $(0.57)$ \\
\hline & HHI W-Bar & 0.029 & 0.029 & 0.029 & 0.029 & 0.029 \\
\hline & Marginal Effect at HHI W-Bar & 1.31 & 2.64 & 2.93 & 1.87 & 1.96 \\
\hline & & $(0.76)$ & $(0.37)$ & $(0.37)$ & $(0.41)$ & $(0.52)$ \\
\hline & Total Effect & -0.08 & 0.17 & 0.31 & -0.02 & 0.10 \\
\hline & & $(0.18)$ & $(0.15)$ & $(0.16)$ & $(0.16)$ & $(0.17)$ \\
\hline & P-value on F on Cubic & 0 & 0 & 0 & 0 & 0.0002 \\
\hline & $\mathrm{N}$ & 798 & 798 & 798 & 798 & 798 \\
\hline \multirow{10}{*}{ OCC 2} & HHI Bar & 0.351 & 0.351 & 0.351 & 0.351 & 0.351 \\
\hline & Marginal Effect at HHI Bar & 0.1 & 0.39 & 0.56 & 0.13 & 0.05 \\
\hline & & $(0.55)$ & $(0.34)$ & $(0.33)$ & $(0.32)$ & $(0.35)$ \\
\hline & HHI W-Bar & 0.058 & 0.058 & 0.058 & 0.058 & 0.058 \\
\hline & Marginal Effect at HHI W-Bar & 0.37 & 0.80 & 0.86 & 0.41 & 0.24 \\
\hline & & $(0.50)$ & $(0.28)$ & $(0.28)$ & $(0.28)$ & $(0.32)$ \\
\hline & Total Effect & 0.08 & 0.12 & 0.15 & -0.11 & -0.11 \\
\hline & & $(0.07)$ & $(0.06)$ & $(0.06)$ & $(0.07)$ & $(0.07)$ \\
\hline & P-value on F on Cubic & 0 & 0 & 0 & 0.002 & 0.05 \\
\hline & $\mathrm{N}$ & 2130 & 2130 & 2130 & 2130 & 2130 \\
\hline \multicolumn{7}{|c|}{ Fixed Effects } \\
\hline & Year & & $\mathrm{X}$ & $\mathrm{X}$ & $\mathrm{X}$ & $\mathrm{X}$ \\
\hline & Occ & & & & $\mathrm{X}$ & $\mathrm{X}$ \\
\hline & Division & & & $\mathrm{X}$ & & $\mathrm{X}$ \\
\hline
\end{tabular}

This table presents a division level unweighted estimation of the effect of HHI on wage with 0,1 , and 2 digit occupation controls. HHI Bar represents the average concentration in an occupation and division level labor market, and HHI W-Bar represents the average concentration faced by a guest worker (HHI W-Bar is weighted by the number of employees requested in a certified LCA). Moving from left to right, a battery of fixed effect controls are added to the regression, as indicated in the bottom panel. Standard Errors (in parentheses) are robust. 
Table 25: H-2B: Census State Linear Analysis Regression of Log Wage on HHI, Unweighted

\begin{tabular}{|c|c|c|c|c|c|c|}
\hline & & 1 & 2 & 3 & 4 & 5 \\
\hline & HHI & 0.21 & 0.22 & 0.16 & . & . \\
\hline \multirow[t]{3}{*}{ Occ 0} & & $(0.09)$ & $(0.08)$ & $(0.14)$ & . & . \\
\hline & $\mathrm{N}$ & 905 & 905 & 905 & . & . \\
\hline & $\mathrm{HHI}$ & 0.11 & 0.12 & 0.12 & 0.01 & -0.02 \\
\hline \multirow[t]{3}{*}{ Occ 1} & & $(0.03)$ & $(0.03)$ & $(0.03)$ & $(0.03)$ & $(0.03)$ \\
\hline & $\mathrm{N}$ & 3580 & 3580 & 3580 & 3580 & 3580 \\
\hline & HHI & 0.10 & 0.11 & 0.11 & -0.03 & -0.05 \\
\hline \multirow[t]{2}{*}{ Occ 2} & & $(0.02)$ & $(0.02)$ & $(0.02)$ & $(0.02)$ & $(0.02)$ \\
\hline & $\mathrm{N}$ & 7127 & 7127 & 7127 & 7127 & 7127 \\
\hline \multicolumn{7}{|c|}{ Fixed } \\
\hline \multicolumn{7}{|c|}{ Effects } \\
\hline & Year & & $X$ & $X$ & $X$ & X \\
\hline & Occ & & & & $X$ & $X$ \\
\hline & Division & & & $X$ & & $X$ \\
\hline
\end{tabular}


Table 26: H-2B: Census State Cubic Analysis Regression of Log Wage on HHI, Unweighted

\begin{tabular}{|c|c|c|c|c|c|c|}
\hline & & 1 & 2 & 3 & 4 & 5 \\
\hline \multirow{10}{*}{ OCC 0} & HHI Bar & 0.120 & 0.120 & 0.120 & . & . \\
\hline & Marginal Effect at HHI Bar & 0.13 & 0.55 & 0.27 & . & . \\
\hline & & $(0.53)$ & $(0.51)$ & $(0.68)$ & . & . \\
\hline & HHI W-Bar & 0.042 & 0.042 & 0.042 & . & . \\
\hline & Marginal Effect at HHI W-Bar & 0.10 & 0.53 & 0.25 & . & . \\
\hline & & $(0.51)$ & $(0.48)$ & $(0.65)$ & . & . \\
\hline & Total Effect & 0.25 & 0.26 & 0.19 & . & . \\
\hline & & $(0.13)$ & $(0.11)$ & $(0.20)$ & . & . \\
\hline & P-value on $\mathrm{F}$ on Cubic & 0.14 & 0.03 & 0.69 & . & . \\
\hline & $\mathrm{N}$ & 905 & 905 & 905 & . & . \\
\hline \multirow{10}{*}{ OCC 1} & HHI Bar & 0.412 & 0.412 & 0.412 & 0.412 & 0.412 \\
\hline & Marginal Effect at HHI Bar & 0.49 & 0.57 & 0.72 & 0.23 & 0.20 \\
\hline & & $(0.20)$ & $(0.18)$ & $(0.18)$ & $(0.19)$ & $(0.18)$ \\
\hline & HHI W-Bar & 0.095 & 0.095 & 0.095 & 0.095 & 0.095 \\
\hline & Marginal Effect at HHI W-Bar & 0.63 & 0.73 & 0.91 & 0.91 & 0.26 \\
\hline & & $(0.20)$ & $(0.19)$ & $(0.18)$ & $(0.21)$ & $(0.20)$ \\
\hline & Total Effect & 0.15 & 0.17 & 0.19 & 0.04 & 0.02 \\
\hline & & $(0.03)$ & $(0.03)$ & $(0.03)$ & $(0.04)$ & $(0.04)$ \\
\hline & P-value on F on Cubic & 0 & 0 & 0 & 0.45 & 0.50 \\
\hline & $\mathrm{N}$ & 3580 & 3580 & 3580 & 3580 & 3580 \\
\hline \multirow{10}{*}{ OCC 2} & HHI Bar & 0.538 & 0.538 & 0.538 & 0.538 & 0.538 \\
\hline & Marginal Effect at HHI Bar & 0.25 & 0.21 & 0.34 & -0.17 & -0.21 \\
\hline & & $(0.17)$ & $(0.16)$ & $(0.16)$ & $(0.16)$ & $(0.13)$ \\
\hline & HHI W-Bar & 0.15 & 0.15 & 0.15 & 0.15 & 0.15 \\
\hline & Marginal Effect at HHI W-Bar & 0.31 & 0.27 & 0.44 & -0.15 & -0.21 \\
\hline & & $(0.18)$ & $(0.17)$ & $(0.16)$ & $(0.19)$ & $(0.15)$ \\
\hline & Total Effect & 0.12 & 0.13 & 0.15 & -0.04 & -0.07 \\
\hline & & $(0.03)$ & $(0.03)$ & $(0.02)$ & $(0.03)$ & $(0.02)$ \\
\hline & P-value on F on Cubic & 0.0001 & 0 & 0 & 0.2868 & 0.0177 \\
\hline & $\mathrm{N}$ & 7127 & 7127 & 7127 & 7127 & 7127 \\
\hline \multicolumn{7}{|c|}{ Fixed Effects } \\
\hline & Year & & $X$ & $X$ & $X$ & $X$ \\
\hline & Occ & & & & $X$ & $X$ \\
\hline & State & & & $\mathrm{X}$ & & $\mathrm{X}$ \\
\hline
\end{tabular}

$\overline{\text { This table presents a state level unweighted estimation of the effect of HHI on wage with } 0,1 \text {, and } 2 \text { digit occupation }}$ controls. HHI Bar represents the average concentration in an occupation and division level labor market, and HHI W-Bar represents the average concentration faced by labor market (HHI W-Bar is weighted by the number of employees requested in a certified LCA). Moving from left to right, a battery of fixed effect controls are added to the regression, as indicated in the bottom panel. Standard Errors (in parentheses) are clustered at the state level. 
Table 27: H-2B: Census State Linear Analysis Regression of Log Wage on HHI, Weighted

\begin{tabular}{ccccccc}
\hline & & 1 & 2 & 3 & 4 & 5 \\
\hline \hline \multirow{3}{*}{ Occ 0} & HHI & 0.11 & 0.14 & -0.06 &. &. \\
& & $(0.18)$ & $(0.15)$ & $(0.18)$ &. &. \\
& $\mathrm{N}$ & 905 & 905 & 905 &. &. \\
\hline \multirow{3}{*}{ Occ 1 } & HHI & 0.19 & 0.24 & 0.28 & 0.08 & 0.05 \\
& & $(0.06)$ & $(0.05)$ & $(0.04)$ & $(0.05)$ & $(0.05)$ \\
& $\mathrm{N}$ & 3580 & 3580 & 3580 & 3580 & 3580 \\
\hline \multirow{5}{*}{ Occ 2 } & HHI & 0.053 & 0.10 & 0.10 & -0.04 & -0.06 \\
& & $(0.04)$ & $(0.03)$ & $(0.03)$ & $(0.03)$ & $(0.03)$ \\
& $\mathrm{N}$ & 7127 & 7127 & 7127 & 7127 & 7127 \\
\hline & Fixed & & & & & \\
& Effects & & & & & $\mathrm{X}$ \\
& Year & & & $\mathrm{X}$ & $\mathrm{X}$ & $\mathrm{X}$ \\
& Occ & & & $\mathrm{X}$ & & $\mathrm{X}$ \\
\hline \hline
\end{tabular}

This table presents a state level unweighted estimation of the effect of HHI on wage with 0,1 , and 2 digit occupation controls. Moving from left to right, a battery of fixed effect controls are added to the regression, as indicated in the bottom panel. Standard Errors (in parentheses) are clustered at the state level. 
Table 28: H-2B: Census State Cubic Analysis Regression of Log Wage on HHI, Weighted

\begin{tabular}{|c|c|c|c|c|c|c|}
\hline & & 1 & 2 & 3 & 4 & 5 \\
\hline \multirow{10}{*}{ OCC 0} & HHI Bar & 0.12 & 0.12 & 0.12 & . & . \\
\hline & Marginal Effect at HHI Bar & 0.09 & 0.79 & 0.06 & . & . \\
\hline & & $(0.71)$ & $(0.49)$ & $(0.53)$ & . & . \\
\hline & HHI W-Bar & 0.042 & 0.042 & 0.042 & . & . \\
\hline & Marginal Effect at HHI W-Bar & -0.08 & 0.62 & -0.02 & . & . \\
\hline & & $(0.66)$ & $(0.46)$ & $(0.47)$ & . & . \\
\hline & Total Effect & 0.71 & 0.56 & 0.17 & . & . \\
\hline & & $(0.33)$ & $(0.20)$ & $(0.31)$ & . & . \\
\hline & P-value on $\mathrm{F}$ on Cubic & .046 & 0.06 & 0.89 & . & . \\
\hline & $\mathrm{N}$ & 905 & 905 & 905 & . & . \\
\hline \multirow{10}{*}{ OCC 1} & HHI Bar & 0.412 & 0.412 & 0.412 & 0.412 & 0.412 \\
\hline & Marginal Effect at HHI Bar & -0.37 & -0.04 & 0.31 & -0.25 & -0.30 \\
\hline & & $(0.39)$ & $(0.28)$ & $(0.25)$ & $(0.33)$ & $(0.28)$ \\
\hline & HHI W-Bar & 0.095 & 0.095 & 0.095 & 0.095 & 0.095 \\
\hline & Marginal Effect at HHI W-Bar & -0.15 & 0.27 & 0.64 & -0.02 & -0.08 \\
\hline & & $(0.36)$ & $(0.22)$ & $(0.23)$ & $(0.28)$ & $(0.28)$ \\
\hline & Total Effect & 0.09 & 0.11 & 0.16 & -0.02 & -0.04 \\
\hline & & $(0.07)$ & $(0.05)$ & $(0.04)$ & $(0.06)$ & $(0.06)$ \\
\hline & P-value on $\mathrm{F}$ on Cubic & 0.0016 & 0.0001 & 0 & 0.0731 & 0.0931 \\
\hline & $\mathrm{N}$ & 3580 & 3580 & 3580 & 3580 & 3580 \\
\hline \multirow{10}{*}{ OCC 2} & HHI Bar & 0.5379 & 0.5379 & 0.5379 & 0.5379 & 0.5379 \\
\hline & Marginal Effect at HHI Bar & -0.32 & -0.31 & -0.18 & -0.56 & -0.61 \\
\hline & & $(0.24)$ & $(0.22)$ & $(0.17)$ & $(0.24)$ & $(0.16)$ \\
\hline & HHI W-Bar & 0.1505 & 0.1505 & 0.1505 & 0.1505 & 0.1505 \\
\hline & Marginal Effect at HHI W-Bar & -0.15 & -0.07 & 0.07 & -0.39 & -0.45 \\
\hline & & $(0.25)$ & $(0.21)$ & $(0.16)$ & $(0.24)$ & $(0.17)$ \\
\hline & Total Effect & -0.002 & 0.03 & 0.04 & -0.11 & -0.13 \\
\hline & & $(0.04)$ & $(0.03)$ & $(0.03)$ & $(0.04)$ & $(0.03)$ \\
\hline & P-value on F on Cubic & 0.075 & 0.002 & 0.0009 & 0.001 & 0.0001 \\
\hline & $\mathrm{N}$ & 7127 & 7127 & 7127 & 7127 & 7127 \\
\hline \multicolumn{7}{|c|}{ Fixed Effects } \\
\hline & Year & & $X$ & $\mathrm{X}$ & $X$ & $X$ \\
\hline & Occ & & & & $X$ & $\mathrm{X}$ \\
\hline & State & & & $\mathrm{X}$ & & $\mathrm{X}$ \\
\hline
\end{tabular}

This table presents a state level unweighted estimation of the effect of HHI on wage with 0,1 , and 2 digit occupation controls. HHI Bar represents the average concentration in an occupation and division level labor market, and HHI W-Bar represents the average concentration faced by a guest worker (HHI W-Bar is weighted by the number of employees requested in a certified LCA). Moving from left to right, a battery of fixed effect controls are added to the regression, as indicated in the bottom panel. Standard Errors (in parentheses) are clustered at the state level. 
Table 29: H-2A: Linear Regression of Log Wage on HHI, Unweighted

\begin{tabular}{ccccc}
\hline & & 1 & 2 & 3 \\
\hline \hline \multirow{3}{*}{ Census Region } & HHI & 1.9336 & -0.6254 & 4.3158 \\
& & $(1.314)$ & $(1.2486)$ & $(0.966)$ \\
& $\mathrm{N}$ & 48 & 48 & 48 \\
\hline \multirow{3}{*}{ Census Division } & $\mathrm{HHI}$ & 1.6096 & 1.2196 & 0.9475 \\
& & $(0.5009)$ & $(0.4276)$ & $(0.4093)$ \\
& $\mathrm{N}$ & 108 & 108 & 108 \\
\hline \multirow{2}{*}{ State } & $\mathrm{HHI}$ & -0.0488 & -0.0395 & 0.0323 \\
& & $(0.0802)$ & $(0.0780)$ & $(0.1037)$ \\
& $\mathrm{N}$ & 601 & 601 & 601 \\
\hline
\end{tabular}

\section{Fixed Effects}

Year

Geography

$\mathrm{X} \quad \mathrm{X}$

X

This table presents an unweighted estimation of the effect of HHI on wage at the Census Region, Census Division, and State geographical levels. Moving from left to right, a battery of fixed effect controls are added to the regression, as indicated in the bottom panel. Standard Errors (in parentheses) are clustered at the geographical level.

Table 30: H-2A: Linear Regression of Log Wage on HHI, Weighted

\begin{tabular}{ccccc}
\hline & & 1 & 2 & 3 \\
\hline \hline \multirow{3}{*}{ Census Region } & HHI & 4.1171 & 2.0059 & 3.5206 \\
& & $(1.4254)$ & $(0.6763)$ & $(1.1039)$ \\
& $\mathrm{N}$ & 48 & 48 & 48 \\
\hline \multirow{3}{*}{ Census Division } & $\mathrm{HHI}$ & 2.5188 & 1.7303 & 0.6226 \\
& & $(0.6297)$ & $(0.3487)$ & $(0.4858)$ \\
& $\mathrm{N}$ & 108 & 108 & 108 \\
\hline \multirow{2}{*}{ State } & $\mathrm{HHI}$ & -0.0163 & -0.0733 & -0.1390 \\
& & $(0.3167)$ & $(0.2781)$ & $(0.2670)$ \\
& $\mathrm{N}$ & 601 & 601 & 601 \\
\hline
\end{tabular}

\section{Fixed Effects}

Year

Geography

$\mathrm{X} \quad \mathrm{X}$

$\mathrm{X}$

This table presents a weighted estimation of the effect of HHI on wage at the Census Region, Census Division, and State geographical levels. Moving from left to right, a battery of fixed effect controls are added to the regression, as indicated in the bottom panel. Standard Errors (in parentheses) are clustered at the geographical level. 
Table 31: H-2A: Cubic Regression of Log Wage on HHI, Unweighted

\begin{tabular}{|c|c|c|c|c|}
\hline & & 1 & 2 & 3 \\
\hline \multirow{9}{*}{$\begin{array}{l}\text { Census } \\
\text { Region }\end{array}$} & HHI Bar & 0.0120 & 0.0120 & 0.0120 \\
\hline & Marginal Effect at HHI Bar & 1664.9063 & $\begin{array}{l}1786.5380 \\
(4550222)\end{array}$ & $\begin{array}{c}380.4654 \\
(2959730)\end{array}$ \\
\hline & HHI W-Bar & 0.0106 & 0.0106 & 0.0106 \\
\hline & Marginal Effect at HHI W-Bar & 1486.0388 & 1594.3598 & 340.1646 \\
\hline & & (464.1980) & $(405.8742)$ & $(264.3788)$ \\
\hline & Total Effect & $4.40 \mathrm{e}+04$ & $4.72 \mathrm{e}+04$ & 9907.0336 \\
\hline & & $(1.38 \mathrm{e}+04)$ & $(1.21 \mathrm{e}+04)$ & (7758.8819) \\
\hline & P-value on F on Cubic & 0.0100 & 0.0029 & 0.0002 \\
\hline & $\mathrm{N}$ & 48 & 48 & 48 \\
\hline \multirow{9}{*}{$\begin{array}{l}\text { Census } \\
\text { Division }\end{array}$} & HHI Bar & 0.0216 & 0.0216 & 0.0216 \\
\hline & Marginal Effect at HHI Bar & $\begin{array}{l}302.3119 \\
(95.6070)\end{array}$ & $\begin{array}{l}266.7028 \\
(91.4304)\end{array}$ & $\begin{array}{c}94.3996 \\
(44.4606)\end{array}$ \\
\hline & HHI W-Bar & 0.0190 & 0.0190 & 0.0190 \\
\hline & Marginal Effect at HHI W-Bar & 267.7870 & 236.2481 & 83.6693 \\
\hline & & $(84.6005)$ & $(80.8658)$ & (39.4046) \\
\hline & Total Effect & 4245.1054 & 3743.3641 & 1319.9881 \\
\hline & & $(1353.9795)$ & $(1300.5006)$ & $(620.2819)$ \\
\hline & P-value on F on Cubic & 0.0001 & 0.0001 & 0.0015 \\
\hline & $\mathrm{N}$ & 108 & 108 & 108 \\
\hline \multirow{8}{*}{ State } & HHI Bar & 0.1368 & 0.1368 & 0.1368 \\
\hline & Marginal Effect at HHI Bar & $\begin{array}{c}0.5155 \\
(0.3707)\end{array}$ & $\begin{array}{c}0.5340 \\
(0.3685)\end{array}$ & $\begin{array}{l}-0.1000 \\
(0.3040)\end{array}$ \\
\hline & HHI W-Bar & 0.0649 & 0.0649 & 0.0649 \\
\hline & Marginal Effect at HHI W-Bar & 0.5520 & 0.5693 & -0.1120 \\
\hline & & $(0.3842)$ & $(0.3829)$ & $(0.3261)$ \\
\hline & Total Effect & $\begin{array}{c}-0.0835 \\
(0.0809)\end{array}$ & $\begin{array}{c}-0.0716 \\
(0.0720)\end{array}$ & $\begin{array}{c}0.0330 \\
(0.0858)\end{array}$ \\
\hline & P-value on F on Cubic & 0.0561 & 0.0790 & 0.6860 \\
\hline & $\mathrm{N}$ & 601 & 601 & 601 \\
\hline \multicolumn{5}{|c|}{ Fixed Effects } \\
\hline & Year & & $\mathrm{X}$ & $\mathrm{X}$ \\
\hline & Geography & & & $\mathrm{X}$ \\
\hline
\end{tabular}

This table presents an unweighted estimation of the effect of HHI on wage at the Census Region, Census Division, and State geographical levels. HHI Bar represents the average concentration in a geographically defined labor market, and HHI W-Bar represents the average concentration faced by a guest worker (HHI W-Bar is weighted by the number of employees requested in a certified LCA). Moving from left to right, a battery of fixed effect controls are added to the regression, as indicated in the bottom panel. Standard Errors (in parentheses) are clustered at the geographical level. 
Table 32: H-2A: Cubic Regression of Log Wage on HHI, Weighted

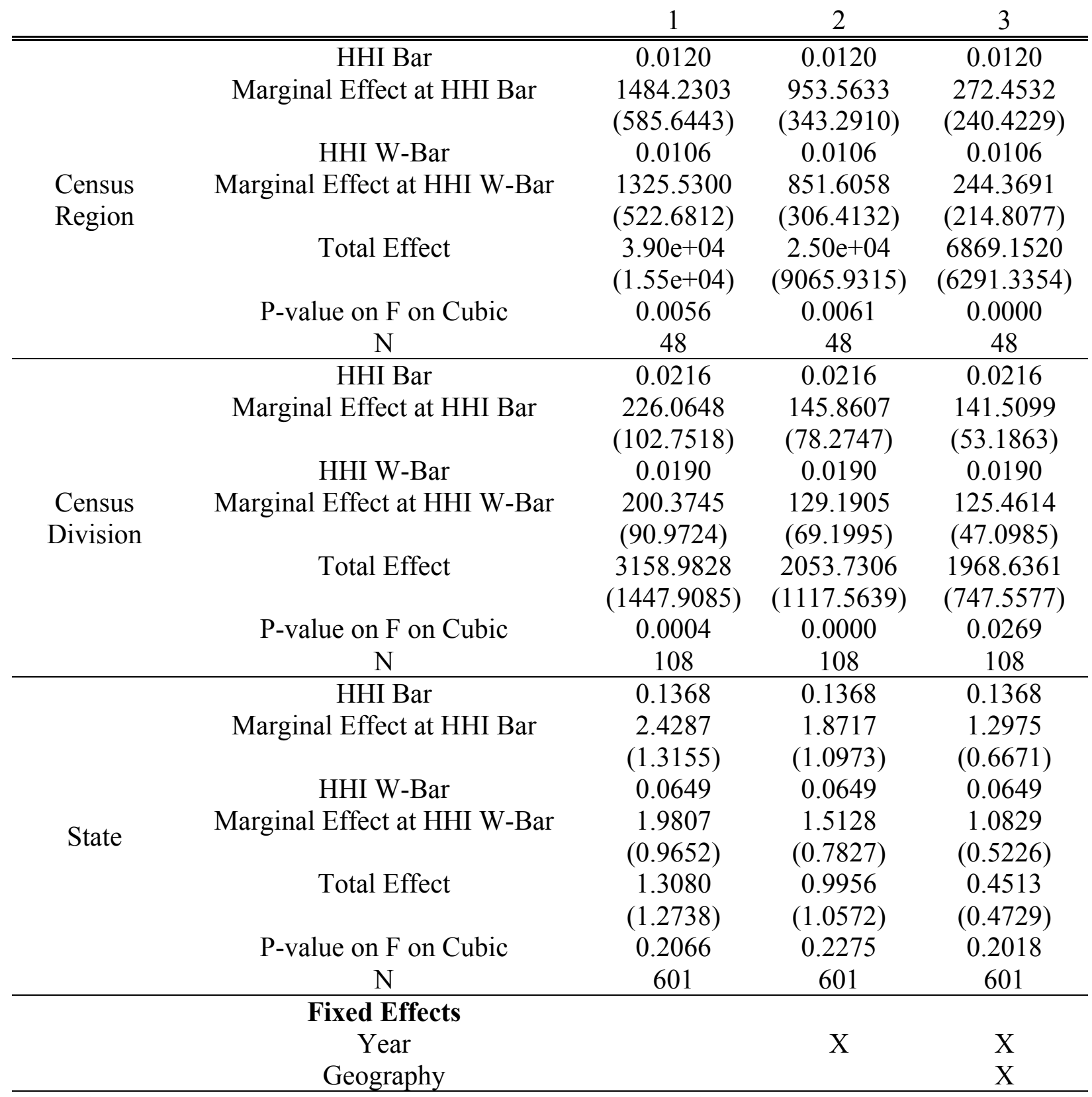

This table presents a weighted estimation of the effect of HHI on wage at the Census Region, Census Division, and State geographical levels. HHI Bar represents the average concentration in a geographically defined labor market, and HHI W-Bar represents the average concentration faced by a guest worker (HHI W-Bar is weighted by the number of employees requested in a certified LCA). Moving from left to right, a battery of fixed effect controls are added to the regression, as indicated in the bottom panel. Standard Errors (in parentheses) are clustered at the geographical level. 
Table 33: Instrumental Variables Results

\begin{tabular}{|c|c|c|c|c|}
\hline & & & Linear & Cubic \\
\hline \multirow{6}{*}{ Direct } & \multirow{3}{*}{ Unweighted } & Total Effect & $2-0.15$ & -0.28 \\
\hline & & & $(0.06)$ & $(1.87)$ \\
\hline & & First Stage F & 439.77 & 0.64 \\
\hline & \multirow{3}{*}{ Weighted } & Total Effect & -1.36 & -3.89 \\
\hline & & & $(0.69)$ & (21.08) \\
\hline & & First Stage F & 15.89 & 0.11 \\
\hline \multirow{6}{*}{ Inverse } & \multirow[t]{3}{*}{ Unweighted } & Total Effect & 0.31 & -0.05 \\
\hline & & & $(0.10)$ & $(0.81)$ \\
\hline & & First Stage F & 108.61 & 0.31 \\
\hline & \multirow{3}{*}{ Weighted } & First Stage F & -0.41 & -1.06 \\
\hline & & & $(0.37)$ & $(0.82)$ \\
\hline & & Total Effect & 9.75 & 0.11 \\
\hline
\end{tabular}

This table presents results from instrumental variables estimations. The top panel uses an instrument of the average number of firms in other commuting zones in the same occupation and year; the bottom panel uses the average of the inverse of the number for firms. All estimates include year, two-digit occupation, and commuting zone fixed effects, with standard errors clustered at the commuting zone level. 